Natália Kazumi Gushiken

Estudo de compósito formado por nanopartículas de ouro em matriz polimérica como substratos para análise SERS 
Natália Kazumi Gushiken

\section{Estudo de compósito formado por nanopartículas de ouro em matriz polimérica como substratos para análise SERS}

Dissertação de Mestrado apresentado ao Programa de Pós-Graduação em Engenharia Elétrica da Escola Politécnica da Universidade de São Paulo para obtenção do título de Mestre em Ciências. 
UNIVERSIDADE DE SÃO PAULO

ESCOLA POLITÉCNICA

Natália Kazumi Gushiken

\section{Estudo de compósito formado por nanopartículas de ouro em matriz polimérica como substratos para análise SERS}

Dissertação de Mestrado apresentado ao Programa de Pós-Graduação em Engenharia Elétrica da Escola Politécnica da Universidade de São Paulo para obtenção do título de Mestre em Ciências.

Área de Concentração:

Microeletrônica

Orientadora:

Prof $^{a} \operatorname{Dr}^{\mathrm{a}}$. Maria Cecília B. S. Salvadori 
Autorizo a reprodução e divulgação total ou parcial deste trabalho, por qualquer meio convencional ou eletrônico, para fins de estudo e pesquisa, desde que citada a fonte.

Este exemplar foi revisado e corrigido em relação à versão original, sob responsabilidade única do autor e com a anuência de seu orientador.

São Paulo, de de

Assinatura do autor:

Assinatura do orientador:

\section{Catalogação-na-publicação}

Gushiken, Natália Kazumi

Estudo de compósito formado por nanopartículas de ouro em matriz polimérica como substratos para análise SERS / N. K. Gushiken -versão corr. -- São Paulo, 2019.

$82 \mathrm{p}$.

Dissertação (Mestrado) - Escola Politécnica da Universidade de São Paulo. Departamento de Engenharia de Sistemas Eletrônicos.

1.Materiais Compósitos 2.Nanopartículas 3.Plasma (Microeletrônica) 4.Filmes Finos 5.Espectroscopia Raman I.Universidade de São Paulo. Escola Politécnica. Departamento de Engenharia de Sistemas Eletrônicos II.t. 
Dedico este trabalho à todos os professores que participaram da minha formação. Sem eles, esta conquista não seria possível. 


\section{Agradecimentos}

Primeiramente, ao Conselho Nacional de Desenvolvimento Científico e Tecnológico (CNPq) pela concessão da bolsa de mestrado.

À Fundação de Amparo à Pesquisa do Estado de São Paulo (FAPESP), Coordenação de Aperfeiçoamento de Pessoal de Nível Superior (CAPES) e Financiadora de Estudos e Projetos (Finep), pelo apoio financeiro concedido à diversos equipamentos do LFF.

À toda equipe do Laboratório de Filmes Finos, principalmente à Prof ${ }^{\mathrm{a}}$ Dra. Maria Cecília B. S. Salvadori pela orientação neste trabalho. Aos companheiros de laboratório: Fernanda e Leonardo, por toda ajuda na parte experimental e discussões valiosas; Nataly, pelas conversas e por sua alegria contagiante; Raissa, pelas conversas e por toda a ajuda no LTEX; Robinson, Roman e Wagner pela amizade e pelo companheirismo, muito obrigada à todos vocês! Agradeço também à Irina, que mesmo tendo passado pouco tempo por aqui, trouxe uma amizade valiosa!

À Prof ${ }^{\mathrm{a}}$ Dra. Marcia L. A. Temperini e ao seu aluno de Doutorado, Giordano Toscano Paganoto, do Laboratório Espectroscopia Molecular do Instituto de Química da USP, por toda a ajuda na obtenção dos espectros SERS e UV-Vis e as simulações GMM apresentados neste trabalho. Ainda, agradeço por todas as sugestões e esclarecimentos, muito obrigada!

Ao meu querido amigo, Gustavo Bertoni, por toda sua amizade e por me acompanhar nesta jornada!

Ao Shihan Moriyama, pelos seus ensinamentos valiosos, que levarei por toda a vida.

Agradeço também ao Sr. Nildemar A. M. Ferreira do Instituto de Pesquisas Energéticas e Nucleares, Centro de Ciência e Tecnologia de Materiais (IPEN, CCTM) pela assistência na obtenção das imagens por Microscopia Eletrônica de Transmissão.

À minha família: meus pais, Lidia e Carlos, que sempre incentivaram os meus estudos. Em especial à minha mãe, pelo apoio incondicional; meus irmãos, Mário e Patrícia, pelos momentos de descontração e por todo o companheirismo; meu avô, Mário Gushiken, por nunca questinar minhas escolhas; e meus avós (in memoriam), Helena F. Gushiken, Haruko Hokama e Koichi Hokama por todo o apoio e amor que me deram quando em vida...

Por útlimo, agradeço ao karma que me foi dado, permitindo viver na mesma época de tantas pessoas maravilhosas.

Muito obrigada à todos! 
"One of the sins is to lie to yourself. If you're not honest to your heart, that's a bad thing. I was lying to myself. I started to following what my heart would say. I started to correct things I was doing that I knew were wrong." (NISHIMURA, KODO - Monge Budista) "Mesmo que o processo seja lento, toda caminhada começa com o primeiro passo." (MASHIMA, HIRO; Lucy Heartfilia, Fairy Tail) 


\section{Resumo}

GUSHIKEN, N. K. Estudo de compósito formado por nanopartículas de ouro em matriz polimérica como substratos para análise SERS. 2019. 82 p. Dissertação (Mestrado) - Escola Politécnica, Universidade de São Paulo, São Paulo, 2019.

Um dos principais desafios no sensoriamento químico e biológico se encontra na detecção de traços de uma dada substância (analito), podendo chegar ao regime de detecção de uma única molécula. Uma forma de se obter este regime de detecção é por meio de análises utilizando a técnica SERS (Surface-Enhanced Raman Spectroscopy) utilizando substratos contendo nanoestruturas metálicas. Neste contexto, um material compósito formado por nanopartículas de ouro localizadas abaixo da superfície de um polímero, o polimetilmetacrilato (PMMA), foi estudado para a utilização como substratos para SERS. Neste trabalho, as nanopartículas foram produzidas através da implantação iônica de baixa energia (49 eV) de ouro em filme fino de PMMA utilizando plasma de arco catódico. O diâmetro médio da nanopartícula para dose de $0,75 \times 10^{16}$ átomos $/ \mathrm{cm}^{2}$ é de $(4,25$ $\pm 0,02) \mathrm{nm}$. Verificou-se que, utilizando esta técnica, as nanopartículas são formadas a uma profundidade de $10 \mathrm{~nm}$ abaixo da superfície do polímero. Utilizando esse material como substrato SERS, análises com analito Rodamina 6G (R6G) foram realizadas, e como fonte de excitação, um laser com comprimento de onda de $633 \mathrm{~nm}$. Desta forma, verificou-se a presença dos picos característicos da R6G com concentração de $10 \mu \mathrm{M}$, nos espectros obtidos, o que não foi possível para um substrato de PMMA sem implantação de ouro. Neste trabalho, pôde-se verificar que a dose utilizada na implantação iônica influencia na intensidade do espectro, de forma que foi observado o aumento da intensidade do sinal SERS com o aumento da dose de implantação no intervalo de 0,64 a 1,02 x $10^{16}$ átomos $/ \mathrm{cm}^{2}$. Outro efeito observado foi a ocorrência de uma maior intensidade do sinal SERS quando se mantém a camada de PMMA sobre a camada compósita, isto é, sem expor as nanopartículas através da remoção da camada de polímero acima delas. Este comportamento pode ser explicado pelo efeito do intumescimento do PMMA, pela solução de R6G, que pode favorecer o aprisionamento das moléculas de R6G na camada de polímero sobre a camada compósita. O melhor resultado foi obtido ao aquecer os substratos a $150{ }^{\circ} \mathrm{C}$ por 6 horas. O aquecimento, ao contrário do que se imaginava, não aumenta o tamanho da nanopartícula, mas torna a distribuição de geometrias das nanopartículas mais homogênea, fato que é corroborado através das micrografias obtidas por microscopia eletrônica de transmissão e pelas análises estatísticas. Utilizando a técnica de Espectrofotometria na região Ultravioleta-Visível (UV-Vis) para análise dos substratos que passaram pelo aquecimento, verificou-se um deslocamento de aproximadamente $40 \mathrm{~nm}$ do pico de extinção, para a região do vermelho, no espectro do substrato sem a camada de PMMA sobre a camada compósita, além de uma diminuição da extinção. Este resultado 
indica que a camada de PMMA sobre as nanopartículas influencia as propriedades ópticas do substrato, de forma que ocorre o a variação da extinção em função da espessura da camada de PMMA. Além disso os espectros UV-Vis obtidos após o aquecimento dos substratos também corroboram o fato de que há alteração na geometria das nanopartículas.

Palavras-chaves: Nanopartículas. Implantação iônica. Filmes finos. SERS. 


\section{Abstract}

GUSHIKEN, N. K. Study of composite formed by gold nanoparticles in polymer matrix as substrates for SERS analysis. 2019. 82 p. Dissertação (Mestrado) - Escola Politécnica, Universidade de São Paulo, São Paulo, 2019.

One of the main challenges in chemical and biological sensing lies in the detection of traces of a given substance (analyte) and can reach the detection regime of a single molecule. One way of obtaining this detection regime is through the Surface-Enhanced Raman Spectroscopy (SERS) technique using substrates containing metal nanostructures. In this context, a composite material formed by gold nanoparticles buried in the surface of a polymer, polymethylmethacrylate (PMMA) has been studied as substrates for SERS. In this work, the nanoparticles were produced by low energy gold ion implantation $(49 \mathrm{eV})$, in thin film of PMMA, using cathodic arc plasma. We found that, using this technique, the nanoparticles are formed $10 \mathrm{~nm}$ below the surface of the polymer, with mean nanoparticle diameter of $(4.25 \pm 0.02) \mathrm{nm}$ at a dose of $0.75 \times 10^{16}$ atoms $/ \mathrm{cm}^{2}$. Using this material as SERS substrate, we performed analyzes with analyte Rhodamine 6G (R6G), and as a source of excitation, a laser with wavelength of $633 \mathrm{~nm}$. In this way, we verified the presence of the characteristic peaks of Rhodamine $6 \mathrm{G}$, with concentration of $10 \mu \mathrm{M}$, which was not possible for a PMMA substrate without gold implantation. In this work, it was verified that the dose used in the gold ion implantation influences the intensity of the spectrum, so that the increase of the SERS signal intensity was observed with the increase of the implantation dose in the range of $0.64 \times 10^{16}$ to $1.02 \times 10^{16}$ atoms $/ \mathrm{cm}^{2}$. Another observed effect was the occurrence of a higher intensity of the SERS signal when the PMMA layer was maintained on the composite layer, i.e. without exposing the nanoparticles by removing the polymer layer above them. This behavior can be explained by the swelling effect, which may favor the entrapment of R6G molecules in the polymer layer above the composite layer. The best signal was obtained after annealing the substrates at 150 ${ }^{\circ} \mathrm{C}$ for 6 hours. The annealing does not increase the size of nanoparticles, but makes the distribution of geometries more homogeneous, a fact that is corroborated by the micrographs obtained by transmission electron microscopy and by the statistical analyzes. Using the Spectrophotometry technique in the Ultraviolet-Visible (UV-Vis) region, there was a redshift of approximately $40 \mathrm{~nm}$ of the extinction peak of the sample without the PMMA layer above the composite layer, in addition there was a decrease in the extinction. Also, the obtained UV-Vis spectra of the annealed sample corroborate to the fact that there is alteration in the nanoparticles geometry.

Key-words: Nanoparticles. Ion Implantation. Thin films. SERS 


\section{Lista de ilustrações}

Figura 1 - Formação do plasma de superfície, envolvendo a origem do dipolo elétrico e o efeito da força restauradora. . . . . . . . . . . . . . . . . . 22

Figura 2 - Estrutura molecular do monômero de PMMA. . . . . . . . . . . . . . . 26

Figura 3 - Processo por litografia por feixe de elétrons utilizando o PMMA como resiste positivo. (a) PMMA original; (b) Sensibilização do PMMA; (c) Remoção da região sensibilizada. . . . . . . . . . . . . . . . . . 26

Figura 4 - Esquema do implantador formado pelo canhão de plasma, filtro de partículas e porta amostra. . . . . . . . . . . . . . . 27

Figura 5 - Representação, em cross-section, do processo de formação do degrau de ouro. (a) Traço com marcador de retroprojetor, (b) deposição de ouro e (c) formação do degrau após a remoção da tinta do marcador. . . . . . 28

Figura 6 - Desenho esquemático do microscópio eletrônico de varredura. . . . . . 31

Figura 7 - Simulações de Monte Carlo das trajetórias dos elétrons no volume de

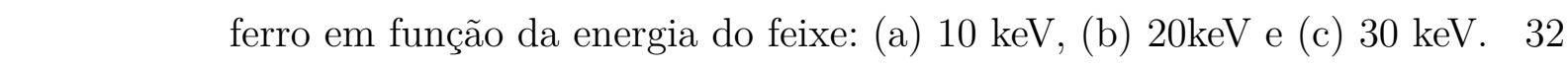

Figura 8 - Simulações de Monte Carlo das trajetórias dos elétrons ao utilizar um

feixe com energia de $20 \mathrm{keV}$ em função do da amostra: (a) Prata e (b)

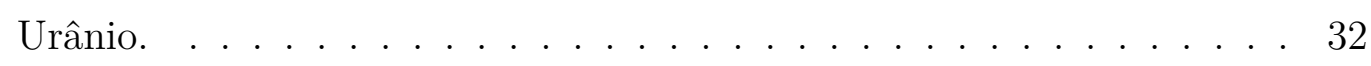

Figura 9 - Forças de Van der Waals em função da distância ponta-amostra. . . . . 34 Figura 10 - Esquemas dos mecanismos de espalhamento: (a) Rayleigh, (b) Stokes e (c) anti-Stokes. . . . . . . . . . . . . . . . 36

Figura 11 - Representação da vista em cross-section no filme de PMMA (a) original (b) após a deposição do ouro e (c) após a revelação da camada de

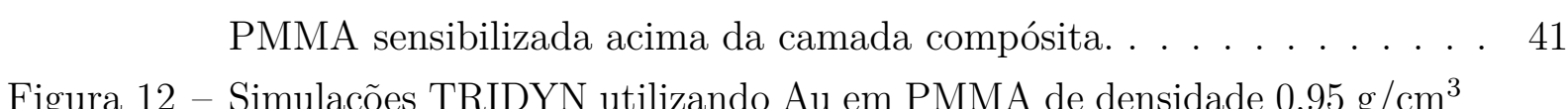

Figura 12 - Simulações TRIDYN utilizando Au em PMMA de densidade $0,95 \mathrm{~g} / \mathrm{cm}^{3}$ variando a energia de implantação. . . . . . . . . . . . . . . . . . . . 42

Figura 13 - Simulações TRIDYN utilizando Au em PMMA de densidade $1,2 \mathrm{~g} / \mathrm{cm}^{3}$ variando a energia de implantação. . . . . . . . . . . . . . . . . . . . 42

Figura 14 - Vista de topo dos cortes de PMMA indicam a presença de nanopartículas após os processos de implantação e de revelação. . . . . . . . . . . . . . . 43

Figura 15 - Estrutura molecular da R6G. . . . . . . . . . . . . . . . . . . . 44

Figura 16 - Espectro SERS obtido para (a) um substrato de PMMA com nanopar-

\begin{tabular}{|c|}
\hline tículas de ouro tratado com $10 \mu \mathrm{M}$ de RG6, (b) um substrato tratado \\
\hline
\end{tabular}
com 1 nM de RG6 e para (c) um substrato "branco". . . . . . . . . . . 45

Figura 17 - Espectro SERS obtido para substratos de PMMA com doses de ouro de (a) $0,64 \times 10^{16}$, (b) $0,81 \times 10^{16}$ e (c) $1,02 \times 10^{16}$ átomos $/ \mathrm{cm}^{2}$, tratados com $10 \mu \mathrm{M}$ de RG6. . . . . . . . . . . . . . . . . . . 45 
Figura 18 - Comparativo entre o sinal da rodamina depositada por spin-coating (a)

\begin{tabular}{|c|c|}
\hline & na amostra "revelada" e (b) na amostra "não revelada". \\
\hline 9 & Comparativo entre o sinal da rodamina depositada por deep-coating (a) \\
\hline & na amostra "revelada" e (b) na amostra "não revelada". \\
\hline 20 & Espectro SERS da R6G em diferentes tipos de substratos: PMMA \\
\hline & sem nanopartículas de ouro (preto), não é possível observar os picos \\
\hline & característicos da R6G; amostra "não revelada" - AuNPs enterradas \\
\hline & (vermelho); amostra "revelada" - AuNPs expostas (azul); amostra "não \\
\hline & revelada" com aquecimento (verde). Dos \\
\hline & $0,85 \times 10^{16}$ átomos $/ \mathrm{cm}^{2}$ e (b) $0,83 \times 10^{16}$ átomos $/ \mathrm{cm}^{2}$. \\
\hline
\end{tabular}

Figura 21 - Vista de topo dos cortes de PMMA com AuNPs: (a) sem aquecimento; (b) após aquecimento. Dose de implantação $0,83 \times 10^{16}$ átomos $/ \mathrm{cm}^{2} . \quad$. 50

Figura 22 - Resultados das simulações de fator de intensificação SERS das nanopartículas de ouro (a) "não aquecidas" e (b) "aquecidas". . . . . . . . . . 51

Figura 23 - Histogramas de circularidade do compósito AuNPs/PMMA "não aquecido" (azul) e "aquecido" (vermelho). . . . . . . . . . . . . . . . . . . 52

Figura 24 - Histogramas da razão de aspecto do compósito AuNPs/PMMA "não aquecido" (azul) e "aquecido" (vermelho). . . . . . . . . . . . . . . 52

Figura 25 - Espectro UV-vis comparando uma amostra "revelada" com a "não

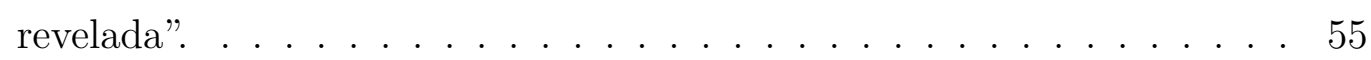

Figura 26 - Espectro UV-vis comparando as amostras "aquecida" e "não aquecida", com dose de implantação de $0,65 \times 10^{16}$ átomos $/ \mathrm{cm}^{2}$. . . . . . . . . . . 56

Figura 27 - Perfil em cross-section da imagem obtida por AFM de PMMA litografado por feixe de elétrons com corrente $40 \mathrm{pA}$. (a) dose $30 \mu \mathrm{C} / \mathrm{cm}^{2}$; (b)

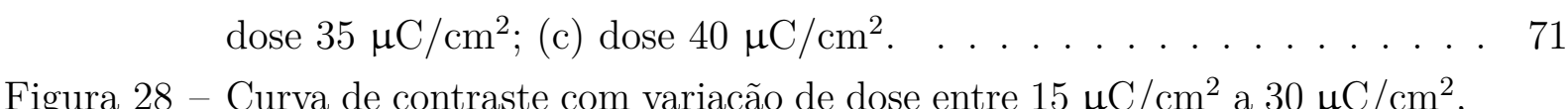
com corrente do feixe igual à $40 \mathrm{pA}$. . . . . . . . . . . . . . . 72

Figura 29 - Perfil em cross-section de PMMA litografado por feixe de elétrons ao utilizar dose de $30 \mu \mathrm{C} / \mathrm{cm}^{2}$ (a) para corrente de $30 \mathrm{pA} \mathrm{e} \mathrm{(b)} \mathrm{para} \mathrm{corrente}$ de $40 \mathrm{pA} . \ldots \ldots \ldots \ldots \ldots . \ldots \ldots . \ldots \ldots 73$

Figura 30 - Secagem da grade com papel de filtro . . . . . . . . . . . . . . . . 74

Figura 31 - Parâmetros das curvas log-normal da amostra não aquecida. . . . . . . 77

Figura 32 - Parâmetros das curvas log-normal da amostra aquecida. . . . . . . . . 78 


\section{Lista de tabelas}

Tabela 1 - Parâmetros de entrada utilizados nas simulações utilizando o PMMA como alvo. . . . . . . . . . . . . . . . . . . . . . . . 39

Tabela 2 - Resultados das simulações TRIM apresentando a profundidade da máxima concentração. . . . . . . . . . . . . . . . . . 42

Tabela 3 - Resultados de diâmetro médio e distância entre as nanopartículas das amostras "não aquecida" e "aquecida", e os respectivos erros padrão. . 50

Tabela 4 - Resultados dos valores mais prováveis de razão de aspecto e circularidade, e os respectivos erros padrão, das nanopartículas contidas no compósito AuNPs/PMMA "não aquecido" e "aquecido". . . . . . . . . . . . . . 53

Tabela 5 - Resultados de rugosidade RMS da superfície do PMMA, e seu respectivo erro padrão; AuNPs/PMMA formados com dose de $0,83 \times 10^{16}$ átomos $/ \mathrm{cm}^{2} 53$

Tabela 6 - Parâmetros utilizados na obtenção dos espectros SERS. . . . . . . . . . 76

Tabela 7 - Potência média do laser de comprimento de onda de $633 \mathrm{~nm}$. . . . . . . 76

Tabela 8 - Parâmetros e resultados do cálculo do tamanho da partícula através dos espectros UV-Vis. . . . . . . . . . . . . . . . . . 8 80 


\section{Lista de abreviaturas e siglas}

AFM Atomic Force Microscopy/Microscope - Microscopia/Microscópio de Força Atômica

AuNPs $\quad$ Au Nanoparticles - Nanopartículas de Au (ouro)

CAD $\quad$ Computer Assisted Design

EDS Energy Dispersive Spectroscopy - Espectroscopia por Dispersão de Energia

EF Enhancement Factor - Fator de intensificação SERS

$\mathrm{EF}_{E M} \quad$ Fator de intensificação eletromagnético

GMM $\quad$ Generalized multiparticle Mie

HOMO Highest Occupied Molecular Orbital - orbital molecular ocupado mais alto

IFUSP Instituto de Física da Universidade de São Paulo

IPA Isopropyl alcohol - Álcool isopropílico

IQ-USP Instituto de Química da Universidade de São Paulo

LAMFI Laboratório de Materiais e Feixes Iônicos

LEM Laboratório de Espectroscopia Molecular

LFF $\quad$ Laboratório de Filmes Finos

LUMO Lowest Unoccupied Molecular Orbital - orbital molecular desocupado mais baixo

MET Microscopia/Microscópio Eletrônico de Transmissão

MEV Microscopia/Microscópio Eletrônico de Varredura

MIBK Methyl isobutyl ketone - Metil isobutil cetona

NPGS Nanometer Pattern Generation System - Sistema de geração de padrões para litografia por feixe de elétrons

PDMS Polydimethylsiloxane - Polidimetilsiloxano 
PMMA Polimetilmetacrilato

R6G Rodamina 6G

RBS Rutherford Backscattering Spectroscopy - Espectrometria de Espalhamento Rutherford

rpm Rotações por minuto

SERS Surface-Enhanced Raman Spectroscopy - Espectroscopia Raman amplificada por superfície

SPM Scanning Probe Microscopy/Microscope - Microscopia/Microscópio de Varredura por Sonda

STM Scanning Tunneling Microscopy/Microscope - Microscopia/Microscópio de Varredura por Tunelamento

TEM Transmission Electron Microscopy/Microscope-Microscopia/Microscópio Eletrônico de Transmissão

TRIDYN Código TRIM considerando alterações dinâmicas durante as interações íon-matéria

TRIM Transport of Ions in Matter - Código de simulação de interação de íons com a matéria

UV Ultravioleta

UV-Vis Ultravioleta-Visível, referente à técnica de Espectrofotometria na região do Ultravioleta-Visível

AuNPs/PMMA Nanopartículas de ouro em PMMA 


\section{Lista de símbolos}

\begin{tabular}{|c|c|}
\hline$\lambda$ & Comprimento de onda \\
\hline$R$ & Raio da partícula \\
\hline $\mathrm{Cu}$ & Elemento químico Cobre \\
\hline $\mathrm{Ag}$ & Elemento químico Prata \\
\hline $\mathrm{Au}$ & Elemento químico Ouro \\
\hline$\kappa(\lambda)$ & Coeficiente de absorção \\
\hline$N$ & Número de esferas por unidade de volume do material \\
\hline$V$ & Volume da esfera \\
\hline$\varepsilon(\lambda)$ & Função dielétrica do metal \\
\hline$\varepsilon_{1}(\lambda)$ & Parte real da função dielétrica do metal \\
\hline$\varepsilon_{2}(\lambda)$ & Parte imaginária da função dielétrica do metal \\
\hline$\varepsilon_{m}$ & Constante dielétrica do meio \\
\hline$A(\lambda)$ & Absorção \\
\hline$L$ & Caminho óptico \\
\hline$\sigma$ & Condutividade Elétrica \\
\hline$\phi$ & Dose de implantação \\
\hline$x$ & Razão de concentração das doses de implantação $\phi / \phi_{0}$ \\
\hline$\phi_{0}$ & Dose de saturação do sistema compósito \\
\hline$\sigma_{0}$ & Condutividade de saturação \\
\hline$x_{c}$ & Concentração crítica (limiar de percolação) \\
\hline$t$ & Expoente crítico \\
\hline$\phi_{c}$ & Dose crítica \\
\hline$\rho_{A u}$ & Densidade do ouro $\left[\mathrm{g} / \mathrm{cm}^{3}\right]$ \\
\hline $\mathrm{M}_{A u}$ & Massa molar do ouro $[\mathrm{g} / \mathrm{mol}]$ \\
\hline
\end{tabular}




\begin{tabular}{|c|c|}
\hline $\mathrm{N}_{A}$ & Número de Avogadro [átomos/mol] \\
\hline$I$ & Corrente de tunelamento \\
\hline$V$ & Diferença de potencial entre a ponta e amostra no STM \\
\hline$c$ & Constante relacionado ao material e a ponta no STM \\
\hline$d$ & Distância entre a ponta e a amostra \\
\hline$k$ & Fator cinemático \\
\hline$E_{1}$ & Energia do íon retro-espalhado \\
\hline$E_{0}$ & Energia inicial do íon \\
\hline$M_{1}$ & Massa do íon \\
\hline$M_{2}$ & Massa do átomo do alvo \\
\hline$\theta$ & Ângulo de retro-espalhamento \\
\hline$\pi$ & Ângulo Pi. Equivalente à $180^{\circ}$ \\
\hline$v_{0}$ & Estado fundamental do nível vibracional \\
\hline$v_{1}$ & Estado excitado do nível vibracional \\
\hline$r$ & Estado virtual do nível vibracional \\
\hline$P_{T r a}$ & Potência transmitida \\
\hline$P_{I n c}$ & Potência da radiação incidente \\
\hline$P_{\text {Ext }}$ & Potência de extinção \\
\hline$P_{A b s}$ & Potência de absorção \\
\hline$P_{E s p}$ & Potência de espalhamento \\
\hline$\sigma_{E x t}$ & Seção de choque de extinção \\
\hline$\sigma_{A b s}$ & Seção de choque de absorção \\
\hline$\sigma_{E s p}$ & Seção de choque de espalhamento \\
\hline $\mathrm{c}_{m}$ & Concentração de moléculas \\
\hline$\varepsilon_{E x t}$ & Coeficiente de extinção molar \\
\hline $\mathrm{H}$ & Elemento químico Hidrogênio \\
\hline
\end{tabular}


C Elemento químico Carbono

O Elemento químico Oxigênio

$h_{0} \quad$ Espessura original do filme de PMMA [nm]

$h_{1} \quad$ Espessura do filme de PMMA após a implantação iônica [nm]

$h_{2} \quad$ Espessura do filme de PMMA após a etapa de revelação [nm]

$\rho_{P M M A} \quad$ Densidade do PMMA $\left[\mathrm{g} / \mathrm{cm}^{3}\right]$

$T_{G} \quad$ Temperatura de transição vítrea

$T_{G_{P M M A}} \quad$ Temperatura de transição vítrea do PMMA

${ }^{\circ} \mathrm{C} \quad$ Graus Celsius

E Amplitude do campo elétrico local

$E_{\text {inc }} \quad$ Amplitude do campo elétrico da radiação incidente

$\vec{k} \quad$ Vetor de onda

$\overrightarrow{E_{0}} \quad$ Amplitude do campo elétrico da radiação

$+\infty \quad$ Infinito à direita

$T_{F_{A u}} \quad$ Temperatura de fusão do ouro

y0 Offset da curva de ajuste log-normal

xc Mediana da curva de ajuste log-normal

w Desvio padrão do logaritmo

A Área sob a curva de ajuste log-normal

D Diâmetro da nanopartícula

$n \quad$ Componente real do índice de refração

$k \quad$ Componente imaginário do índice de refração 


\section{Sumário}

Introdução . . . . . . . . . . . . . . . . . . . . . . . . 20

Fundamentos Teóricos . . . . . . . . . . . . . . . 22

Ressonância de Plasma de Superfície . . . . . . . . . . . . . . . . . 22

Percolação em Compósitos . . . . . . . . . . . . . . . . . . . . . . 23

I Materiais e Métodos $\quad 25$

1 Preparação de amostras . . . . . . . . . . . . . . . 26

1.1 Polimetilmetacrilato (PMMA) … . . . . . . . . . . . . 26

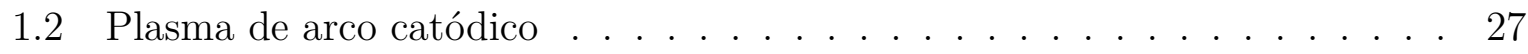

1.3 Medida de taxa de deposição utilizando plasma de arco catódico . . . . . . 28

$1.4 \quad$ Litografia por feixe de elétrons . . . . . . . . . . . . . . . . . . . . 29

1.5 Implantação de ouro com plasma de arco catódico . . . . . . . . . . 30

2 Técnicas de Caracterização $\ldots \ldots \ldots \ldots \ldots \ldots \ldots \ldots$

2.1 Microscopia Eletrônico de Varredura (MEV) … . . . . . . . . . . 31

$2.2 \quad$ Microscopia Eletrônica de Transmissão (MET) $\ldots \ldots \ldots \ldots \ldots$. . . . . . 32

$2.3 \quad$ Microscopia de Varredura por Sonda (Scanning Probe Microscopy -SPM) 33

$2.4 \quad$ Rutherford Backscattering Spectrometry (RBS) . . . . . . . . . . 34

$2.5 \quad$ Espectroscopia Raman $\ldots \ldots \ldots \ldots \ldots \ldots \ldots \ldots \ldots \ldots$

$2.5 .1 \quad$ Espectroscopia Raman Intensificada por Superfície $\ldots \ldots \ldots$. . . 36

$2.6 \quad$ Espectrofotometria na região Ultravioleta-Visível (UV-Vis) . . . . . . . . . 37

2.6 .1 Lei de Beer-Lambert . . . . . . . . . . . . . . . 38

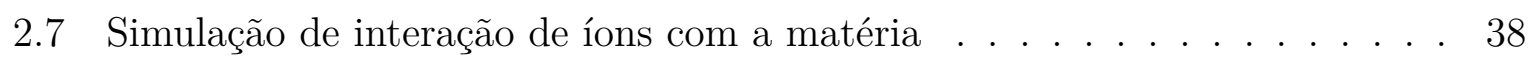

2.7 .1 Transport of ions in matter (TRIM) _ . . . . . . . . . 38

2.7 .2 TRIDYN $\ldots \ldots \ldots \ldots \ldots \ldots \ldots$

II Resultados 40

3 Resultados e Discussões . . . . . . . . . . . . . . . . . . 41

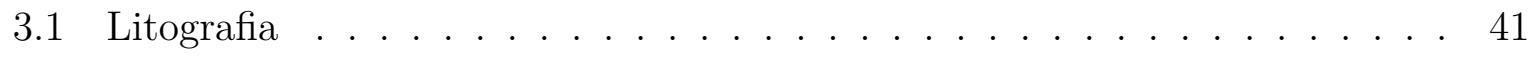

3.2 Simulações TRIM e TRIDYN $\ldots \ldots \ldots \ldots \ldots \ldots$

3.3 Microscopia Eletrônica de Transmissão de compósito AuNPs/PMMA . . . 43

3.4 Resultados das medidas SERS $\ldots \ldots \ldots \ldots \ldots$. . . . . . . . . . . 44

$3.5 \quad$ Microscopia Eletrônica de Transmissão de compósito AuNPs/PMMA após tratamento térmico . . . . . . . . . . . . . . . . . . 49

$3.6 \quad$ Resultados das medidas de Espectrofotometria UV-Vis $\ldots \ldots \ldots \ldots . .54$ 


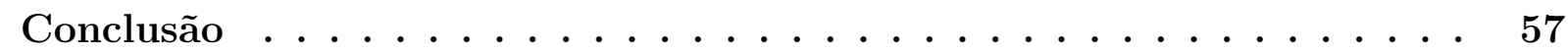

Perspectivas Futuras . . . . . . . . . . . . . . . . . 61

Referências. .......................... 62

\begin{tabular}{ll}
\hline Apêndices & 69
\end{tabular}

\begin{tabular}{|lll}
\hline APÊNDICE & A Limpeza de substratos e fabricação do filme de PMMA & $\mathbf{7 0}$
\end{tabular}

APÊNDICE B Calibração da Litografia . . . . . . . . . . . . . 71

APÊNDICE C Procedimentos para revelar filmes de PMMA em grades de Microscopia Eletrônica de Transmissão . . . . . . . . 74

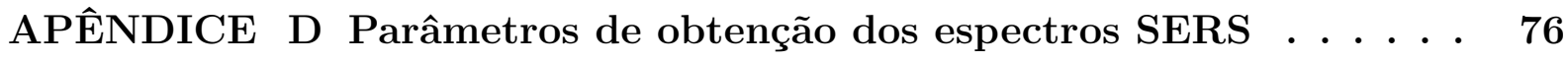

APÊNDICE E Parâmetros das curvas log-normal ajustadas aos histo-

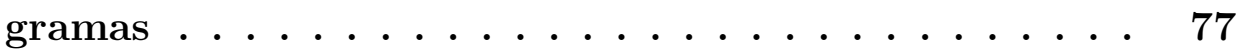

APÊNDICE F Cálculo do tamanho da partícula através do espectro UV-Vis . . . . . . . . . . . . . . . 79

APÊNDICE G Apresentação em Congresso Nacional: XLIII Congresso da Sociedade Brasileira de Biofísica . . . . . . . . . . . . 81 


\section{Introdução}

Nanopartículas metálicas exibem propriedades ópticas e elétricas diferentes do material em forma de bulk, assim existe um grande interesse no estudo deste material devido à grande variedade de aplicações, tais como óptica, eletrônica, sensoriamento, catálise, imageamento em biomedicina, entre outros [1-3]. Tendo isto em vista, um dos principais desafios no sensoriamento químico e biológico se encontra na detecção de traços de uma dada substância (analito), podendo chegar idealmente ao regime de detecção de uma única molécula. Uma forma possível de se obter esta detecção é por meio de medidas por SERS (Surface-Enhanced Raman Spectroscopy) utilizando substratos contendo nanoestruturas metálicas [4 8], no caso deste trabalho, nanopartículas de ouro (AuNPs) formadas abaixo da superfície do polimetilmetacrilato (PMMA). Esta abordagem permite a formação de nanopartículas no interior do substrato e com a vantagem de protegê-las do meio ambiente, garantindo a estabilidade da camada compósita [9, 10].

Existem diversos métodos, químicos e físicos, que têm sido desenvolvidos para a síntese das nanopartículas metálicas, tais como redução química, redução eletroquímica, foto-redução, vaporização por laser, sputtering, deposição por feixe de elétrons, entre outros [1, 2, 11, 15]. Neste trabalho, o material compósito foi produzido por meio da implantação iônica de baixa energia $(49 \mathrm{eV})$ de ouro em PMMA utilizando plasma de arco catódico. A formação das nanopartículas ocorre espontaneamente e pode ser explicada pela ocorrência de concentração dos átomos metálicos acima do limite de solubilidade no substrato implantado, levando à nucleação e à formação de nanopartículas metálicas [16].

Assim, neste trabalho visamos estudar nanocompósitos formados por nanopartículas de ouro em PMMA como substrato para SERS. As técnicas de caracterização mais relevantes utilizadas foram Microscopia Eletrônica de Transmissão (Transmission Electron Microscopy - TEM), Microscopia de Força Atômica (Atomic Force Microscopy - AFM), Espectrofotometria na região Ultravioleta-Visível (UV-Vis) e SERS. Como complementação, foi utilizada a técnica de RBS (Rutherford Backscattering Spectrometry) para medir a dose do metal implantado. E ainda, recursos computacionais, tais como simulações numéricas com os programas TRIM e TRIDYN, foram realizadas para fornecer o perfil esperado da distribuição dos átomos implantados.

\section{Organização do Texto}

Este trabalho está dividido em três partes. Na primeira parte, serão introduzidos alguns dos fundamentos teóricos importantes para o entendimento deste trabalho, outros fundamentos serão apresentados no decorrer deste texto à medida que forem necessários. Em 
seguida, na Parte [são descritos os procedimentos experimentais utilizados para a fabricação das amostras e os princípios das técnicas de caracterização utilizadas. Na Parte II, são apresentados os resultados obtidos, bem como a análise e discussões destes resultados. Por fim, é dado continuidade ao texto, apresentando as conclusões e sugestões de continuidade deste trabalho. Na Seção de Apêndices, são encontradas as descrições detalhadas de alguns procedimentos realizados neste trabalho e a apresentação em Congresso Nacional. 


\section{Fundamentos Teóricos}

\section{Ressonância de Plasma de Superfície}

Quando uma radiação de comprimento de onda $(\lambda)$ incide em uma partícula de raio $(R)$, onde $R \ll \lambda$, efeitos de superfície passam a se tornar bastante importantes, e por essa razão, as propriedades ópticas de nanopartículas metálicas são dominadas por uma oscilação coletiva dos elétrons de condução em ressonância com a radiação eletromagnética incidente [17]. Metais como $\mathrm{Cu}, \mathrm{Ag}$ e $\mathrm{Au}$, geram partículas estáveis e a frequência de ressonância plasmônica se encontra na região visível do espectro, assim estes metais são os mais utilizados para realizar experimentos relacionados ao plasma de superfície.

Figura 1 - Formação do plasma de superfície, envolvendo a origem do dipolo elétrico e o efeito da força restauradora.

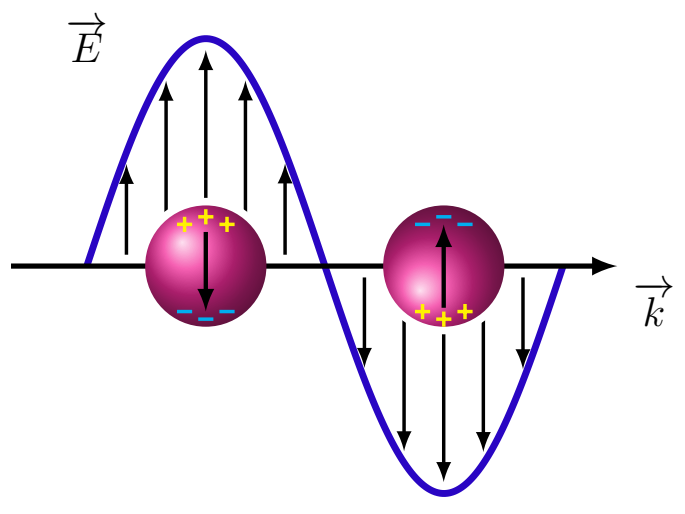

Fonte: Olson et al. 201518
De forma breve, na formação do plasma de superfície, considera-se que as cargas positivas da partícula são imóveis, enquanto que as cargas negativas (elétrons de condução) têm mobilidade quando são sujeitos ao campo elétrico da radiação, induzindo a formação de um dipolo que promove uma força restauradora no sentido de retornar ao equilíbrio, impondo uma frequência de ressonância ao sistema (Figura 1). Assim, na condição $R \ll \lambda$, absorção da radiação é causada principalmente pela oscilação dos dipolos elétricos, e o coeficiente de absorção $\kappa(\lambda)$, devido à esferas metálicas incorporados em um polímero, é dado em função do comprimento de onda $\lambda[17,19]$ :

$$
\kappa(\lambda)=\frac{108 N V \varepsilon_{m}^{3 / 2}}{\lambda} \frac{\varepsilon_{2}}{\left(\varepsilon_{1}+2 \varepsilon_{m}\right)^{2}+\varepsilon_{2}^{2}}
$$

onde $N$ é o número de esferas por unidade de volume do material, $V$ é o volume de cada esfera, $\varepsilon_{1}$ e $\varepsilon_{2}$ são as partes real e imaginária, respectivamente, da função dielétrica do metal $\varepsilon(\lambda)=\varepsilon_{1}(\lambda)+i \varepsilon_{2}(\lambda)$ e $\varepsilon_{m}$ é a constante dielétrica do meio. A absorção $A(\lambda)$ está relacionada com o caminho óptico $L$, que é a profundidade de camada de nanopartículas sob a superfície, e com o coeficiente de absorção $\kappa(\lambda)$ da seguinte forma [20]:

$$
A(\lambda)=\frac{\kappa(\lambda) / \ln (10)}{L}
$$


Para nanopartículas muito menores do que a radiação incidente 21, a extinção é devido à absorção, assim $\kappa(\lambda)$ é equivalente ao coeficiente de extinção. Melhor detalhamento sobre os processos de absorção, espalhamento e extinção da radiação eletromagnética estão descritos na Seção 2.6 .

\section{Percolação em Compósitos}

Os mecanismos de condutividade elétrica em um material compósito formado por nanopartículas metálicas em matriz isolante, podem ser descritos utilizando a teoria de percolação. Desta forma o transporte de elétrons neste material pode ocorrer através de dois processos distintos ou sua combinação: quando as partículas condutoras estão em contato geométrico, o processo é chamado de percolação, que se refere ao fluxo de corrente através de uma rede de resistores [22]; quando as partículas não estão em contato geométrico, o processo de condução ocorre por tunelamento, para dose de ouro de $0,8 \mathrm{x}$ $10^{16}$ átomos $/ \mathrm{cm}^{2}$, a distância entre as nanopartículas para a qual ocorre o tunelamento é de $(0,91 \pm 0,04) \mathrm{nm}[23]$. Ambos os processos podem contribuir simultaneamente, ou seja, o transporte elétrico entre as partículas pode ocorrer devido tanto à percolação como ao tunelamento.

A condutividade elétrica $(\sigma)$ para os materiais nanocompósitos formados por implantação iônica de íons metálicos em um isolante é função da dose de implantação $(\phi)$. Próximo à transição crítica condutor/isolante a condutividade é dada pela de escala:

$$
\sigma \approx \sigma_{0}\left(x-x_{c}\right)^{t}
$$

onde $x$ é a razão de concentração das doses de implantação $\phi / \phi_{0}$, sendo $\phi_{0}$ a máxima dose para a qual o sistema ainda é um nanocompósito (dose de saturação). Para doses maiores que $\phi_{0}$, um filme fino do material implantado estará se formando e o sistema passará a ter características de filme fino; $\sigma_{0}$ é a condutividade de saturação, correspondente à dose $\phi_{0}$ de implantação; $x_{c}$ é a concentração crítica normalizada (limiar de percolação) abaixo da qual o compósito possui praticamente a condutividade do substrato utilizado para a implantação; e $t$ é o expoente crítico.

Para o sistema (Au/PMMA) utilizado neste trabalho, a dose crítica $\phi_{c}$ para a percolação é $\phi_{c}=1 \times 10^{16}$ átomos $/ \mathrm{cm}^{2}$; a dose de saturação, dose máxima para o qual o material continua sendo um compósito, é de cerca de $2 \times 10^{16}$ átomos $/ \mathrm{cm}^{2}$; e o expoente crítico $t=1,64$ [24]. De acordo com modelos da literatura [22], quando $t<2$, podemos concluir que a condutividade do compósito é devido à percolação, sendo desprezível a contribuição do tunelamento no processo [19,25].

Tendo em vista que, para este trabalho, é interessante que se tenham nanopartí- 
culas isoladas para serem utilizadas como substratos SERS, é necessário que a dose de implantação seja abaixo da dose crítica $\left(\phi<\phi_{c} \mid \phi_{c}=1 \times 10^{16}\right.$ átomos $\left./ \mathrm{cm}^{2}\right)$. 


\section{Parte I}

Materiais e Métodos 


\section{Preparação de amostras}

\subsection{Polimetilmetacrilato (PMMA)}

O PMMA é um polímero comumente utilizado como um resiste positivo de alta resolução [27], cuja estrutura molecular do seu monômero $\left(\mathrm{C}_{5} \mathrm{H}_{8} \mathrm{O}_{2}\right)_{n}$ é mostrada na Figura 2, É obtido comercialmente em forma de solução, em diferentes formulações com variações de peso molecular, juntamente com seus respectivos reveladores, que são reagentes que removem somente as regiões expostas a uma fonte de radiação. As fontes de radiação podem consistir em um feixe de elétrons ou de íons, bem como raios $\mathrm{X}$ e deep $U V$ (radiação ultravioleta com comprimento de onda de aproximadamente $250 \mathrm{~nm}$ ) 28.
Figura 2 - Estrutura molecular do monômero de PMMA.

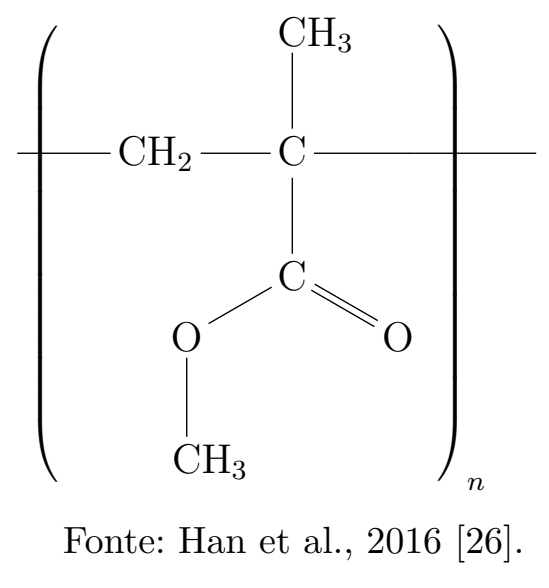

Para processos de litografia, o PMMA é depositado sobre o substrato sólido na forma de um filme fino contínuo e uniforme com espessura de poucos nanômetros a dezenas de micrômetros. Utilizando padrões de litografia, é possível expor áreas do filme à radiação de forma seletiva, como é mostrada na Figura 3. Sendo, o PMMA, um resiste positivo, ocorre a degradação do filme nas regiões nas quais foram expostas à radiação, esta degradação é devido à quebra de ligações das cadeias do polímero, que leva à uma diminuição no peso molecular médio tornando-as solúveis ao revelador 29]. Neste trabalho, os filmes de PMMA foram produzidos a partir de uma solução 950K A2 (2\% de PMMA de peso molecular $950000 \mathrm{~g} / \mathrm{mol}$ em Anisol), Micro-Chem.

Figura 3 - Processo por litografia por feixe de elétrons utilizando o PMMA como resiste positivo. (a) PMMA original; (b) Sensibilização do PMMA; (c) Remoção da região sensibilizada.

(a)

(b)

Feixe de elétrons

nwwwwwwrww
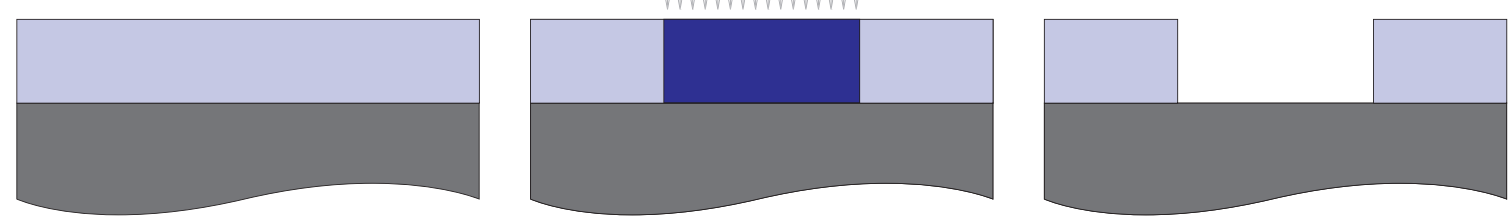

Silício

PMMA

PMMA sensibilizado

Fonte: A autora.

(c) 


\subsection{Plasma de arco catódico}

Um plasma de arco catódico é obtido quando uma descarga em arco é iniciada entre dois eletrodos em vácuo. O termo arco catódico é utilizado, pois os íons são originados pelo catodo [30]. O sistema utilizado (Figura 4) consiste em um canhão de plasma formado por um catodo em forma de bastão cilíndrico feito do material do qual se deseja obter o plasma, no caso deste trabalho, um catodo de ouro. O catodo é envolto em uma cerâmica e é posicionado dentro de um anodo cilíndrico de aço inoxidável. Um gatilho dispara uma descarga pulsada entre os eletrodos, provocando um faiscamento aleatório formando os cathode spots - pequenas áreas com alta densidade de corrente, potência e plasma [31]. A formação dos spots está relacionada à presença de um alto campo elétrico na superfície do catodo devido à algumas características geométricas, como micro protuberâncias, rachaduras, bem como camadas de óxido e partículas de poeira [32]. Devido à ação conjunta do bombardeamento iônico e aquecimento por efeito Joule nas regiões dos spots, o material do catodo é rapidamente transformado do estado sólido para o estado de plasma. Quanto ao anodo, que coleta os elétrons passivamente, não contribui com a formação do plasma, uma vez que possui um nível de corrente relativamente baixo.

Outra característica inerente aos Figura 4 - Esquema do implantador formado cathode spots é a formação de partículas líquidas ou sólidas de aproximadamente 0,1 pelo canhão de plasma, filtro de partículas e porta amostra.

a $10 \mu \mathrm{m}$ em adição à formação do plasma. Em grande parte das aplicações, essas partículas são indesejáveis, e para removê-las do plasma, um filtro de partículas é utilizado.

O filtro de partículas está conectado eletricamente em série com o canhão de plasma, e é formado por um solenoide de cobre enrolado em forma de um quarto de toroide. No centro do filtro se forma um campo magnético tipicamente entre 20 a

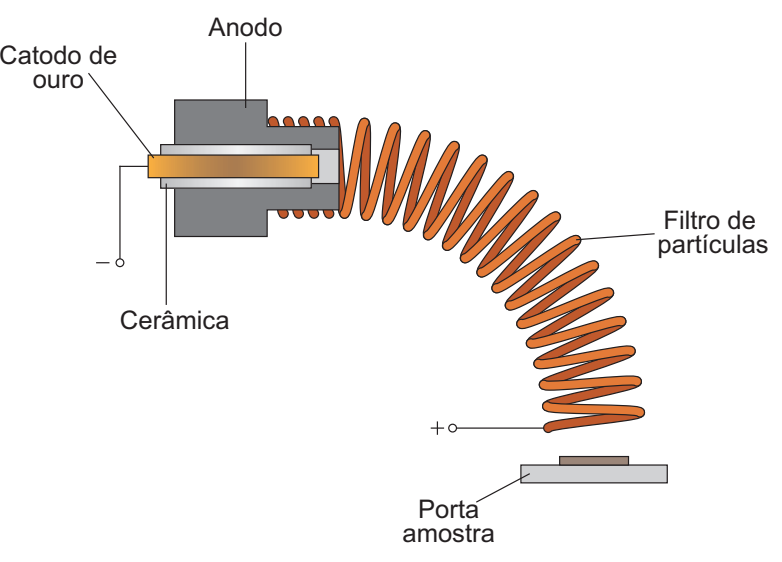

Fonte: Teixeira et al., 2009 |19]. $100 \mathrm{mT}$ que guia o plasma até o porta amostra posicionado na saída do filtro de partículas. Devido à grande inércia das partículas, elas possuem trajetórias praticamente retas, e consequentemente se chocam com as paredes do filtro ou saem pela tangente, assim o plasma chega na amostra praticamente livre de partículas.

O material utilizado na implantação é o ouro. A energia cinética dos íons do plasma é intrínseca à técnica, onde não é necessária a aplicação de bias no substrato, no caso do ouro é de $49 \mathrm{eV}$. Embora seja considerada uma implantação iônica de baixa energia, $49 \mathrm{eV}$ é o suficiente para que ocorra a penetração dos íons de ouro abaixo da superfície do substrato, neste caso o filme de PMMA, em uma profundidade de alguns nanômetros. 
Vale ressaltar que esta técnica, onde os íons têm energia cinética sem aplicação de bias no substrato, também é conhecida como deposição energética [31]. Por meio de simulações teóricas [33], foi visto que a nucleação dos átomos de ouro ocorre já no primeiro pulso da implantação (ou, deposição energética), que equivale à uma dose de $1 \times 10^{14}$ átomos $/ \mathrm{cm}^{2}$.

O sistema que comporta o canhão de plasma está localizado nas dependências do Instituto de Física da Universidade de São Paulo (IFUSP), no Laboratório de Filmes Finos (LFF). O canhão de plasma e o porta amostras estão posicionados dentro de uma câmara de vácuo, na qual está ligada uma bomba mecânica de palhetas de dois estágios para o pré-vácuo, uma bomba turbomolecular e uma bomba criogênica para o alto-vácuo.

\subsection{Medida de taxa de deposição utilizando plasma de arco catódico}

Devido à necessidade de controlar a dose de ouro implantada para a formação das nanopartículas foi necessário caracterizar o sistema de implantação iônica utilizando plasma de arco catódico. Um pedaço de lâmina de silício foi utilizado como substrato de controle, onde a taxa de deposição de ouro é calculada a partir da espessura do filme depositado na lâmina de silício em função do número de pulsos. Para calcular a espessura do filme, a lâmina de silício foi marcada com um traço utilizando um marcador de retroprojetor (Figura 5a), em seguida foi feita a deposição de Au (Figura 5b) sobre a lâmina marcada. Após a deposição a tinta do marcador foi removida delicadamente com um enxágue em acetona, assim a camada de Au formada sobre ela é removida, formando um degrau bem definido (Figura 5c). A altura do degrau, que corresponde à espessura do filme, é medida utilizando AFM (Atomic Force Microscopy).

Figura 5 - Representação, em cross-section, do processo de formação do degrau de ouro. (a) Traço com marcador de retroprojetor, (b) deposição de ouro e (c) formação do degrau após a remoção da tinta do marcador.

(a)

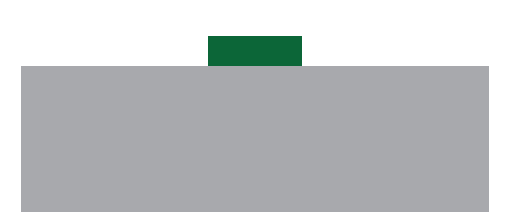

(b)

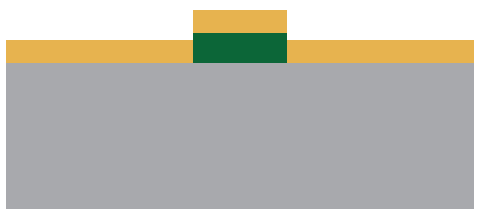

(c)

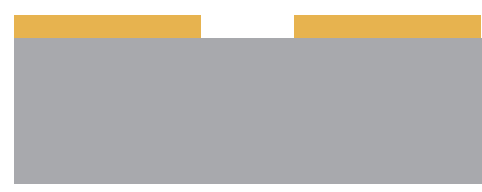

Silício

Marcador de retroprojetor

Ouro depositado

Fonte: A autora.

Foram obtidas três imagens por AFM no modo contato intermitente com uma janela de varredura de $50 \mu \mathrm{m}$ x $50 \mu \mathrm{m}$, em cada imagem foram feitas três medidas de altura de degrau para a obtenção da espessura média do filme de ouro. Dividindo o valor da 
espessura do filme pelo número de pulsos, obtêm-se a taxa de deposição, que corresponde a aproximadamente $0,04 \mathrm{~nm} /$ pulso. Utilizando uma relação entre os valores de densidade do ouro $\left(\rho_{A u}\left[\mathrm{~g} / \mathrm{cm}^{3}\right]\right)$, espessura por pulso $[\mathrm{cm}]$, massa molar do ouro $\left(\mathrm{M}_{A u}[\mathrm{~g} / \mathrm{mol}]\right)$ e o número de Avogadro ( $\mathrm{N}_{A}$ [átomos/mol]) (Equação 1.1), é calculado o número de átomos depositados por pulso (Dose [átomos $\left./ \mathrm{cm}^{2}\right]$ ).

$$
\text { Dose }=\frac{\text { espessura } \cdot \rho_{A u} \cdot N_{A}}{M_{A u}}
$$

Assim, a taxa de $0,04 \mathrm{~nm} /$ pulso corresponde à dose de $2,3 \times 10^{14}$ átomos $/ \mathrm{cm}^{2} /$ pulso. Para a deposição do ouro as amostras foram posicionadas a $7 \mathrm{~cm}$ da saída do filtro de partículas, a pressão de base para acionar o canhão de plasma foi da ordem de $10^{-6}$ Torr com pulsos de plasma com frequência de $1 \mathrm{~Hz}$ e duração de $5 \mathrm{~ms}$; a dose a ser utilizada deve obedecer a condição $\phi<\phi_{c}$, como descrito, anteriormente, na Introdução. Estes parâmetros foram utilizados em todas as amostras fabricadas neste trabalho.

\section{$1.4 \quad$ Litografia por feixe de elétrons}

Com a necessidade de miniaturização dos circuitos integrados, tornou-se necessário o desenvolvimento de novas técnicas litográficas que pudessem produzir padrões em dimensões nanométricas com alta resolução. Para suprimir as limitações da litografia óptica, que utiliza luz visível, surgiu a litografia por feixe de elétrons. Neste trabalho utilizamos um sistema denominado Nanometer Pattern Generation System (NPGS) para a realização de litografia por feixe de elétrons que está diretamente acoplado ao Microscópio Eletrônico da Varredura (MEV), o qual é melhor descrito na Seção 2.1.

O sistema NPGS é composto por um software e hardware que controlam as bobinas de varredura do microscópio, movimentando o feixe de acordo com as coordenadas x,y de desenhos feitos em CAD (Computer Assisted Design). Conversores de sinal digital para analógico transformam as coordenadas do desenho em comandos que controlam as bobinas de varredura. Assim, os padrões do desenho em CAD são reproduzidos sobre a superfície do resiste com precisão nanométrica 34.

Neste trabalho, a litografia foi utilizada para fabricar estruturas que sirvam como referência para medir a espessura do filme de PMMA após cada etapa do procedimento. O objetivo final dessas medidas foi verificar a possibilidade de revelação do PMMA, considerando que a própria implantação iônica possa quebrar suas cadeias poliméricas 29]. Para isso, estruturas foram litografadas por feixe de elétrons viabilizando a medida, por AFM, da espessura original do filme de PMMA. Então, foi realizada implantação de ouro nesse filme e nova medida de espessura (sempre por AFM, neste contexto) para verificar a diminuição de espessura por sputtering. Finalmente a solução reveladora (adquirida 
juntamente com o elétron resiste PMMA) é aplicada ao filme, com a finalidade de verificar se a camada acima das nanopartículas de ouro é removida, o que se verifica através de nova medida da espessura da camada.

Assim é necessário realizar um processo de calibração de litografia para a obtenção dos parâmetros ótimos do feixe de elétrons utilizado na litografia, o que irá garantir uma boa resolução das estruturas. Este processo pode ser visto, em detalhes, no Apêndice B.

\subsection{Implantação de ouro com plasma de arco catódico}

As amostras litografadas (utilizando corrente de feixe de $30 \mathrm{pA}$ e dose de 30 $\mu \mathrm{C} / \mathrm{cm}^{2}$ ) foram analisadas por AFM de contato intermitente, para registro da espessura original dos filmes de PMMA. Então essas amostras foram posicionadas no sistema de vácuo para a implantação de ouro com dose planejada de $0,8 \times 10^{16}$ átomos $/ \mathrm{cm}^{2}$, para a formação da camada compósita abaixo da superfície do polímero. Um pedaço de lâmina de silício foi colocado no porta amostras junto às amostras de interesse, para ser utilizado como amostra de referência. Esta amostra de referência foi utilizada para determinar a dose de ouro implantada utilizando análises por RBS.

Após a implantação, as amostras foram analisadas novamente por AFM de contato intermitente, para verificação da nova espessura dos filmes de PMMA. Posteriormente, as amostras foram tratadas com a solução reveladora (1 MIBK:3 IPA), com o objetivo de, possivelmente, remover a camada de polímero acima da camada compósita. Na sequência, as amostras foram novamente analisadas por AFM de contato intermitente, para verificação da espessura final dos filmes de PMMA. Os resultados destas análises são apresentados na Seção 3.1 . 


\section{Técnicas de Caracterização}

\subsection{Microscopia Eletrônico de Varredura (MEV)}

A microscopia eletrônica de varredura permite a observação e caracterização de materiais heterogêneos orgânicos e inorgânicos em escalas nanométrica (nm) a micrométrica $(\mu \mathrm{m})$. Brevemente, a área a ser analisada no microscópio eletrônico de varredura é irradiada por um feixe de elétrons focalizado, proveniente de um catodo termiônico de tungstênio. Este feixe varre a superfície da amostra e forma imagens a partir de sinais produzidos pela interação entre o feixe de elétrons e a amostra. As interações incluem a emissão de elétrons secundários, elétrons retroespalhados, raios X característicos, entre outros sinais 35.

Figura 6 - Desenho esquemático do microscópio eletrônico de varredura.

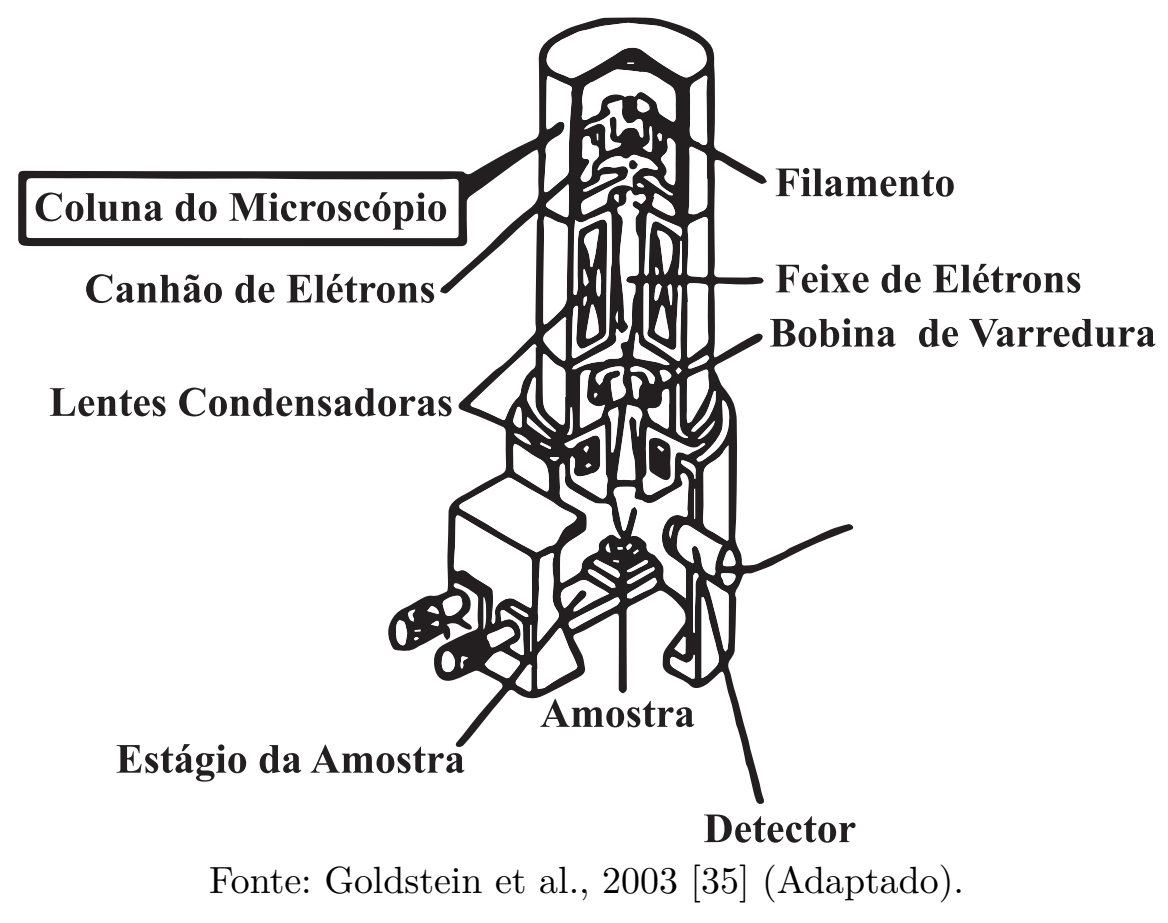

O feixe de elétrons é acelerado por uma diferença de potencial que pode variar de $0,3 \mathrm{kV}$ a $30 \mathrm{kV}$ e passa por um sistema de alinhamento e redução do diâmetro do feixe. Um conjunto de lentes objetivas focalizam o feixe sobre a amostra, que fica posicionada em um estágio motorizado. Bobinas defletoras permitem a varredura do feixe de elétrons sobre a amostra e, ponto a ponto dessa varredura, sinais são detectados da interação entre o feixe e a amostra e registrados digitalmente (Figura 6).

O volume de interação entre o feixe de elétrons e a região de incidência na amostra tem profundidade da ordem de um a poucos micrômetros. Essa variação é dependente do material da amostra e de parâmetros do feixe (Figuras 7 e 8). Quanto maior for a 
tensão aceleradora maior será o volume de interação (Figura 7) e pior será a resolução da imagem [35, 36].

Figura 7 - Simulações de Monte Carlo das trajetórias dos elétrons no volume de ferro em função da energia do feixe: (a) $10 \mathrm{keV}$, (b) $20 \mathrm{keV}$ e (c) $30 \mathrm{keV}$.

(a)

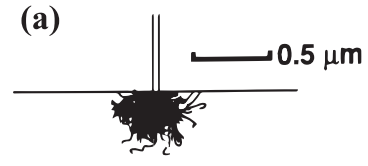

(b)

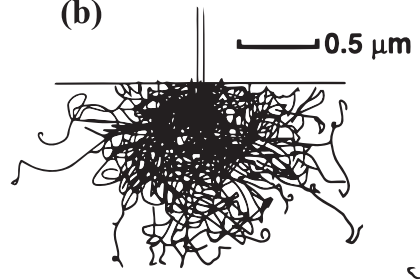

(c)

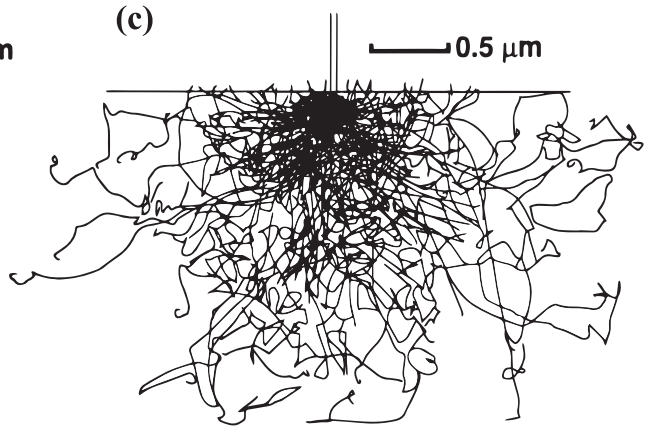

Fonte: Goldstein et al. 2003 35 (Adaptado).

Figura 8 - Simulações de Monte Carlo das trajetórias dos elétrons ao utilizar um feixe com energia de 20 keV em função do da amostra: (a) Prata e (b) Urânio.

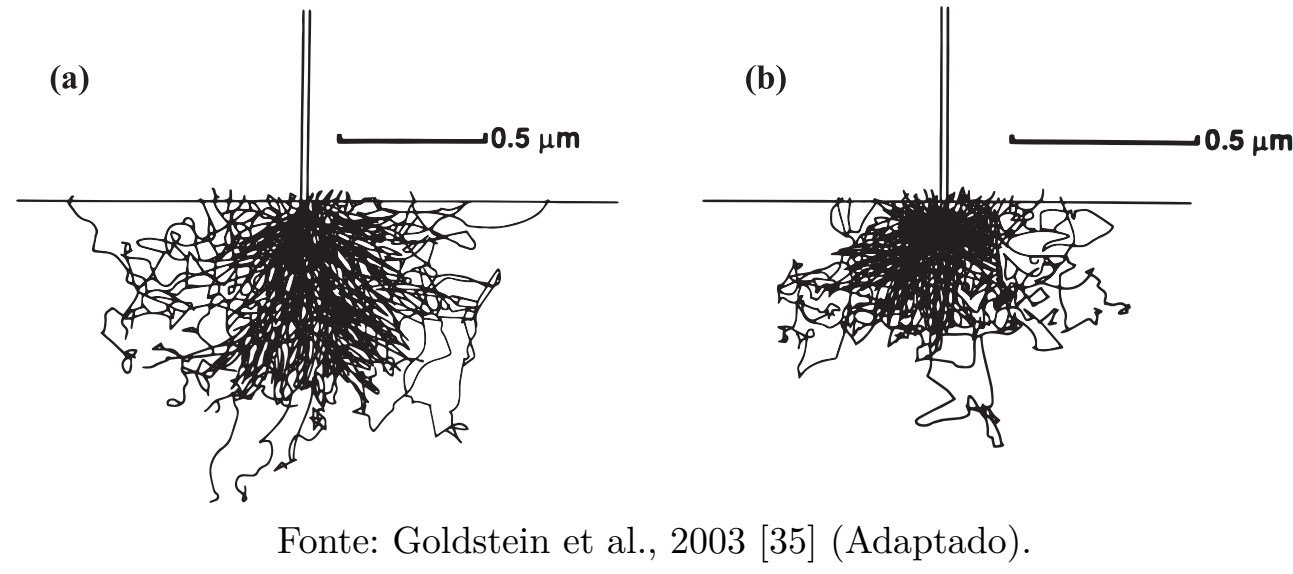

Os sinais de maior interesse para o MEV são os elétrons secundários e retroespalhados, pois estes variam principalmente com as diferenças topográficas da superfície da amostra. Assim devido ao volume de interação e ao efeito de sombras gerado pelo contraste dos elétrons secundários e retroespalhados, é obtido uma imagem de aparência tridimensional, que é um dos maiores responsáveis pela popularidade da técnica.

\subsection{Microscopia Eletrônica de Transmissão (MET)}

O microscópio eletrônico de transmissão é utilizado para obter informações estruturais sobre amostras finas, tipicamente com espessura inferior a $100 \mathrm{~nm}$ [37]. O feixe é formado por um canhão de elétrons acelerado a $100 \mathrm{keV}$, ou mais, e projetados na amostra através de um conjunto de lentes condensadoras. Durante o processo de interação entre o feixe e a amostra, ocorrem processos de espalhamento que permitam obter informações a respeito da amostra. O processo de formação de imagem em um MET é muito similar ao 
da microscopia de luz visível. A amostra é iluminada por uma radiação que é espalhada e, posteriormente, uma lente objetiva forma a imagem da amostra que é ampliada por uma ou duas outras lentes, gerando a imagem final. A grande diferença entre a MET e a microscopia de luz visível é a radiação utilizada, que no caso do MET é um feixe eletrônico, que possui comprimento de onda da ordem de fração de Angstrons, o que permite, inclusive, resolução atômica. Outra diferença significativa consiste nas lentes utilizadas na MET, que são lentes magnéticas, cujo o foco pode ser modificado através de variação de corrente em bobinas posicionadas com seu plano perpendicular ao feixe de elétrons. A passagem de feixes eletrônicos nessas lentes magnéticas obedece as mesmas leis da óptica geométricas, tão conhecidas para as lentes de vidro, quando atravessadas por luz visível.

Para obter amostras adequadas para a técnica, foram feitos cortes de PMMA por ultramicrotomia, pela pesquisadora do LFF - IFUSP, Dr ${ }^{\mathrm{a}}$. Fernanda S. Teixeira. Os cortes, de espessura da ordem de $80 \mathrm{~nm}$, foram colocados em grades próprias para utilização no microscópio eletrônico de transmissão. Em seguida foram colocados cuidadosamente no porta amostras do sistema de deposição por plasma de arco catódico juntamente com uma amostra de controle para posterior análise por RBS. A dose projetada para esta deposição foi de $0,8 \times 10^{16}$ átomos $/ \mathrm{cm}^{2}$. Após a deposição, a amostra de controle foi analisada por RBS para medir a dose depositada.

Uma das análises por MET teve o objetivo de verificar se as nanopartículas permanecem no polímero após o processo de revelação, assim, após a deposição, os cortes de PMMA foram revelados e então analisados por MET. A descrição dos procedimentos realizados para revelar os cortes de PMMA sobre a grade está descrita no Apêndice C.

\subsection{Microscopia de Varredura por Sonda (Scanning Probe Microscopy - SPM)}

A microscopia de força atômica (Atomic Force Microscopy - AFM) faz parte de um conjunto de microscopias denominado de Microscopia de Varredura por Sonda (Scanning Probe Microscopy - SPM). O princípio de funcionamento do SPM se baseia em uma sonda que varre a superfície de uma amostra e registra a interação sonda-amostra ponto a ponto da varredura [38 40]. Dependendo do tipo de interação, a microscopia recebe um nome. Os modos principais de SPM são a microscopia de tunelamento (Scanning Tunneling Microscopy - STM) e a microscopia de força atômica.

A modalidade AFM é, basicamente, dividida em três modos: modo contato, nãocontado e contato intermitente. O modo de contato foi o primeiro a ser desenvolvido, cujo conceito foi utilizado como base para desenvolver os modos subsequentes. No AFM, a sonda consiste em uma ponta, geralmente em formato piramidal, presa à extremidade de um cantiléver. A interação ponta-amostra é dada pela força Van der Waals (Figura 9), 
assim é possível operar o microscópio em três regimes dependendo do tipo da força de interação: força repulsiva, atrativa ou em regime intermediário.

Figura 9 - Forças de Van der Waals em função da distância ponta-amostra.

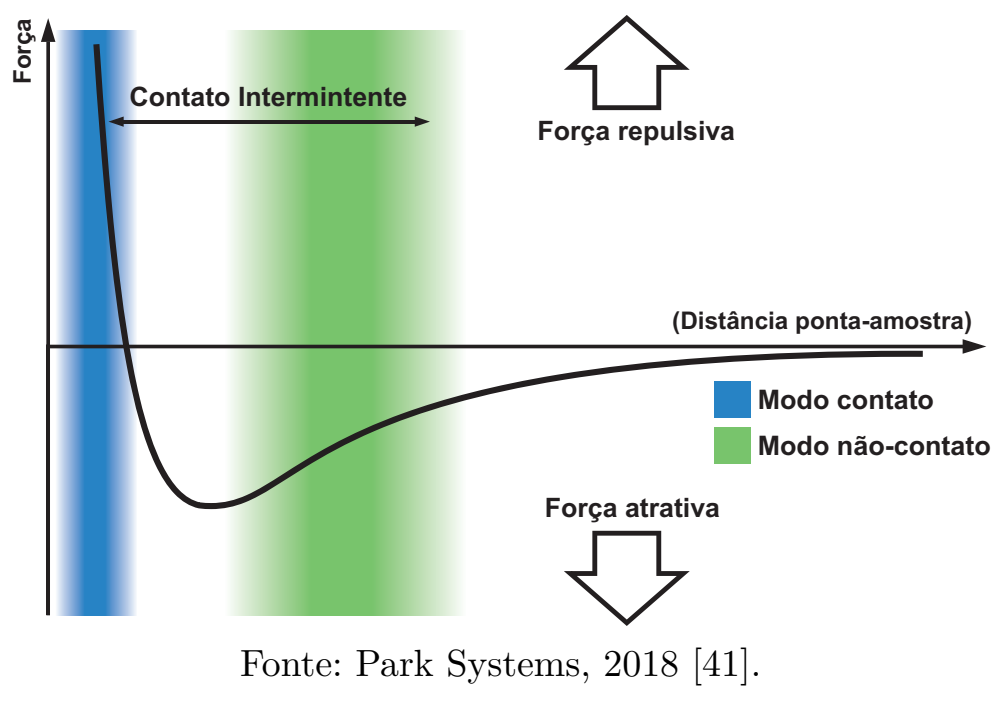

No AFM de contato, a ponta é colocada em contato com a superfície, sofrendo uma força repulsiva, defletindo o cantiléver. No modo AFM de não-contato, o cantiléver oscila sobre a amostra numa situação onde não há o contato entre ponta e amostra, mas há uma interação atômica atrativa.

No modo de contato intermitente do AFM, durante a varredura, o cantiléver oscila próximo a sua frequência de ressonância, e a ponta toca gentilmente a superfície da amostra próximo ao ponto de máxima amplitude de oscilação. Durante a varredura, a amplitude de oscilação do cantiléver sofre variações devido a ponta passar por pontos de diferentes alturas. A variação da amplitude é medida por um detector (fotodiodo) onde incide um feixe de laser que é refletido na extremidade do cantiléver. Para manter a amplitude de oscilação constante, o scanner piezelétrico-z move a amostra verticalmente em cada ponto $\mathrm{x}, \mathrm{y}$ da varredura. As correções em altura são relacionadas às posições x e y e armazenadas, formando a imagem topográfica da superfície da amostra. Para as análises deste trabalho foi utilizado o AFM no modo contato intermitente.

\subsection{Rutherford Backscattering Spectrometry (RBS)}

A técnica RBS mede a energia das partículas de um feixe monoenergético que sofreram espalhamento nos átomos do material em análise (alvo). Durante essa interação os íons do feixe incidente perdem energia, e podem se acomodar no interior do material ou serem retro-espalhados (Backscattering) 42]. Os íons que são retro-espalhados são coletados por um detector que emite um sinal elétrico proporcional à energia do íon. A taxa de redução da energia do íon é determinada por um fator cinemático ( $k$ ) (Equação 2.1), 
que considera a colisão entre os íons do feixe e os átomos do alvo como um espalhamento elástico. Assim, o fator cinemático é calculado ao obter a razão entre a energia do íon retro-espalhado $\left(E_{1}\right)$ e a sua energia inicial $\left(E_{0}\right)$ :

$$
k=\frac{E_{1}}{E_{0}}=\left[\frac{\left(1-\left(M_{1} / M_{2}\right)^{2} \sin (\theta)\right)^{\frac{1}{2}}+\left(M_{1} / M_{2}\right) \cos (\theta)}{1+M_{1} / M_{2}}\right]^{2}
$$

onde $M_{1}$ e $M_{2}$ são as massas do íon e do átomo do alvo, respectivamente, e $\theta$ é o ângulo do retro-espalhamento, que assume valores entre $0 \leq \theta \leq \pi$.

As amostras de referência para RBS foram produzidas de acordo com a Seção 1.5. Os espectros RBS das amostras de referência foram obtidos junto ao Laboratório de Materiais e Feixes Iônicos (LAMFI) do IFUSP. Para o cálculo da dose de ouro, foi utilizado o SIMNRA 6.0, que é um programa de simulação de espectros gerados por técnicas baseadas em análises de espalhamento de íons com energia da ordem de $\mathrm{MeV}$, como no caso do RBS 43]. Neste programa, parâmetros experimentais são inseridos, e o espectro gerado pela simulação é ajustado ao espectro experimental, obtendo o valor da dose de ouro utilizado na implantação iônica.

\subsection{Espectroscopia Raman}

O efeito em que se baseia a Espectroscopia Raman foi documentado pela primeira em 1928 por C. V. Raman [44] em um artigo onde foi descrito a observação experimental do espalhamento inelástico da luz visível, rendendo o prêmio Nobel de Física em 1930 [45]. No espalhamento inelástico, a radiação proveniente de uma fonte de luz monocromática atinge um objeto, uma fração desta radiação é refletida, enquanto que o restante dela é transmitida para dentro do material. Da radiação transmitida, uma parcela é absorvida em forma de calor e a outra é retransmitida em forma de luz espalhada com energia maior ou menor do que a radiação incidente. Esta diferença corresponde à transição vibracional da molécula.

Os processos de espalhamento inelástico são classificados como espalhamento (1) Stokes e (2) anti-Stokes. (1) A molécula no estado fundamental ao colidir com o fóton, passa para um estado intermediário, ou virtual, e decai para um estado vibracionalmente excitado de energia, desta forma, o fóton espalhado terá energia menor do que o incidente. (2) A molécula, já num estado excitado, ao colidir com o fóton, decai para o estado fundamental, cedendo energia ao fóton, assim, o fóton espalhado tem energia maior do que o incidente. A intensidade do sinal no espalhamento Stokes é maior em relação ao espalhamento anti-Stokes, pois o primeiro depende da população do estado vibracional fundamental, enquanto que o segundo depende da população de estados vibracionais excitados, que 
por sua vez, segue a distribuição de Boltzmann [46]. Quando, após a interação do fóton com a molécula, esta volta ao mesmo nível de energia inicial e o fóton é espalhado sem modificação de frequência, o espalhamento é dado como elástico, recebendo a denominação de espalhamento Rayleigh. A Figura representa os mecanismos de espalhamento (a) Rayleigh, (b) Stokes e (c) anti-Stokes, com níveis vibracionais representados pelo estado fundamental $v_{0}$, o estado excitado $v_{1}$, e o estado virtual $r$ 47, 48.

Figura 10 - Esquemas dos mecanismos de espalhamento: (a) Rayleigh, (b) Stokes e (c) antiStokes.

(a)

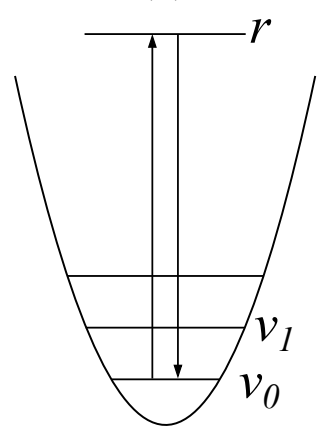

(b)

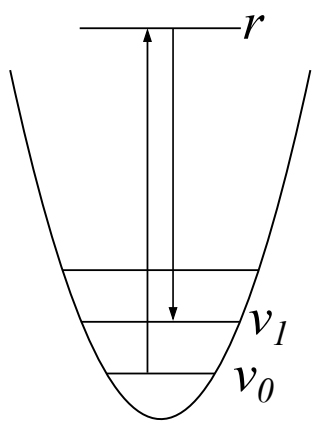

(c)

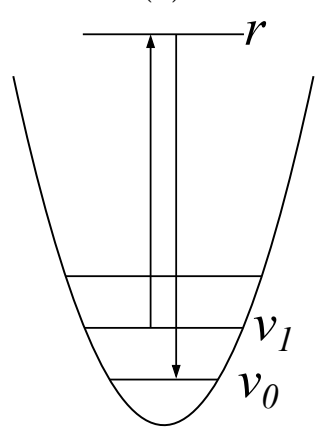

Fonte: Rodrigues, 2013 47; Millen, Faria e Temperini, 2005 48].

\subsubsection{Espectroscopia Raman Intensificada por Superfície}

A Espectroscopia Raman Intensificada por Superfície (Surface-Enhanced Raman Spectroscopy - SERS) consiste em um efeito devido à intensificação, em várias ordens de grandeza, do espalhamento Raman, descrito anteriormente, de moléculas adsorvidas em superfícies metálicas, como por exemplo coloides de alguns metais, filmes finos metálicos, entre outras possibilidades [49].

Os modelos que tiveram maior aceitação da comunidade científica que buscam explicar o mecanismo responsável pelo aparecimento do efeito SERS foram o eletromagnético e o químico [49,50]. No modelo eletromagnético a intensificação do campo eletromagnético próximo à superfície do metal é devido à resposta das moléculas aos intensos campos elétricos gerados, localmente, por uma oscilação coletiva de elétrons livres presentes na superfície de pequenas estruturas metálicas [51]. No modelo químico, considera-se um sistema formado pela molécula (analito) e o metal no qual a molécula está adsorvida. A formação deste sistema permite a ocorrência de transferências de carga entre o HOMO (Highest Occupied Molecular Orbital) ou o LUMO (Lowest Unoccupied Molecular Orbital) da molécula e o nível de Fermi do metal [52 54]. Neste modelo, é considerado que o nível de Fermi do metal se situa entre os orbitais HOMO e o LUMO do analito, assim a transferência de carga pode ocorrer tanto no sentido metal $\rightarrow$ molécula quanto molécula $\rightarrow$ metal, dependendo da natureza da molécula [47,55]. 
Os substratos para SERS são projetados para operar com excitações na região do espectro visível ao infravermelho-próximo (com comprimento de onda da ordem de 400 a $1000 \mathrm{~nm}$ ). Os metais mais utilizados para a fabricação de substratos SERS, em geral, são ouro e a prata, pois estes metais têm as propriedades ópticas "ideais" para sustentar a ressonância plasmônica na faixa do visível ao infravermelho-próximo [56].

As medidas SERS foram realizadas utilizando o equipamento (Renishaw In Via Raman Microscope) do Laboratório de Espectroscopia Molecular (LEM) do Instituto de Química da Universidade de São Paulo (IQ-USP), excitando as amostras com um comprimento de onda de $633 \mathrm{~nm}$.

\subsection{Espectrofotometria na região Ultravioleta-Visível (UV- Vis)}

A espectrofotometria UV-Vis tem aplicações em diversas áreas do conhecimento, como química, física, bioquímica e farmacologia [1-3]. Esta técnica é bastante utilizada na quantificação de compostos orgânicos e inorgânicos, na determinação da constante de equilíbrio e sua dependência com parâmetros como concentração e temperatura, na identificação de cromóforos em macromoléculas e polímeros e na caracterização de materiais, entre outras aplicações 20,57,58]. Além destas aplicações, a espectrofotometria UV-Vis é uma das formas mais simples de caracterização óptica dos plasmons de superfície de nanopartículas metálicas que constituem o substrato SERS. Uma das possibilidades de se efetuar essa medida é através de medidas de absorção obtidas por meio da configuração de transmissão da luz pelo filme fino (substrato SERS) em um espectrofotômetro comum [56. Para as medidas apresentadas neste trabalho, foi utilizado o espectrofotômetro Shimadzu, UV-3101PC UV-VIS-NIR Spectrophotometer, disponível no LEM - IQ-USP.

A espectrofotometria UV-Vis se baseia em medidas de absorção da radiação eletromagnética, que pode estar nas regiões visível ou ultra violeta do espectro. Uma forma típica de determinar a absorção, consiste em realizar medidas da potência de uma radiação eletromagnética transmitida através de uma amostra. No caso de amostras contendo nanopartículas metálicas, quando esta radiação eletromagnética atravessa a amostra, ocorrem processos de absorção e espalhamento (elástico ou inelástico), assim a potência transmitida $P_{\text {Tra }}$ é menor do que a potência da radiação incidente $P_{\text {Inc }}$. A diferença $P_{I n c}-P_{T r a}$ é denominada potência de extinção $P_{E x t}$. Para a maioria das aplicações, apenas a absorção e o espalhamento contribuem para a extinção, desta forma há uma conservação de energia [56]:

$$
P_{E x t}=P_{A b s}+P_{E s p}
$$


onde $P_{A b s}$ e $P_{E s p}$ são as potências de absorção e espalhamento, respectivamente. Assim, a seção de choque de extinção $\sigma_{E x t}$ pode ser definida como:

$$
\sigma_{E x t}=\sigma_{A b s}+\sigma_{E s p}
$$

\subsubsection{Lei de Beer-Lambert}

A lei de Beer-Lambert é aplicada as soluções contendo solutos completamente dissolvido no solvente. A potência $P_{\text {Tra }}$ de uma radiação eletromagnética transmitida através de uma solução com concentração de moléculas $c_{m}[\mathrm{M}]$ por caminho óptico $L[\mathrm{~m}]$ está relacionada a potência $P_{I n c}$ da seguinte forma:

$$
P_{T r a}=P_{I n c} e^{\left(-N_{A} \sigma_{E x t} c_{m} L\right)}
$$

onde $N_{A}$ é o número de Avogadro. Sendo a transmitância $T$, usualmente definida como a relação $P_{\text {Tra }} / P_{\text {Inc }}$, a absorbância utilizada em análises por UV-Vis é dada por [56,59]:

$$
A=-\log _{10}(T)=\log _{10}\left(\frac{P_{I n c}}{P_{T r a}}\right)=\frac{N_{A} \sigma_{E x t} c_{m} L}{\ln (10)}=\varepsilon_{E x t} c_{m} L
$$

O termo $\varepsilon_{E x t}=N_{A} \sigma_{E x t} / \ln (10)$ é denominado coeficiente de extinção molar da solução e é função do comprimento de onda da radiação e do composto. A Equação 2.5 é chamada de Lei de Beer-Lambert. Uma vez que para moléculas o espalhamento é desprezível, a extinção é causada somente por absorção, ou seja, $\sigma_{E x t}=\sigma_{A b s}$.

Os princípios descridos anteriormente, sobre a Lei de Beer-Lambert, são válidos para diluições. Os mesmos princípios podem ser aplicados para soluções coloidais, e podem ser estendidos para medidas de extinção em filmes finos utilizados como substratos SERS. Desta forma, utilizamos a espectrofotometria UV-Vis para obter a frequência do plasmon de superfície dos filmes do material compósito composto por nanopartículas de Au em PMMA sobre vidro.

\subsection{Simulação de interação de íons com a matéria}

\subsubsection{Transport of ions in matter (TRIM)}

O TRIM é um programa, livre para uso acadêmico, de simulação baseado no método de Monte Carlo que calcula a interação entre íons e um alvo amorfo. O programa utiliza diversas aproximações físicas que reduzem o tempo de processamento sem afetar a precisão dos cálculos de forma significativa. As duas mais importantes aproximações utilizadas no simulador são (a) a utilização de uma fórmula analítica para determinar 
colisões subsequentes entre átomos e (b) usar o conceito de caminho livre médio entre as colisões, onde somente as colisões significativas para a simulação são consideradas. Estas aproximações são descritas em detalhes na Referência [60].

Os dados de entrada inseridos no TRIM são (a) o material do feixe de íons e sua energia, no caso deste trabalho é o $\mathrm{Au}$ com $49 \mathrm{eV}$ e (b) o material do alvo, no caso o PMMA com estequiometria $8 \mathrm{H}-5 \mathrm{C}$ - 2O, portanto com porcentagens de 53,3\%, 33,3\% e 13,3\%, respectivamente. Além disso, são considerados os parâmetros de energia de ligação de bulk e energia de ligação de superfície, como mostra a Tabela 1.

Tabela 1 - Parâmetros de entrada utilizados nas simulações utilizando o PMMA como alvo.

\begin{tabular}{cccc}
\hline Elemento & Estequiometria (\%) & $\begin{array}{c}\text { Energia de ligação } \\
\text { de bulk (eV) }\end{array}$ & $\begin{array}{c}\text { Energia de ligação } \\
\text { de superfície (eV) }\end{array}$ \\
\hline H & 53,3 & 3 & 2 \\
C & 33,3 & 3 & 7,41 \\
O & 13,3 & 3 & 2 \\
\hline
\end{tabular}

Fonte: Biblioteca interna do TRIM.

\subsubsection{TRIDYN}

O TRIDYN é um programa de simulação baseado no código do TRIM. O diferencial desse programa consiste em levar em conta alterações na composição do alvo durante a implantação, devido à presença de íons implantados e ao sputtering do material da amostra ao longo da simulação 61]. Assim, o TRIDYN é mais adequado, quando comparado ao TRIM, no caso da composição do substrato ser alterada de forma significativa durante o processo de implantação, o que ocorre com altas doses, como no caso deste trabalho.

As simulações com TRIDYN foram realizadas utilizando os mesmos parâmetros mostrados na Tabela 1, além de outros parâmetros necessários para o programa como a dose de implantação e a profundidade máxima de penetração em que deve ser considerada a variação da composição do alvo. 


\section{Parte II}

\section{Resultados}




\section{Resultados e Discussões}

\subsection{Litografia}

A espessura de PMMA foi avaliada através de medidas das estruturas litografadas, por AFM, antes e depois do processo de implantação iônica de ouro e da revelação do PMMA modificado. Os padrões de litografia foram fabricados de acordo com o processo descrito no Apêndice B, permitindo a medida, por AFM, da espessura original do filme de PMMA (Figura 11a), o que designamos como $h_{0}$. Após a implantação de ouro - com os parâmetros descritos na Subseção 1.5- em amostras litografadas, a espessura do filme de PMMA foi medida (neste contexto, sempre por AFM), o que designamos como $h_{1}$ (Figura 11b. Assim, a diferença $\left(h_{1}-h_{0}\right)$ será a variação da espessura do filme devido ao efeito do sputtering, que equivale a aproximadamente $7 \mathrm{~nm}$. Em seguida, as amostras foram submetidas ao processo de revelação, e novamente, foi realizada a medida de espessura, obtendo $h_{2}$ (Figura 11c).

Figura 11 - Representação da vista em cross-section no filme de PMMA (a) original (b) após a deposição do ouro e (c) após a revelação da camada de PMMA sensibilizada acima da camada compósita.

(a)

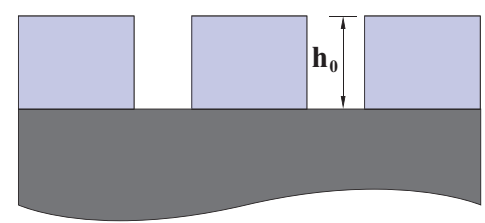

(b)

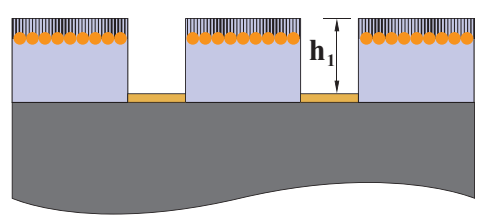

(c)

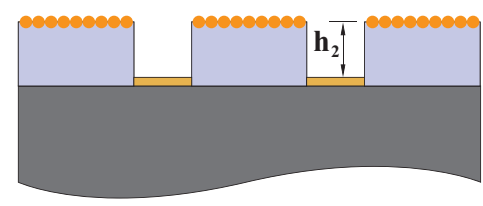

Silício $\quad \square$ PMMA $\quad$ 盂 PMMA modificado $\quad \square$ Ouro

Fonte: A autora.

A diferença $\left(h_{2}-h_{1}\right)$ resulta em uma diminuição de espessura equivalente à aproximadamente $10 \mathrm{~nm}$, comprovando que a própria implantação iônica é capaz de quebrar as cadeias poliméricas do PMMA, de forma que a camada de polímero acima da camada de nanopartículas de ouro é removida. Com essas medidas, também podemos concluir que a camada compósita é formada a uma profundidade da ordem de $10 \mathrm{~nm}$ abaixo da superfície do PMMA. Este valor é compatível com valores obtidos por microscopia eletrônica de transmissão da camada compósita em vista de cross-section, que foram obtidos de forma independente a este trabalho, cujos resultados serão publicados pelo grupo. 


\subsection{Simulações TRIM e TRIDYN}

Foram feitas diferentes simulações variando a energia dos íons $(\mathrm{E}=49 \mathrm{eV} ; 500 \mathrm{eV}$; $1 \mathrm{keV})$, considerando o PMMA de diferentes densidades $\left(\rho_{P M M A}=0,95 \mathrm{~g} / \mathrm{cm}^{3} ; 1,2 \mathrm{~g} / \mathrm{cm}^{3}\right)$, para verificar a influência da energia do íon incidente e da densidade do PMMA em relação ao perfil de profundidade gerado pela implantação. A Tabela 2 mostra os resultados ao utilizar simulações com o código TRIM.

Utilizando o TRIDYN, foi Tabela 2 - Resultados das simulações TRIM apresentando considerada a dose de $0,8 \times 10^{16}$ a profundidade da máxima concentração. átomos $/ \mathrm{cm}^{2}$, variando a energia dos íons e utilizando diferentes densidades do PMMA (Figuras 12 e 13), com os mesmos parâmetros considerados no TRIM.

\begin{tabular}{clcc}
\cline { 2 - 4 } & \multicolumn{3}{c}{ Profundidade $(\mathbf{n m})$} \\
\hline Energia $(\mathbf{e V})$ & $\mathbf{4 9}$ & $\mathbf{0 , 5 k}$ & $\mathbf{1 k}$ \\
\hline$\rho_{P M M A}=0,95 \mathrm{~g} / \mathrm{cm}^{3}$ & 4,5 & 9,7 & 12,1 \\
$\rho_{P M M A}=1,2 \mathrm{~g} / \mathrm{cm}^{3}$ & 3,9 & 8,2 & 10,1 \\
\hline
\end{tabular}

Fonte: A autora.

Figura 12 - Simulações TRIDYN utilizando Au em PMMA de densidade 0,95 g/ $\mathrm{cm}^{3}$ variando a energia de implantação.
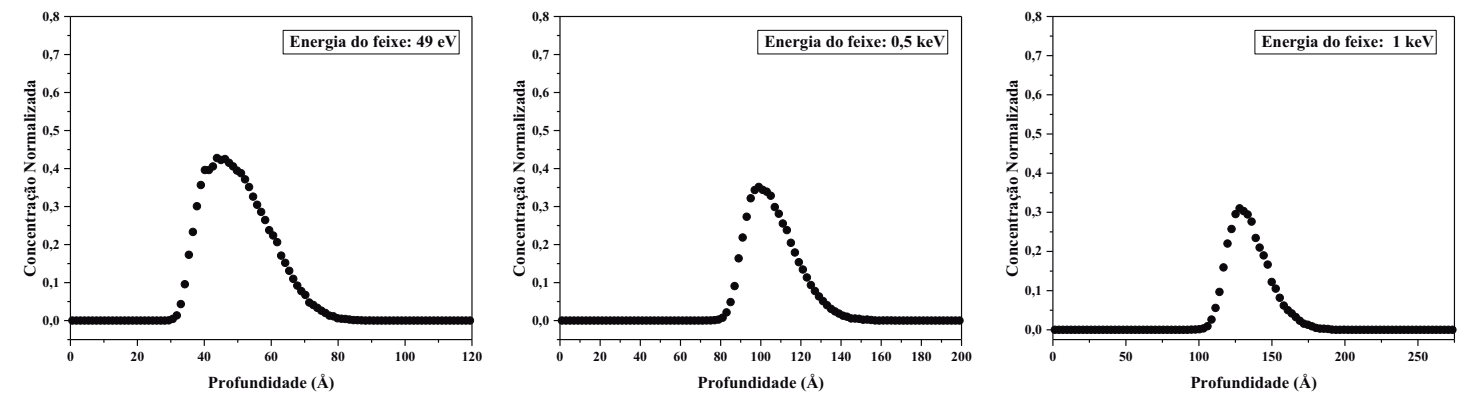

Fonte: A autora.

Figura 13 - Simulações TRIDYN utilizando Au em PMMA de densidade $1,2 \mathrm{~g} / \mathrm{cm}^{3}$ variando a energia de implantação.
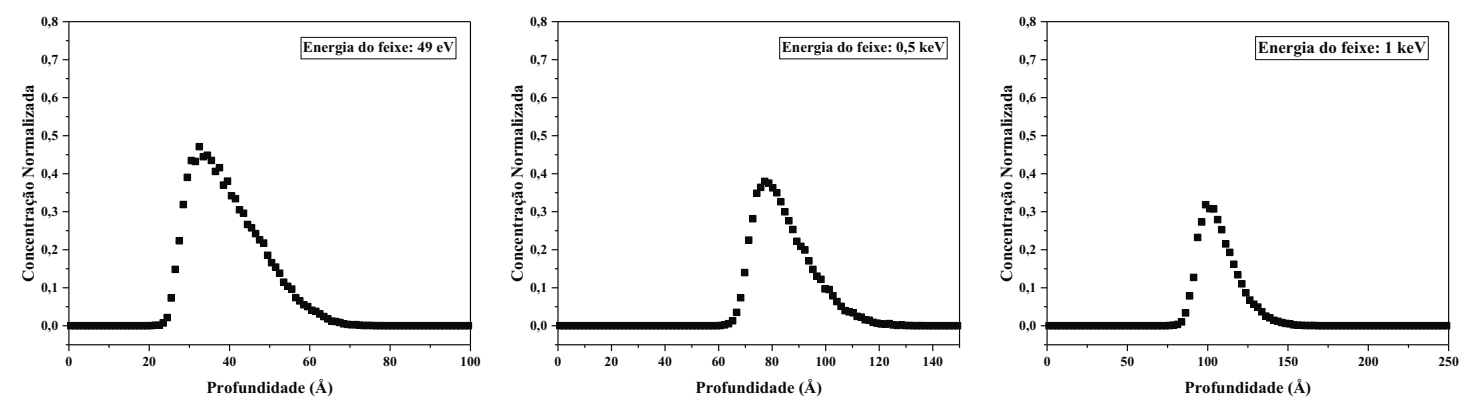

Fonte: A autora.

Analisando as simulações TRIM e TRIDYN, notamos pequenas variações entre profundidades máximas de concentração de ouro, o que também ocorre com a variação da densidade do PMMA considerada. Mas, considerando a implantação de ouro com energia 
de $49 \mathrm{eV}$, observamos uma profundidade máxima da concentração de ouro entre 4 e $5 \mathrm{~nm}$, para densidade do PMMA de 0,95 $\mathrm{g} / \mathrm{cm}^{3}$, e entre 3 e $4 \mathrm{~nm}$, para densidade do PMMA de $1,2 \mathrm{~g} / \mathrm{cm}^{3}$. No entanto, vimos na seção anterior que a profundidade onde se encontram as nanopartículas de ouro no PMMA é de $10 \mathrm{~nm}$. Através de simulações por TRIM e TRIDYN, a energia necessária para atingir a profundidade de $10 \mathrm{~nm}$ seria de cerca de $0,5 \mathrm{keV}$ e $1 \mathrm{keV}$, para as densidades $0,95 \mathrm{~g} / \mathrm{cm}^{3}$ e $1,2 \mathrm{~g} / \mathrm{cm}^{3}$, respectivamente (Figuras 12 e 13), o que não corresponde ao nosso experimento. Um efeito a ser considerado é uma possível difusão das nanopartículas de ouro no PMMA 62 66 durante a implantação, o que precisa ser confirmado em outros experimentos.

\subsection{Microscopia Eletrônica de Transmissão de compósito AuNPs/PMMA}

Como mencionado na Seção 2.2, foram obtidos cortes ultrafinos de PMMA (com aproximadamente $80 \mathrm{~nm}$ de espessura) sobre grades próprias para MET, onde foi implantado ouro. A amostra de silício, colocada junto à amostra de PMMA na implantação, foi analisada por RBS, determinando uma dose de implantação de 0,75 x $10^{16}$ átomos $/ \mathrm{cm}^{2}$. Após a implantação, os cortes de PMMA foram tratados com a solução reveladora (1 MIBK:3 IPA) e analisados por MET, com o objetivo de verificar se as nanopartículas permanecem no polímero após o processo de revelação. As imagens obtidas da vista de topo (Figura 14) mostram claramente a presença das nanopartículas após a revelação, mas isso não indica que a revelação exponha a camada compósita, já que uma imagem de vista de topo não é adequada para se obter esta informação.

Figura 14 - Vista de topo dos cortes de PMMA indicam a presença de nanopartículas após os processos de implantação e de revelação.
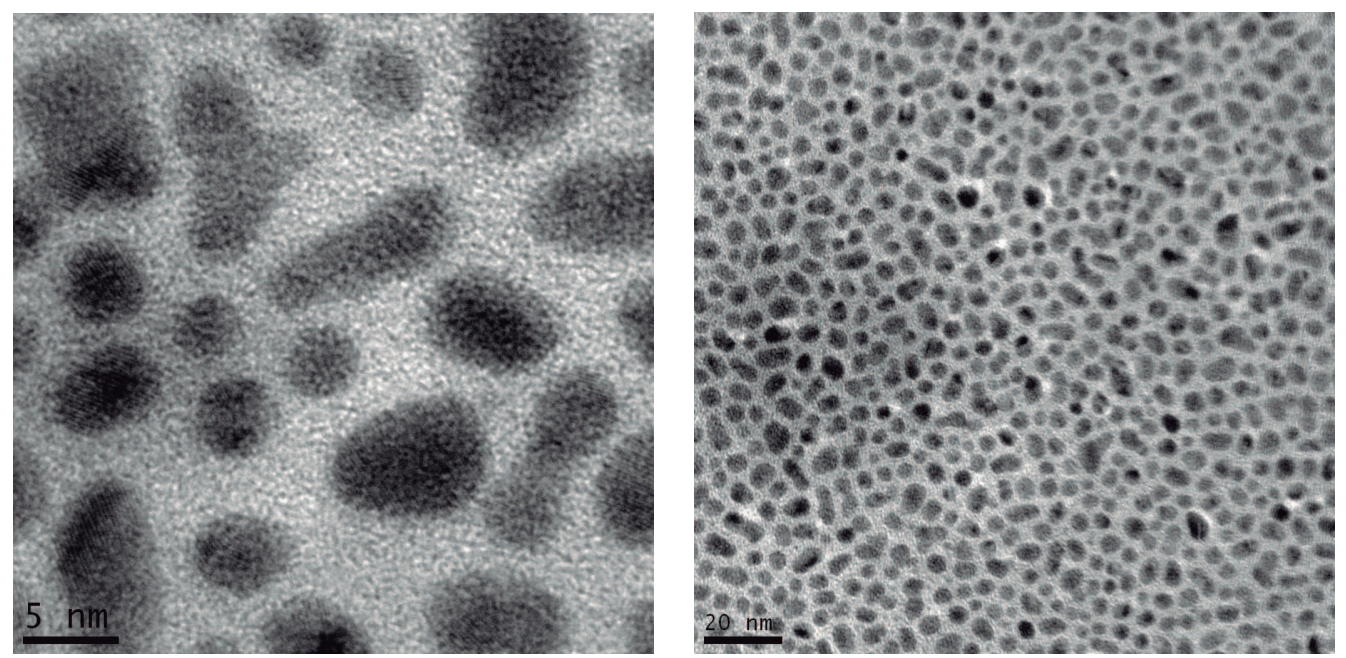

Fonte: A autora. 
Com o programa de tratamento de imagens Image- $J$, pode-se quantificar o tamanho médio das partículas a partir das imagens de MET. Assim, obtivemos um diâmetro médio de $(4,25 \pm 0,02) \mathrm{nm}$, para a dose de implantação de $0,75 \times 10^{16}$ átomos $/ \mathrm{cm}^{2}$.

\subsection{Resultados das medidas SERS}

Os nanocompósitos formado por nanopartículas de ouro em matriz de PMMA foram avaliados quanto à sua qualidade como substrato para realização de SERS. Para isso foi utilizado a substância sonda (ou analito) Rodamina 6G (R6G), da fabricante Sigma-Aldrich, cuja estrutura molecular pode ser vista abaixo, na Figura 15 . Todos os cuidados tomados para a obtenção das medidas SERS, como lente objetiva e potência do laser utilizados, tempo de acumulação, entre outros, podem ser consultados nas Tabelas 6 e 7. presentes no Apêndice D.

Inicialmente foram testados três substratos de PMMA implantados com dose de $0,6 \times 10^{16}$ átomos $/ \mathrm{cm}^{2}$ de ouro e revelados, expondo as nanopartículas de ouro. Foram usadas duas diluições do analito R6G para teste: $10 \mu \mathrm{M}$ e $1 \mathrm{nM}$, além do chamado substrato "branco", sem analito. Para a aplicação do analito ao substrato, o
Figura 15 - Estrutura molecular da R6G.

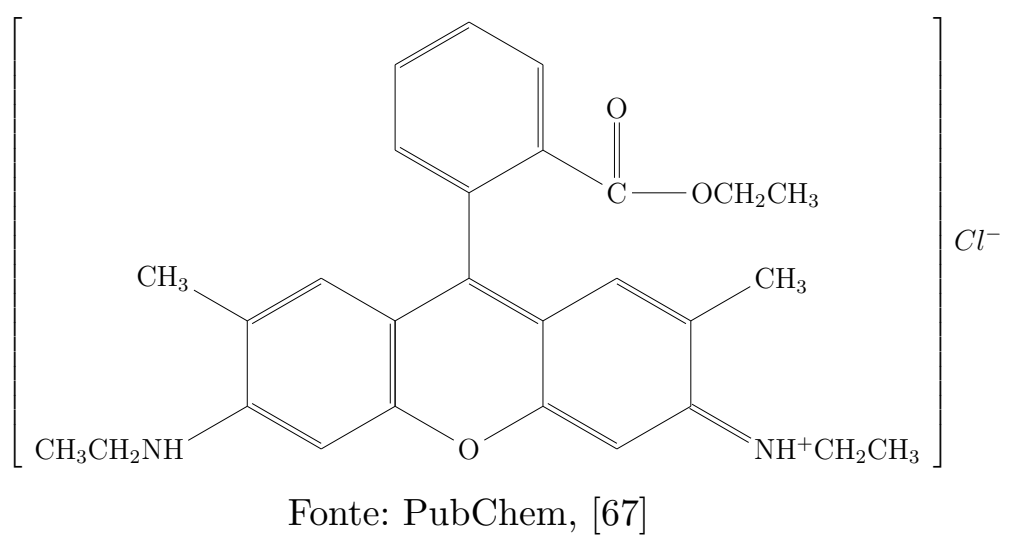
volume de $20 \mu \mathrm{L}$ de cada solução de R6G foi colocado em dois dos três substratos e, para a secagem, as amostras foram mantidas em um dessecador com sílica à pressão ambiente por cerca de $24 h$.

Os espectros SERS obtidos são apresentados na Figura 16. O melhor resultado, apesar de ruidoso, se refere ao substrato com concentração de analito R6G de $10 \mu \mathrm{M}$ (Figura 16a). O espectro referente ao substrato branco não apresenta os picos característicos do analito, o que já identifica o substrato de PMMA com nanopartículas de ouro como um substrado SERS. O espectro obtido para amostra com concentração de R6G de 1 nM (Figura 16b) é muito similar ao substrato branco (Figura 16c), o que identifica que a referida concentração não é adequada para avaliar nossos substratos. Assim, na sequência deste trabalho, passamos a utilizar uma diluição de $10 \mu \mathrm{M}$ para obtenção dos espectros SERS do analito.

Na Figura 16a é possível identificar os picos referentes ao analito R6G [68]. A banda identificada com um asterisco $\left(^{*}\right)$ nos três espectros, está relacionado ao espalhamento por multi-fônons gerado no substrato de silício [69], que é um efeito de segunda ordem do 
processo de espalhamento Raman, onde dois fônons de momento igual e oposto participam na formação do espectro [70].

Figura 16 - Espectro SERS obtido para (a) um substrato de PMMA com nanopartículas de ouro tratado com $10 \mu \mathrm{M}$ de RG6, (b) um substrato tratado com $1 \mathrm{nM}$ de RG6 e para (c) um substrato "branco".

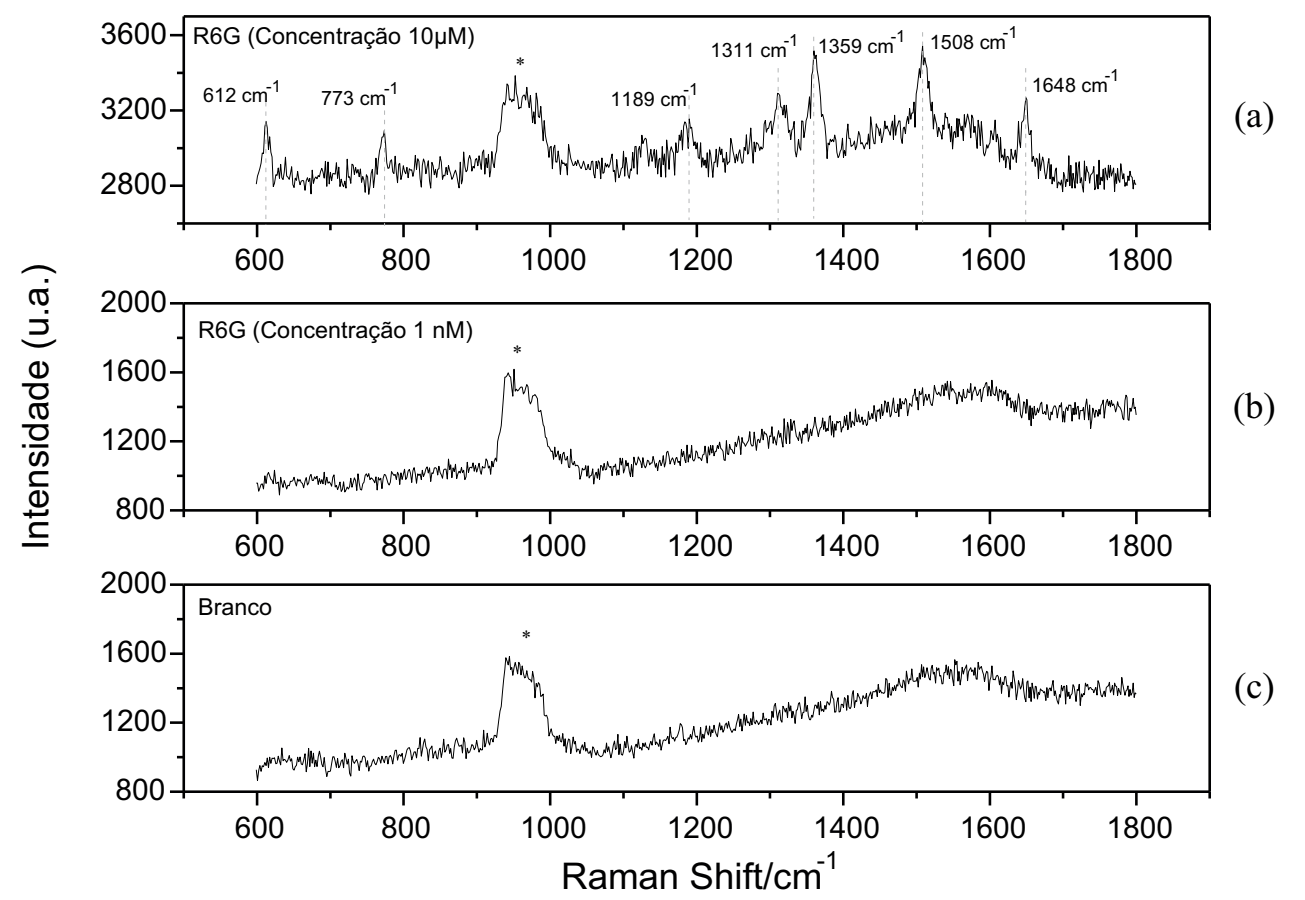

Fonte: A autora.

Com o objetivo de verificar a Figura 17 - Espectro SERS obtido para substratos influência de dose de ouro implantada em PMMA, como substrato para SERS, foram preparadas amostras com diferentes doses. As doses utilizadas foram $0,64 \times 10^{16}$ átomos $/ \mathrm{cm}^{2}, 0,81 \times 10^{16}$ átomos $/ \mathrm{cm}^{2}$ e $1,02 \times 10^{16}$ átomos $/ \mathrm{cm}^{2}$ para amostras sem revelação (Figura 17). A dose máxima utilizada $\left(1,02 \times 10^{16}\right.$ átomos $/ \mathrm{cm}^{2}$ ) corresponde à dose crítica $\phi_{c}$, ou seja, para doses acima de $\phi_{c}$ ocorre a percolação, o que não é interessante para este trabalho, como já foi mencionado na Seção referente à Percolação em Compósitos na Introdução.

Nos espectros SERS obtidos para de PMMA com doses de ouro de (a) $0,64 \times 10^{16}$, (b) $0,81 \times 10^{16}$ e (c) $1,02 \times$ $10^{16}$ átomos $/ \mathrm{cm}^{2}$, tratados com $10 \mu \mathrm{M}$ de RG6.

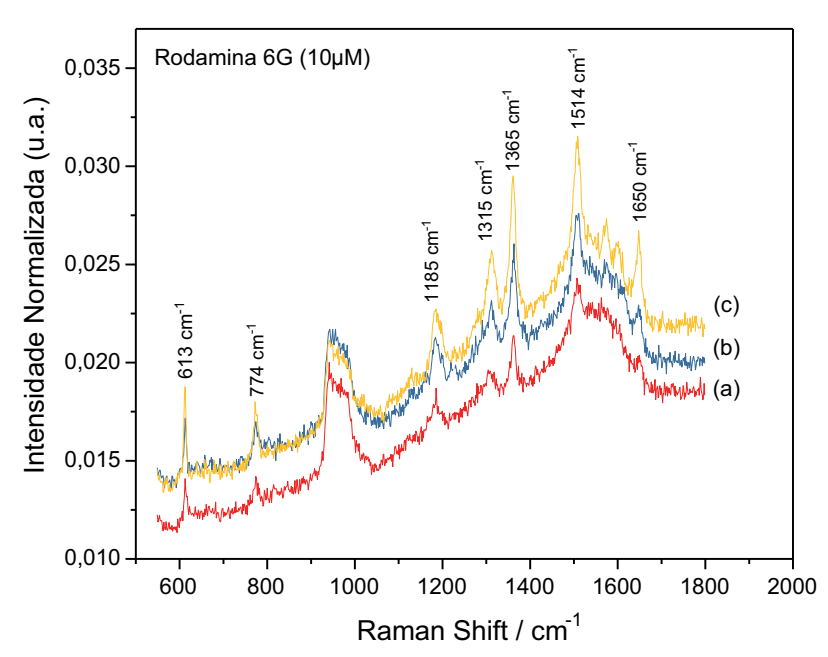

Fonte: A autora.

esses diferentes substratos, apresentados na Figura 17, observam-se os picos característicos 
da R6G. Assim, foi possível observar o aumento da intensidade do sinal com o aumento da dose de implantação, que pode estar relacionado à diminuição da distância entre as partículas para doses maiores.

Outro aspecto analisado foi o efeito da revelação do PMMA após implantação de ouro, expondo as nanopartículas. Para isso, foram utilizados duas amostras de PMMA com dose de $0,6 \times 10^{16}$ átomos $/ \mathrm{cm}^{2}$ de ouro implantado, uma foi revelada e a outra não. A rodamina foi então aplicada depositando-se $5 \mu \mathrm{L}$ da solução de R6G com concentração de $10 \mu \mathrm{M}$ sobre cada substrato posicionado em um spinner. Após um minuto, o spinner foi acionado em uma velocidade de $2000 \mathrm{rpm}$ por 50 segundos. Em seguida, as amostras foram armazenadas em um dessecador, em vácuo, por cerca de 24h. Os espectros SERS da rodamina sobre esses dois substratos são apresentados na Figura 18, onde se verifica que a amostra "revelada" (Figura 18a) possui uma intensidade menor do que a "não revelada" (Figura 18b), diferente do esperado. A ideia em revelar as amostras de PMMA após a implantação do ouro, visa expor as nanopartículas de ouro. Assim, considerando que as nanopartículas expostas tomem um formato de meia-esferas, devem existir regiões de alta concentração de campo elétrico (hot-spots) [10,11 que favorecem o efeito SERS. No entanto, a intensificação do sinal SERS já foi observada em substratos contendo uma camada de material isolante envolvendo as nanopartículas [6 8, 71,74], o que corrobora nossos resultados.

Figura 18 - Comparativo entre o sinal da rodamina depositada por spin-coating (a) na amostra "revelada" e (b) na amostra "não revelada".

(a)

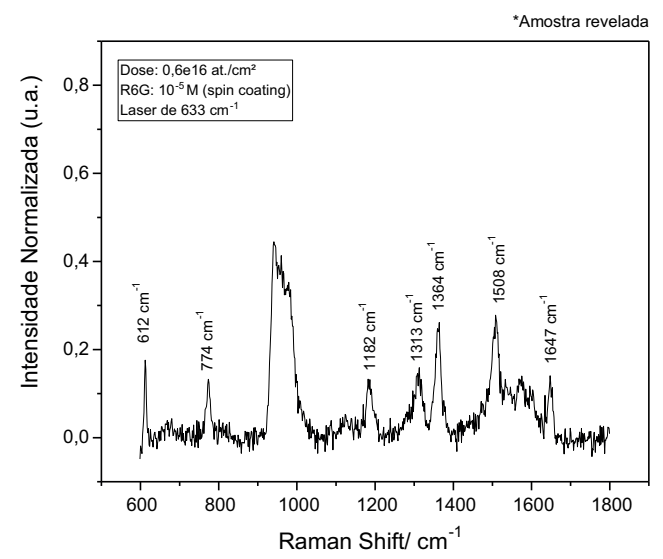

(b)

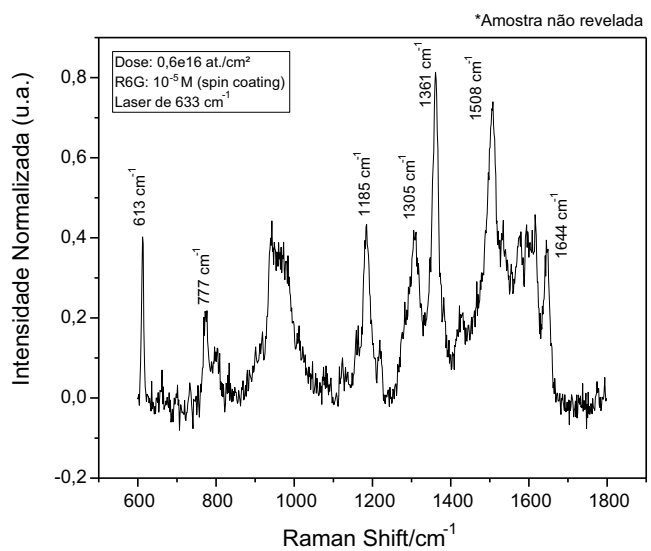

Fonte: A autora.

O experimento para analisar o efeito da revelação do PMMA após a implantação de ouro foi repetido, mas utilizando-se um método diferente para a deposição do analito R6G sobre os substratos. As amostras de PMMA foram preparadas da mesma forma descrita acima e, após a revelação de uma delas, foram submersos em R6G com concentração de $10 \mu \mathrm{M}$ por cerca de $24 \mathrm{~h}$. Em seguida, as amostras foram enxaguadas em água deionizada e secas com jato de gás nitrogênio. Os espectros SERS da rodamina sobre esses dois 
substratos são apresentados na Figura 19, onde se verifica, da mesma forma, que a amostra "revelada" (Figura 19a) possui uma intensidade menor do que a "não revelada" (Figura $19 \mathrm{~b})$.

Figura 19 - Comparativo entre o sinal da rodamina depositada por deep-coating (a) na amostra "revelada" e (b) na amostra "não revelada".

(a)

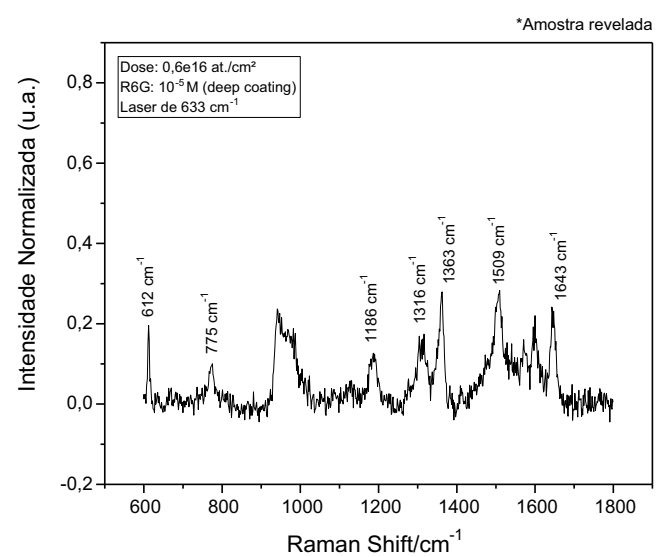

(b)

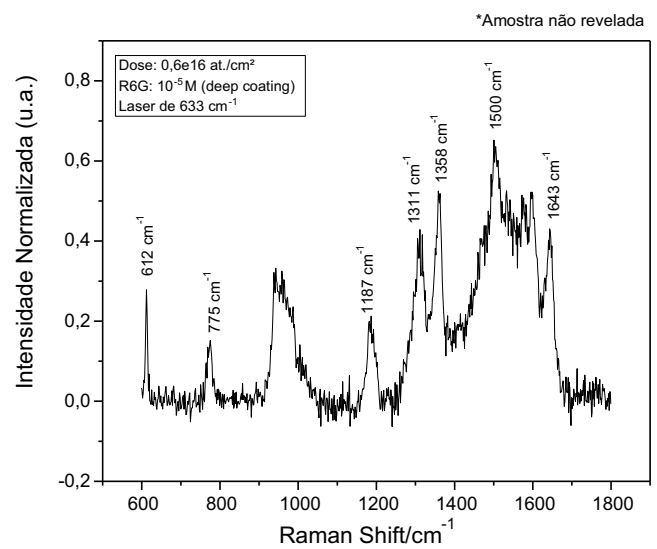

Fonte: A autora.

Também, é interessante notar que houve diferença na intensidade do sinal do espectro SERS ao utilizar os dois diferentes métodos para a deposição da rodamina sobre os substratos. Esse efeito é mais evidente nos substratos não revelados, onde a intensidade do substrato no qual foi feita a deposição de R6G por spin-coating, obteve melhor resultado, apresentando, inclusive, uma melhor relação sinal/ruído. Assim o método utilizando spin-coating se mostrou mais adequado para a deposição de R6G em nossos substratos.

É conhecido na literatura 7577 que partículas metálicas como ouro e prata são capazes de se incorporar em filmes poliméricos quando aquecido acima da temperatura de transição vítrea $\left(T_{G}\right)$ do polímero. A temperatura acima da $T_{G}\left(T_{G_{P M M A}}=95-106\right.$ ${ }^{\circ} \mathrm{C}$ ) permite a mobilidade das cadeias poliméricas em torno da nanopartícula, levando à alterações nas características geométricas das nanopartículas [78. Desta forma, analisamos o efeito do aquecimento no sinal SERS da amostra formada pelo compósito AuNPs/PMMA. As análises foram realizadas após aquecer o material compósito acima da temperatura de transição vítrea do PMMA $\left(150{ }^{\circ} \mathrm{C}\right)$ durante $6 \mathrm{~h}$ [79], em hotplate na capela de fluxo laminar, com a R6G aplicada após o aquecimento.

A Figura 20 compara os espectros obtidos após o aquecimento com os espectros das amostras "revelada" e "não revelada" com mesma dose de implantação de ouro. Também foi realizada a obtenção do espectro de uma amostra na qual a R6G foi depositada em um substrato de PMMA sem a presença de nanopartículas de ouro. 
Figura 20 - Espectro SERS da R6G em diferentes tipos de substratos: PMMA sem nanopartículas de ouro (preto), não é possível observar os picos característicos da R6G; amostra "não revelada" - AuNPs enterradas (vermelho); amostra "revelada" - AuNPs expostas (azul); amostra "não revelada" com aquecimento (verde). Dose da implantação de ouro: (a) $0,85 \times 10^{16}$ átomos $/ \mathrm{cm}^{2}$ e (b) $0,83 \times 10^{16}$ átomos $/ \mathrm{cm}^{2}$.

(a)

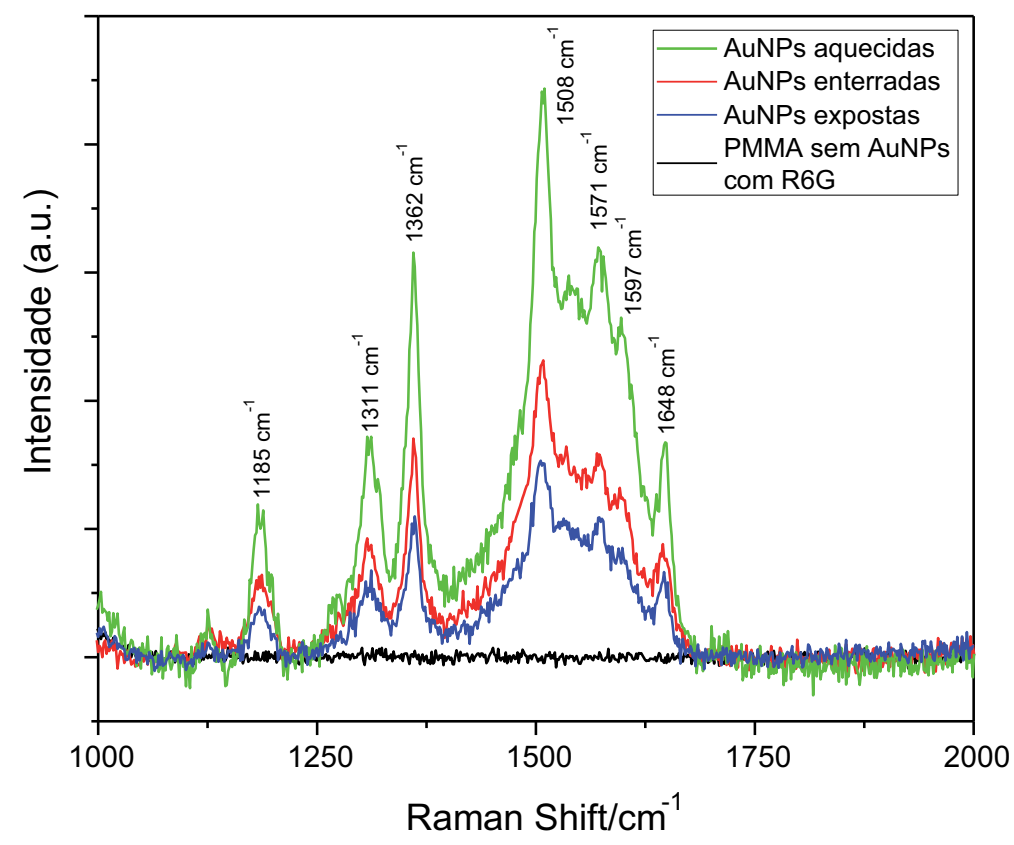

(b)

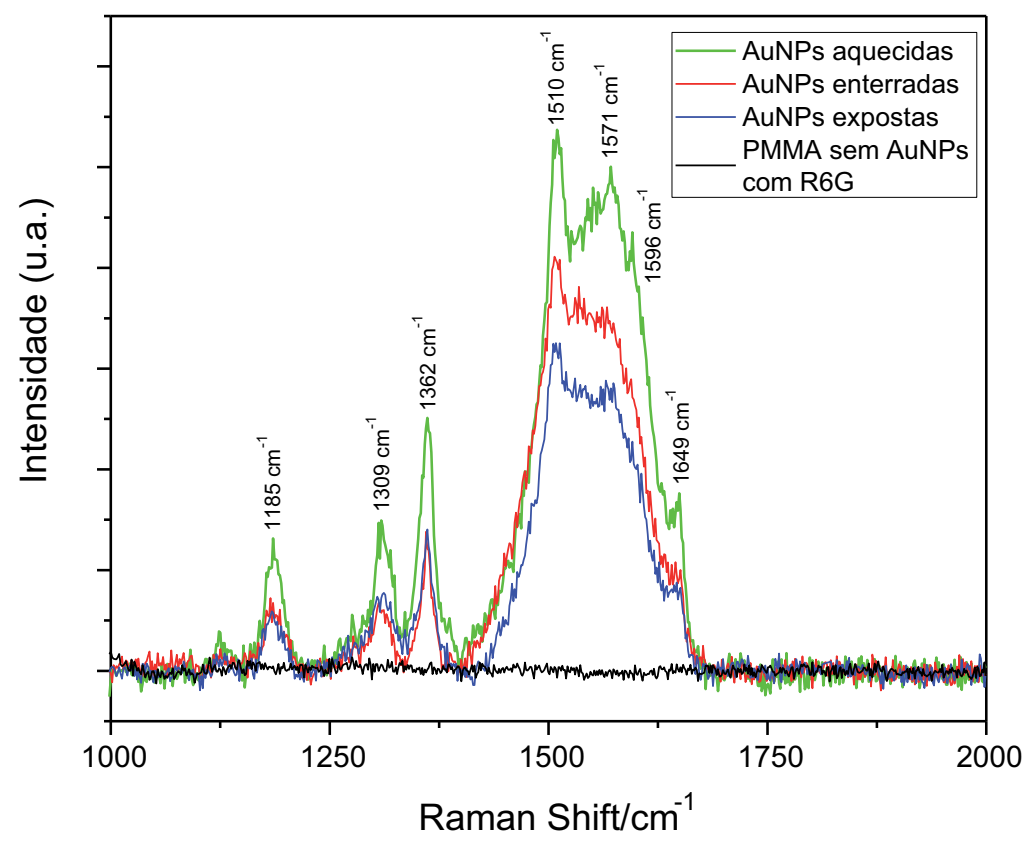

Fonte: A autora.

Na Figura 20a, pode-se notar que o mesmo comportamento visto nos resultados anteriores (Figuras 18 e 19) foi observado, onde a amostra "não revelada" (nanopartículas enterradas) apresenta maior intensidade de sinal do que a amostra "revelada" (nanopartículas expostas). Na Figura 20b, os picos característicos da R6G 1185, 1309 e $1362 \mathrm{~cm}^{-1}$ 
nos substratos "revelado" e "não revelado" se mostraram superpostos. Mas, em ambas as Figuras 20a e 20b, pode-se observar que o espectro da amostra que foi submetida ao aquecimento (curva verde) apresenta maior intensidade de sinal e melhor relação sinal/ruído em comparação os substratos "revelado" (AuNPs expostas) e "não revelado" (AuNPs enterradas). A atribuição das bandas da R6G pode ser consultada na Referência 68.

Nota-se também que o espectro obtido ao utilizar o PMMA com R6G sem a presença das nanopartículas, não apresenta nenhum pico característico da R6G em ambos os resultados apresentados na Figura 20. Isto confirma que os espectros obtidos utilizando, como substrato, o sistema compósito AuNPs/PMMA são, de fato, espectros SERS, assim como foi observado por Ferreira et al. (2012), o que corrobora os nossos resultados.

Como discutido anteriormente, o aquecimento do material compósito leva à mudança nas características geométricas das nanopartículas de ouro, e vimos nas Figuras 20a e 20b que o aquecimento melhora o sinal SERS obtido. Assim é necessário analisar qual o efeito do aquecimento na geometria das nanopartículas. Para esta etapa, obtivemos imagens de microscopia eletrônica de transmissão do compósito AuNPs/PMMA com aquecimento e sem aquecimento. Os resultados destas análises serão apresentados a seguir, na Seção 3.5 .

\subsection{Microscopia Eletrônica de Transmissão de compósito AuNPs/PMMA após tratamento térmico}

As amostras utilizadas foram fabricadas da mesma forma como foi descrita na Seção 3.3 . com dose de implantação, obtida através da análise de espectros de RBS, de 0,83 x $10^{16}$ átomos $/ \mathrm{cm}^{2}$. A Figura 21 mostra a comparação entre as imagens de MET obtidas para o compósito AuNPs/PMMA sem aquecimento (Figura 21a) e após o aquecimento (Figura 21b. A partir das micrografias, foi possível determinar os parâmetros como diâmetro médio e distância entre partículas, cujos resultados podem ser visto na Tabela 3. 
Figura 21 - Vista de topo dos cortes de PMMA com AuNPs: (a) sem aquecimento; (b) após aquecimento. Dose de implantação $0,83 \times 10^{16}$ átomos $/ \mathrm{cm}^{2}$.

(a)

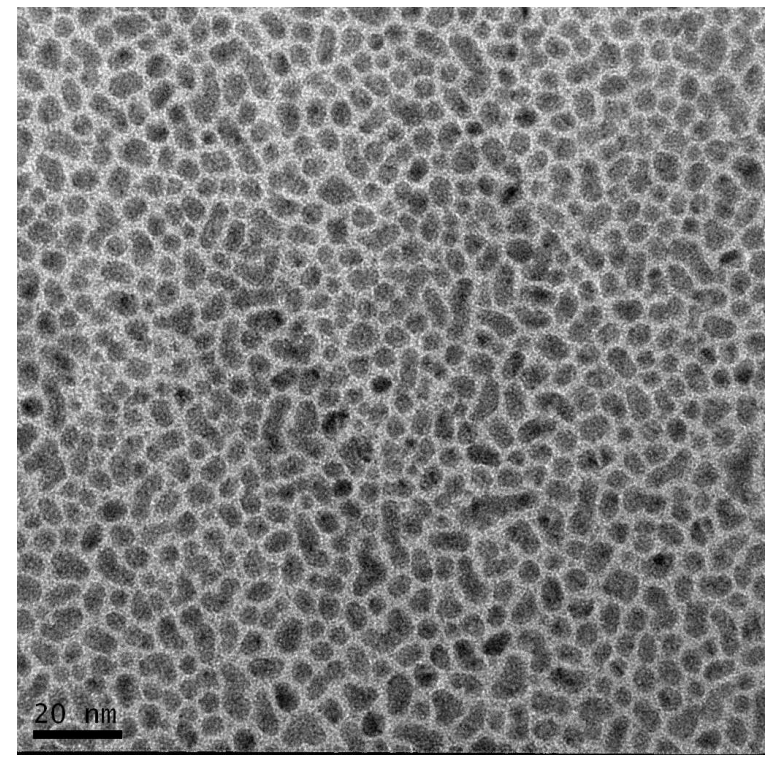

(b)

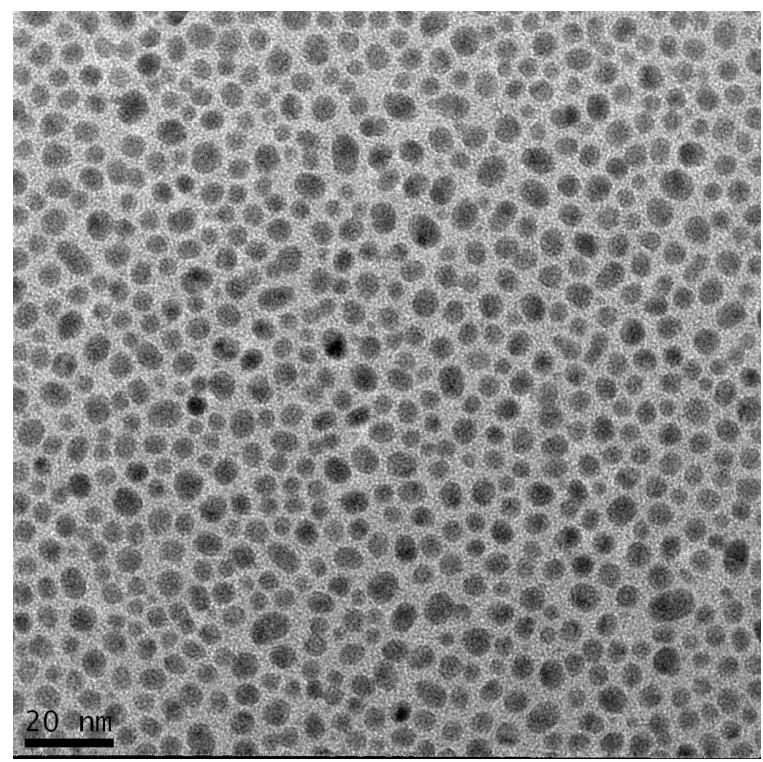

Fonte: A autora.

Tabela 3 - Resultados de diâmetro médio e distância entre as nanopartículas das amostras "não aquecida" e "aquecida", e os respectivos erros padrão.

\begin{tabular}{|c|c|c|}
\hline & Diâmetro médio & $\begin{array}{l}\text { Distância entre } \\
\text { partículas }\end{array}$ \\
\hline $\begin{array}{c}\text { AuNPs/PMMA "não aquecido" } \\
\text { (Figura 21a) }\end{array}$ & $(5,02 \pm 0,03) \mathrm{nm}$ & $(1,47 \pm 0,02) \mathrm{nm}$ \\
\hline $\begin{array}{c}\text { AuNPs /PMMA"aquecido" } \\
\text { (Figura 21b) }\end{array}$ & $(5,03 \pm 0,02) \mathrm{nm}$ & $(1,67 \pm 0,02) \mathrm{nm}$ \\
\hline
\end{tabular}

Fonte: A autora

Verifica-se que não há aumento de tamanho, nem variação de distância entre partículas que sejam significativos, e que possam justificar a melhora no sinal SERS do substrato "aquecido". Fato que é comprovado por simulações do fator de intensificação SERS utilizando o método GMM (Generalized multiparticle Mie). Este método utiliza uma extensão da teoria de Mie para o caso de múltiplas partículas, sendo uma solução semianalítica para o espalhamento de luz por um conjunto arbitrário de esferas isoladas [80]. As simulações foram realizadas em colaboração com o LEM pelo doutorando Giordano Toscano Paganoto, e foi considerado um dímero de nanoesferas com diâmetro de $5 \mathrm{~nm}$, uma vez que o aquecimento não altera significativamente o diâmetro, com separação de 1,5 nm e 1,6 nm, representando as NPs "não aquecidas" e "aquecidas", respectivamente. Foi considerado como meio dielétrico que contém as nanopartículas a água, de forma a simplificar o problema, uma vez que a proposta desta simulação é verificar o efeito do aquecimento, e por consequência, a alteração na distância entre as partículas. O fator de 
intensificação SERS (EF - Enhancement Factor) é normalmente considerado como sendo proporcional à quarta potência do fator $|E| /\left|E_{\text {inc }}\right|$, em que $E$ é a amplitude do campo local e $E_{i n c}$ é a amplitude do campo elétrico da radiação incidente [81. Os resultados das simulações podem ser vistos na Figura 22 . Onde $\vec{k}$ e $\overrightarrow{E_{0}}$ representam o vetor de onda e a amplitude do campo eletromagnético incidente, respectivamente, e $E F_{E M}$ é o fator de intensificação eletromagnético, uma vez que estamos só considerando a intensificação eletromagnética do SERS, considerando o comprimento de onda da radiação incidente em $\lambda=633 \mathrm{~nm}$.

Figura 22 - Resultados das simulações de fator de intensificação SERS das nanopartículas de ouro (a) "não aquecidas" e (b) "aquecidas".
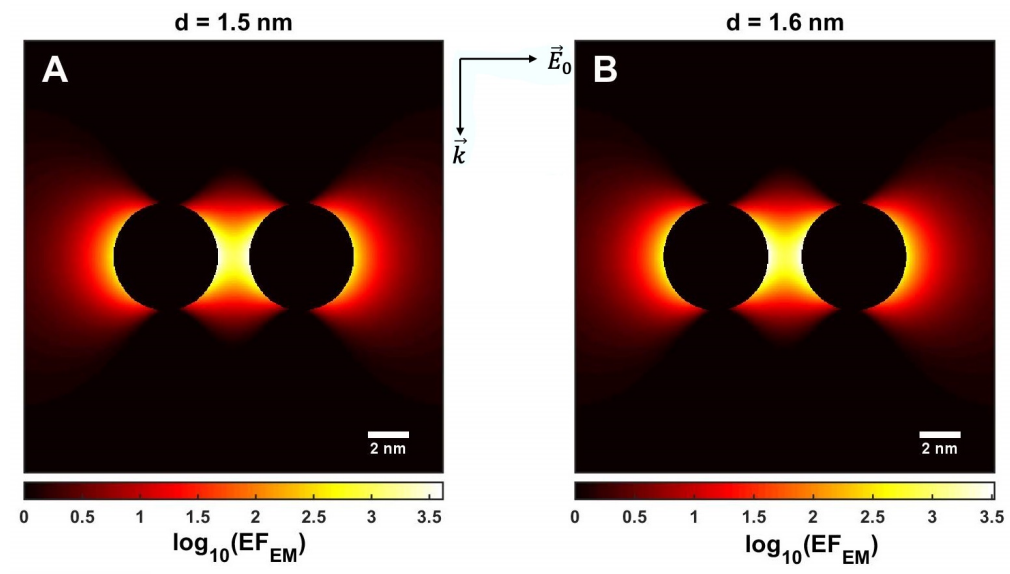

Fonte: Simulações realizadas em colaboração com LEM.

Como o aquecimento não altera consideravelmente o diâmetro e a distância de separação, o fator de intensificação é praticamente o mesmo.

Outro aspecto que deve ser mencionado foi a mudança na geometria das nanopartículas após o aquecimento, de forma que se observa a melhora na uniformidade, uma vez que na amostra "não aquecida" (Figura 21a) existe tanto partículas circulares como partículas alongadas, enquanto que após o aquecimento (Figura 21b) há maior predominância de partículas mais próximas ao formato circular. Tal fato foi verificado nas análises de circularidade e razão de aspecto das nanopartículas (Figuras 23 e 24 e Tabela 4). 
Figura 23 - Histogramas de circularidade do compósito AuNPs/PMMA "não aquecido" (azul) e "aquecido" (vermelho).
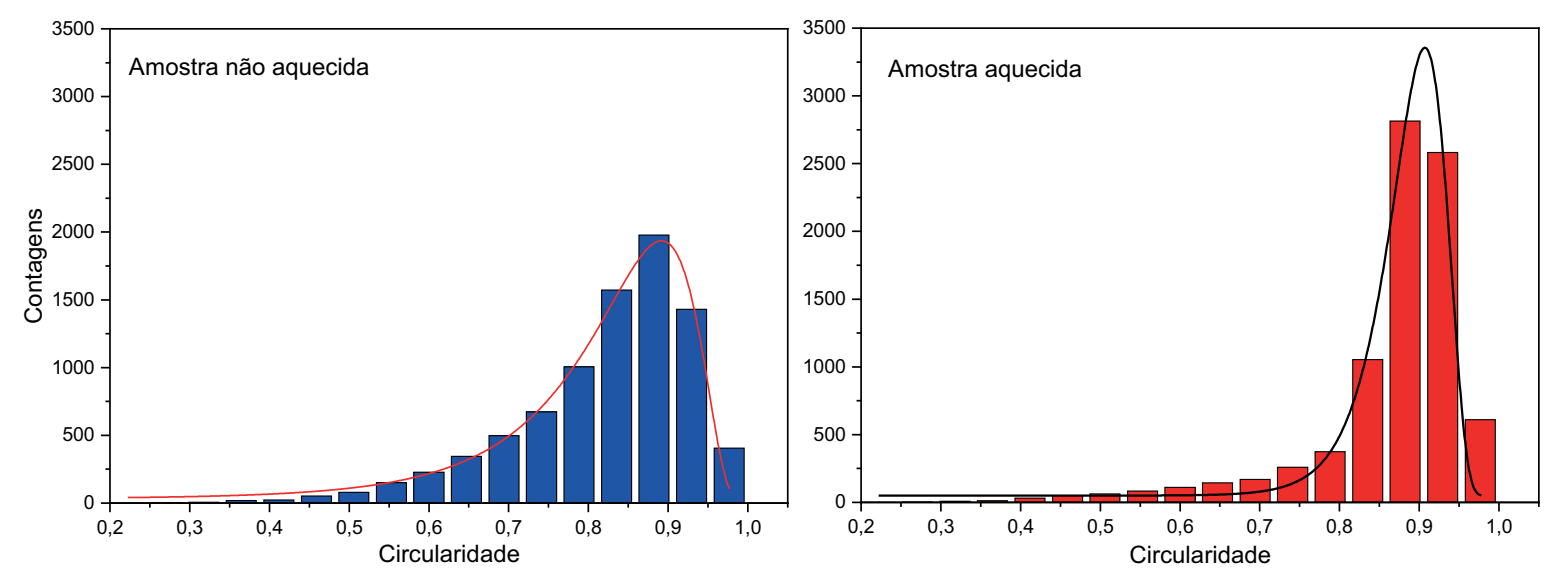

Fonte: A autora.

Figura 24 - Histogramas da razão de aspecto do compósito AuNPs/PMMA "não aquecido" (azul) e "aquecido" (vermelho).
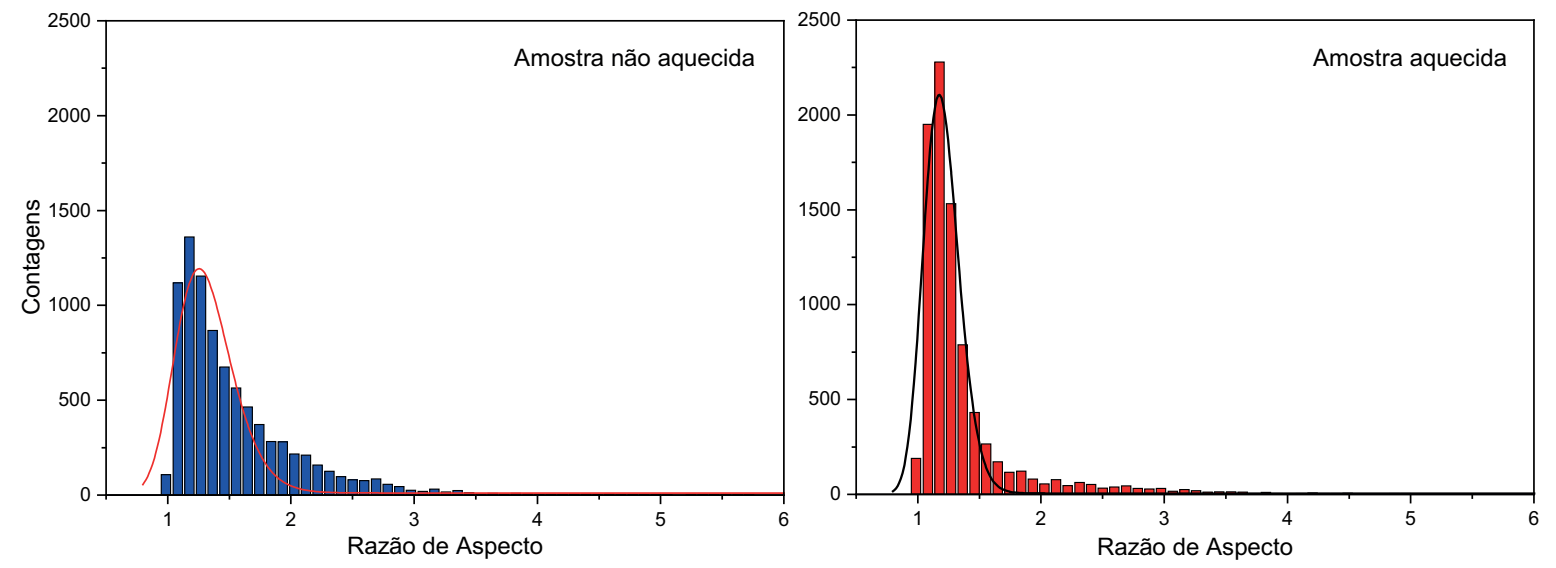

Fonte: A autora.

Os histogramas apresentados nas Figuras 23 e 24, foram ajustados à uma curva de densidade de probabilidades com distribuição log-normal, cujos parâmetros de ajuste são apresentados no Apêndice E. O pico da distribuição está relacionado aos valores mais prováveis de uma determinada característica, no caso a circularidade $\left(4 \pi * a ́ r e a /\right.$ perímetro $\left.^{2}\right)$ e a razão de aspecto ([Eixo maior $] /[$ Eixo menor $]$ da elipse ajustada à nanopartícula) 82]. A circularidade compreende valores entre 0 e 1, onde 1 indica uma circunferência perfeita, e conforme o valor aproxima de 0 , a geometria se aproxima de uma forma cada vez mais alongada. A razão de aspecto compreende valores entre 1 e $+\infty$, onde 1 indica a circunferência perfeita, e conforme o valor tente ao $+\infty$, a geometria tende a um formato cada vez mais alongado. Os resultados são apresentados na Tabela 4. 
Tabela 4 - Resultados dos valores mais prováveis de razão de aspecto e circularidade, e os respectivos erros padrão, das nanopartículas contidas no compósito AuNPs/PMMA "não aquecido" e "aquecido".

\begin{tabular}{ccc}
\cline { 2 - 3 } & Razão de Aspecto & Circularidade \\
\hline AuNPs/PMMA "não aquecido" & $1,26 \pm 0,03$ & $0,89 \pm 0,03$ \\
$\begin{array}{c}\text { (Figura 21a) } \\
\text { AuNPs/PMMA "aquecido" } \\
\text { (Figura 21b) }\end{array}$ & $1,17 \pm 0,02$ & $0,91 \pm 0,02$ \\
\hline
\end{tabular}

Fonte: A autora

Os resultados mostram que tanto para o nanocompósito "não aquecido" quanto para o "aquecido", as nanopartículas apresentam geometria predominante próximas ao formato circular. Além disso, os histogramas corroboram o fato de que o aquecimento homogeiniza a geometria das nanopartículas. Fato que pode ser verificado pelo estreitamento da largura dos histogramas, o que significa que a geometria das nanopartículas presentes no nanocompósito "aquecido" apresentam menor variância do que as presentes no nanocompósito "não aquecido". Desta forma, vale ressaltar que, apesar da temperatura de $150{ }^{\circ} \mathrm{C}$ utilizada no tratamento térmico ser muito intefior à temperatura de fusão do ouro $\left(T_{F_{A u}}=1063\right.$ ${ }^{\circ} \mathrm{C}$ ), a alteração na geometria das nanopartículas se dá devido à propriedades em escala nanométrica que ainda devem ser estudadas.

É visto na literatura que a geometria da nanopartícula melhora o fator de intensificação SERS, de forma que dentre nanopartículas circulares e nanobastonetes, os nanobastonetes apresentam melhor desempenho [83, o que é contrário ao resultado observado por nossos substratos, pois a amostra cuja geometria das nanopartículas se concentra em formatos circulares apresentou melhor desempenho.

Além disso, a rugosidade RMS da superfície do PMMA - tanto para o PMMA sem AuNPs quanto para o nanocompósito AuNPs/PMMA ("não revelado", "revelado" e "aquecido") - foi avaliada. Os resultados estão descritos na Tabela 5.

Tabela 5 - Resultados de rugosidade RMS da superfície do PMMA, e seu respectivo erro padrão; AuNPs/PMMA formados com dose de $0,83 \times 10^{16}$ átomos $/ \mathrm{cm}^{2}$

\begin{tabular}{cc}
\cline { 2 - 2 } & Rugosidade RMS (nm) \\
\hline PMMA sem AuNPs & $0,61 \pm 0,03$ \\
AuNPs/PMMA "não revelado" & $0,61 \pm 0,02$ \\
AuNPs/PMMA "revelado" & $0,69 \pm 0,01$ \\
AuNPs/PMMA "aquecido" & $1,99 \pm 0,02$ \\
\hline
\end{tabular}

Fonte: A autora

É possível perceber que entre as amostras de PMMA sem nanopartículas, AuNPs/PMMA "não revelado" e AuNPs/PMMA "revelado", não há variação significativa de rugosidade que possa ter efeito nos espectros SERS. Porém, para a amostra de AuNPs/PMMA "aquecida", 
a rugosidade aumenta de forma considerável em comparação às outras amostras. Uma vez que esta amostra "aquecida" apresentou melhor desempenho nos espectros SERS, a rugosidade maior pode estar auxiliando na melhora do espectro, de forma que maior quantidade de moléculas de R6G sejam adsorvidas na superfície da amostra [84].

Uma hipótese que deve ser considerada sobre a melhora nos espectros SERS é o fenômeno de intumescimento (em inglês, swelling), que é o aumento do volume do polímero quando este está imerso em um determinado solvente. No PMMA este fenômeno foi estudado ao utilizar água ou álcoois de baixo peso molecular como etanol e metanol [85, e foi verificado a ocorrência do swelling em todos os solventes utilizados, com taxas menores para a água.

Devido ao fato de utilizarmos R6G dissolvida em etanol, o efeito de swelling pode estar favorecendo o aprisionamento das moléculas de R6G na camada de polímero presente sobre as nanopartículas, no caso da amostra de AuNPs/PMMA "não revelada". Além disso o estudo apresentado na Referência [85] descreve que o recobrimento com ouro sobre o PMMA retarda o efeito do swelling. Assim, na amostra de AuNPs/PMMA "revelada", a fina camada de nanopartículas expostas pode estar causando o mesmo efeito observado na literatura, de forma que uma menor quantidade de moléculas de R6G migrem para o interior do PMMA. Assim, a melhora no sinal SERS ocorre devido à uma interação entre a solução do analito e a superfície do substrato. Neste contexto, o aquecimento do polímero também pode estar favorecendo o efeito do swelling, ao permitir uma alteração na morfologia da superfície do PMMA, como pôde ser verificado nos resultados de rugosidade.

Assim, a difusão em profundidade das nanopartículas durante o aquecimento, também deve ser considerado 75] e estudado de forma mais aprofundada, bem como considerar utilizar analitos dissolvidos em diferentes solventes, como a água.

Desta forma, baseando-se nas hipóteses discutidas, torna-se difícil estimar o valor do fator de intensificação SERS. Uma vez que este fator depende da concentração de moléculas de analito adsorvidas no substrato [56], é díficil mensurar este termo uma vez que estamos considerando o efeito do swelling, e por estarmos utilizando o spin coating como forma de deposição de R6G, pois uma parcela da R6G é removida durante a deposição.

\subsection{Resultados das medidas de Espectrofotometria UV-Vis}

Para comparar as propriedades ópticas das amostras formadas pelo compósito de Au/PMMA foi feita a obtenção do espectro UV-vis (Figura 25) para uma amostra "revelada" e "não revelada", utilizando o modo de transmissão para medidas de extinção, utilizando o espectrofotômetro Shimadzu, UV-3101PC UV-VIS-NIR Spectrophotometer, disponível no LEM - IQ-USP. Para a realização das medidas, foi utilizado o filme de PMMA sobre vidro; após a implantação do ouro com dose de 0,6 x $10^{16}$ átomos $/ \mathrm{cm}^{2}$, 
uma das amostras foi "revelada" e outra não. É possível verificar um deslocamento de aproximadamente $40 \mathrm{~nm}$ do pico de extinção para a região do vermelho, no espectro da amostra "revelada", e a diminuição da extinção.

Na literatura 58,73, o deslocamento do pico de extinção no espectro UV-Vis, para a região do vermelho, está relacionado ao aumento do diâmetro da nanopartícula. Uma possibilidade, no caso do nosso substrato, deve-se às nanopartículas de menor diâmetro que podem, em parte, terem sido removidas durante o processo de revelação, em comparação às nanopartículas de maior diâmetro. Além disso, o comportamento da banda de extinção está relacionado ao meio em que as partículas estão contidas [7, 9, 17, 19, 58, 73, 86], assim, também temos presença da camada de polímero acima das nanopartículas influenciando nas propriedades ópticas do nosso material, o que pode explicar o aumento da extinção no espectro da amostra "não revelada". Neste contexto, a variação da extinção com o aumento da espessura de uma camada isolante envolvendo as nanopartículas já foi observado 86, 87, o que corrobora nossos resultados.

As propriedades ópticas da amos- Figura 25 - Espectro UV-vis comparando uma tra que foi submetida ao aquecimento também foram estudadas, considerando a dose de implantação de $0,65 \times 10^{16}$ átomos $/ \mathrm{cm}^{2}$ (Figura 26). Nota-se um aumento expressivo na intensidade do pico de extinção e seu deslocamento para a região do azul em cerca de $70 \mathrm{~nm}$, além do estreitamento da banda plasmônica, após o aquecimento.

Cálculos teóricos descritos pela Referência [19] (vide Apêndice F), indicam a possibilidade do aumento da nanopartícula após o aquecimento, porém como visto na Seção 3.5, não há aumento amostra "revelada" com a "não revelada".

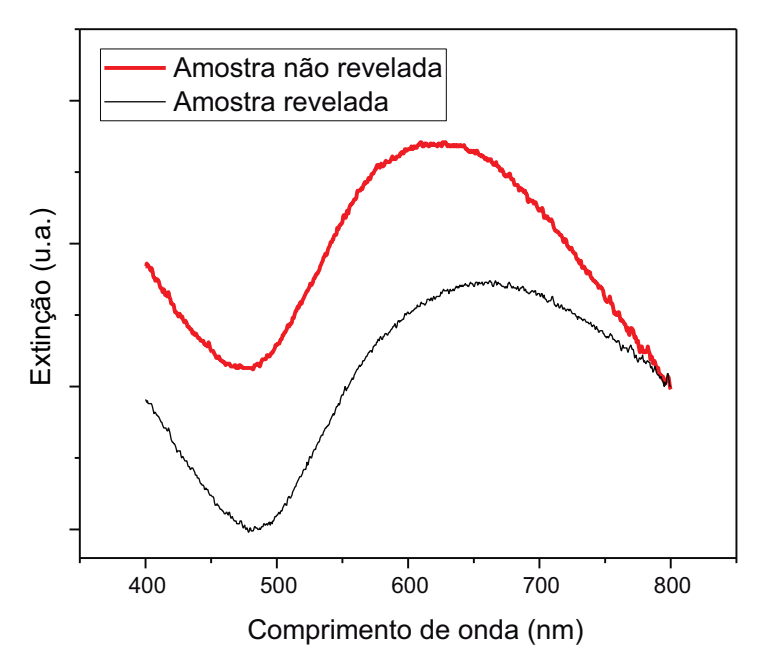

Fonte: A autora.

significativo no tamanho da nanopartícula que justifica o comportamento do espectro UV-Vis.

O alargamento da banda plasmônica ocorre, quando a densidade eletrônica não oscila em fase [58], assim, o espectro que representa a amostra "não aquecida" reflete a presença de nanopartículas de diferentes geometrias, que ocasiona diferentes densidades eletrônicas sejam excitadas em diferentes frequências. Desta forma, o estreitamento da banda plasmônica da amostra "aquecida" está relacionada a homogeneização da geometria das nanopartículas após o aquecimento, fato que é comprovado com a análise de circularidade feita com os resultados de microscopia eletrônica de transmissão apresentados, 
anteriormente, na Seção 3.5 .

Figura 26 - Espectro UV-vis comparando as amostras "aquecida" e "não aquecida", com dose de implantação de $0,65 \times 10^{16}$ átomos $/ \mathrm{cm}^{2}$.

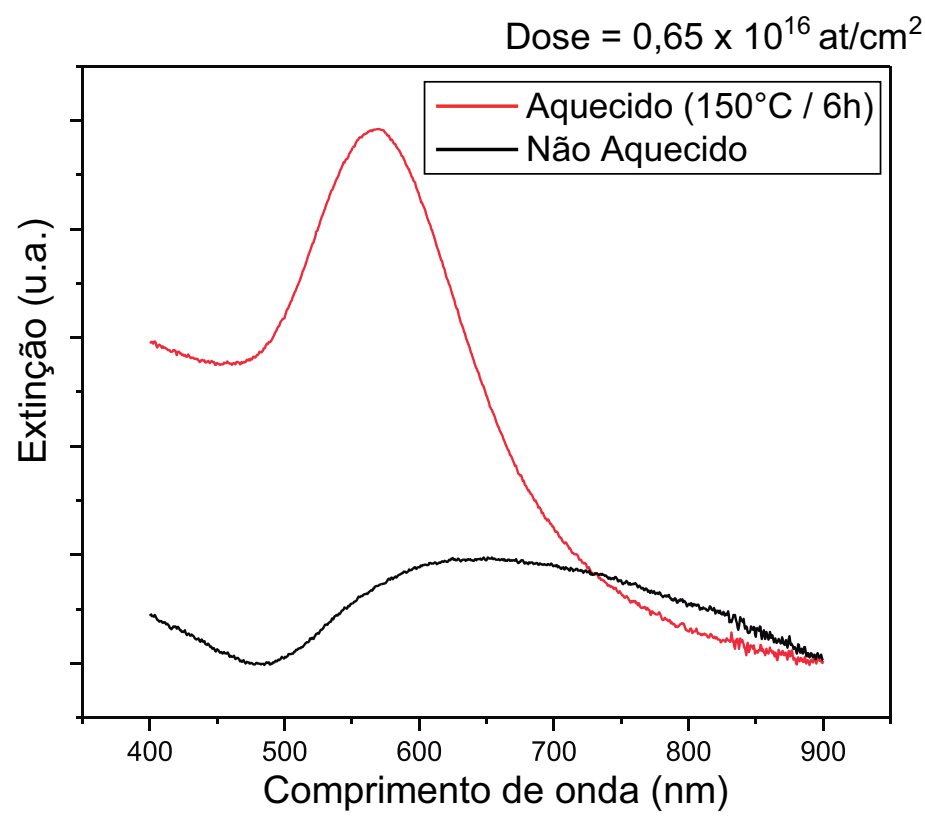

Fonte: A autora. 


\section{Conclusão}

Neste trabalho, obtivemos o material compósito com nanopartículas de ouro incorporadas em um polímero, o PMMA, que são formadas espontaneamente a partir da implantação iônica de baixa energia (49 eV). O filme de PMMA utilizado como matriz para a formação das nanoestruturas possui espessura aproximada de $80 \mathrm{~nm}$, onde a camada compósita se forma a $10 \mathrm{~nm}$ abaixo da superfície como discutido anteriormente na seção 3.1. Comparando com resultados obtidos por simulações TRIM e TRYDIN, a profundidade de penetração é da ordem de $4 \mathrm{~nm}$ para as mesmas condições utilizadas experimentalmente. Uma possível sugestão para a maior profundidade obtida experimentalmente é que estejam ocorrendo processos de difusão na direção contrária a superfície durante a implantação.

O nanocompósito em estudo foi observado por MET onde se observaram partículas isoladas de ouro com diâmetro médio de $(4,25 \pm 0,02) \mathrm{nm}$ para dose de $0,75 \times 10^{16}$ átomos $/ \mathrm{cm}^{2}$.

Com o intuito de avaliar a qualidade deste material compósito como substratos para SERS, foram realizadas medidas utilizando a Rodamina 6G (R6G) como substância sonda. Num primeiro experimento, foram utilizadas diferentes diluições de R6G: $10 \mu \mathrm{M}$ e $1 \mathrm{nM}$, diluídas ambas em etanol. Verificamos a presença dos picos característicos da R6G apenas ao utilizar a concentração de $10 \mu \mathrm{M}$, a qual foi definida como concentração padrão para os demais experimentos.

Outros resultados das avaliações por SERS mostraram um aumento da intensidade dos espectros em função da dose de implantação, identificando as doses maiores, entre as estudadas, como melhor resultado utilizando as amostras "não reveladas". Um resultado importante se refere à ocorrência de uma maior intensidade do sinal quando se mantém a camada de PMMA sobre a camada compósita, isto é, sem o processo de revelação utilizado em outras amostras. Este comportamento pode ser explicado devido ao efeito de intumescimento (swelling), que pode estar favorecendo o aprisionamento das moléculas de R6G na camada de polímero sobre as nanopartículas. Foi visto [85 que uma camada de ouro sobre o PMMA pode retardar este efeito, assim, a camada de nanopartículas expostas pela etapa de revelação pode estar impedindo a migração do analito para dentro do PMMA. Neste contexto, a melhora no sinal SERS ocorre principalmente pela maior concentração de R6G adsorvida na superfície do substrato, o que dificulta a obtenção do fator de intensificação SERS, uma vez que este depende da concentração de moléculas do analito adsorvido na superfície. Desta forma, o maior desafio, é contabilizar estas moléculas, levando em conta que uma parcela da R6G é perdida duranta a etapa de deposição por spin coating. 
Foi considerado realizar um tratamento térmico nas amostras com o nanocompósito, uma vez que o aquecimento acima da temperatura de transição vítrea leva do PMMA à alterações geométricas das nanopartículas [79]. O tratamento térmico foi realizado à $150{ }^{\circ} \mathrm{C}$ durante $6 \mathrm{~h}$, em hotplate, com a R6G aplicada após o tratamento. Os resultados obtidos para as amostras com aquecimento, para doses implantação de 0,85 e 0,83 x 10 16 átomos $/ \mathrm{cm}^{2}$, foram ainda melhores do que os resultados das amostras "não reveladas" de mesma dose. Verificamos, também, que para a amostra de PMMA com R6G e sem nanopartículas, não foi possível observar nenhum pico característico da R6G, desta forma, o substrato estudado é, de fato, um substrato SERS.

Ao analisar a geometria das nanopartículas antes e após o aquecimento, com auxílio de imagens de microscopia eletrônica de transmissão, obtiveram-se diâmetros médio das nanopartículas de $(5,02 \pm 0,03)$ e $(5,03 \pm 0,02)$ nm para as amostras "não aquecida" e "aquecida", respectivamente, ao utilizar dose de $0,83 \times 10^{16}$ átomos $/ \mathrm{cm}^{2}$. Para essa mesma dose, a distância entre partículas foi de $(1,47 \pm 0,02)$ e $(1,67 \pm 0,02) \mathrm{nm}$, para as amostras "não aquecida" e "aquecida", respectivamente. Assim, não houve aumento de tamanho e distância entre partículas significativos que possam explicar a melhora do sinal SERS após o aquecimento.

A razão de aspecto e circularidade também foram investigadas, para a amostra "não aquecida" foram obtidos os valores de $(1,23 \pm 0,03)$ e $(0,89 \pm 0,03)$, respectivamente. Enquanto que para a amostra "aquecida" os valores de razão de aspecto e circularidade foram de $(1,17 \pm 0,02)$ e $(0,91 \pm 0,02)$, respectivamente. Ambas as amostras possuem nanopartículas com geometria predominante próximas ao formato esférico. A partir dos histogramas apresentados nas Figuras 23 e 24 é possível perceber que a amostra "aquecida" possui menor variância em torno do valor mais provável (pico da curva log-normal) de razão de aspecto e circularidade, o que indica uma maior homogeneidade na geometria. Este fato corrobora o que se observa nas micrografias, onde na amostra "não aquecida" temos tanto nanopartículas esféricas como partículas alongadas, enquanto que após o aquecimento há maior predominância de nanopartículas mais próximas ao formato esférico. Porém, é visto na literatura que nanobastonetes possuem melhor desempenho para SERS do que nanopartículas esféricas 83], contrário ao resultado observado em nossos substratos, pois as amostras cuja geometria das nanopartículas se concentra em formatos esféricos apresentou melhor desempenho. A rugosidade RMS das amostras também foram estudadas, onde foram obtidos os valores $(0,61 \pm 0,03),(0,61 \pm 0,02),(0,69 \pm 0,01)$ e $(1,99 \pm 0,02) \mathrm{nm}$ para as amostras de PMMA sem nanopartículas, "não revelada", "revelada" e "aquecida", respectivamente. Pode-se perceber que apenas a amostra "aquecida" apresentou uma alteração significativa no valor da rugosidade, de forma que a rugosidade possa estar favorecendo o efeito SERS ao permitir que uma maior quantidade de moléculas de R6G migrem para dentro do filme de PMMA sobre as nanopartículas. 
Ao investigar as propriedades ópticas do material nanocompósito, através da espectrofotometria UV-Vis, é possível verificar que a extinção é reduzida quando não se tem a presença da camada de polímero sobre as nanopartículas, isto é, utilizando o processo de revelação. Uma vez que o comportamento da banda de extinção está relacionado ao meio em que as partículas estão contidas, a camada de polímero acima das nanopartículas pode estar influenciando as propriedades ópticas do material.

Embora modelos teóricos para cálculo do tamanho da nanopartícula através do espectro UV-Vis estimem o aumento do tamanho da nanopartícula após o aquecimento, as micrografias mostram que não ocorre o aumento significativo das nanopartículas, e sim a homogenização da geometria. E este resultado é refletido no espectro UV-Vis obtido de uma amostra após o aquecimento, pois o alargamento da banda plasmônica está relacionada às oscilações fora de fase da densidade eletrônica, que ocasiona em diferentes densidades eletrônicas sendo excitadas em diferentes frequências. Assim o estreitamento da banda plasmônica se deve à homogenização da geometria das nanopartículas após o aquecimento.

Analisando todos os resultados obtidos neste trabalho, percebemos que o material estudado tem um potencial tecnológico interessante e que deve ser estudado mais profundamente. Pois, através da técnica de fabricação utilizada, foi possível produzir nanopartículas de ouro isoladas que se formam espontaneamente, e que estão protegidas do meio ambiente por uma camada de polímero de aproximadamente $10 \mathrm{~nm}$ sobre elas. Além disso, há a possibilidade de moléculas de alguma substância de interesse ser aprisionada no polímero de forma espontânea, quando consideramos o efeito do swelling.

Finalizando, os aspectos mais importantes deste trabalho foram:

1. As nanopartículas são formadas a aproximadamente $10 \mathrm{~nm}$ abaixo da superfície. Este resultado é diferente dos resultados obtidos por simulações TRIM e TRYDIN, assim, processos de difusão devem ser considerados.

2. A intensidade SERS do substrato "não revelado" aumenta em função da dose de implantação utilizada até o valor aqui estudado de $1,02 \times 10^{16}$ átomos $/ \mathrm{cm}^{2}$.

3. Há maior intensidade de sinal quando as nanopartículas estão enterradas, ou seja, onde não foi realizado o processo de revelação (exposição das nanopartículas). Assim não é necessário expor as nanopartículas para a obtenção do sinal SERS.

4. O aquecimento não aumenta o tamanho das nanopartículas, mas homogeniza a sua geometria.

5. O sinal SERS da R6G foi observado nas amostras "revelada", "não revelada" e após o aquecimento da amostra "não revelada", na qual foi obtido melhor sinal. A melhora no sinal pode ser explicada devido à uma interação entre a solução do 
analito e a superfície da amostra (substrato), como reflexo do efeito de swelling. Desta forma, torna-se necessário o estudo aprofundado utilizando outros tipos de solução do analito, como a R6G dissolvida em água.

6. Devido à interação analito-superfície, torna-se difícil estimar o valor do fator de intensificação SERS, uma vez que é difícil mensurar a concentração de moléculas de analito adsorvidas no substrato. 


\section{Perspectivas Futuras}

É conhecido que outros metais como prata e cobre também podem ser utilizados para a fabricação de substratos SERS, porém, a dificuldade em utilizar estes materiais é a sua reatividade, em especial, com oxigênio [4 8]. Neste contexto, a abordagem utilizada neste trabalho permite a formação de nanopartículas isoladas no interior de um substrato de PMMA, de forma que o metal fique protegido do meio ambiente, garantindo a estabilidade da camada compósita. Uma vez que não é necessário remover a camada de polímero acima das nanopartículas, é possível utilizar estes metais sem que haja alteração na composição das nanopartículas devido à interação com o meio ambiente. Assim, torna-se interessante um estudo utilizando outros metais.

Durante a revisão de literatura percebeu-se que as dimensões nanopartículas de ouro utilizadas para a obtenção de espectros SERS são de cerca de 2 a 10 vezes maiores do que as nanopartículas utilizadas neste trabalho. E como vimos, apenas uma etapa de aquecimento não é capaz de alterar significativamente o tamanho das nanopartículas. Assim, uma forma possível de aumentar o tamanho das nanopartículas é realizar etapas sucessivas de implantação iônica e aquecimento, e monitorar o comportamento das nanopartículas através de microscopia eletrônica de transmissão, ou até mesmo, estudar o comportamento óptico do material, por espectrofotometria UV-Vis.

De forma a aprofundar e complementar este trabalho, diferentes velocidades de rotação do spinner podem ser utilizados, e assim determinar os parâmetros ótimos de deposição do analito para a obtenção de um bom sinal SERS. Também poderão ser utilizado diferentes parâmetros de aquecimento e o monitoramento do comportamento das nanopartículas, para que também sejam determinados os parâmetros ótimos de aquecimento a fim de obter o melhor sinal SERS.

Como não foi possível determinar o fator de intensificação, devido às dificuldades já descritas anteriormente, é necessário o estudo de metodologias que auxiliem na determinação da concentração de moléculas, e também uma forma de estudar a migração da R6G dentro do PMMA. Neste contexto, também se torna interessante o estudo deste material nanocompósito utilizando outros tipos de analitos, bem como utilizando a da R6G dissolvida em água. 


\section{Referências}

[1] DEEPAK, F. L. Metal Nanoparticles and Clusters: Advances in Synthesis, Properties and Applications. [S.1.]: Springer, 2017. Citado 2 vezes nas páginas 20 e 37.

[2] DEORE, A. V.; BHORASKAR, V.; DHOLE, S. Low-energy electron irradiation assisted diffusion of gold nanoparticles in polymer matrix. Radiation Physics and Chemistry, Elsevier, v. 96, p. 97-100, 2014. Citado 2 vezes nas páginas 20 e 37.

[3] NICOLAIS, L.; CAROTENUTO, G. Metal-polymer nanocomposites. [S.l.]: John Wiley \& Sons, 2004. Citado 2 vezes nas páginas 20 e 37.

[4] ZHANG, L. et al. Large-scale growth of sharp gold nano-cones for single-molecule sers detection. RSC Advances, Royal Society of Chemistry, v. 6, n. 4, p. 2882-2887, 2016. Citado 2 vezes nas páginas 20 e 61 .

[5] HERRERA, G. M.; PADILLA, A. C.; HERNANDEZ-RIVERA, S. P. Surface enhanced raman scattering (sers) studies of gold and silver nanoparticles prepared by laser ablation. Nanomaterials, Multidisciplinary Digital Publishing Institute, v. 3, n. 1, p. 158-172, 2013. Citado 2 vezes nas páginas 20 e 61 .

[6] RAO, V. K.; RADHAKRISHNAN, T. Tuning the sers response with ag-au nanoparticleembedded polymer thin film substrates. ACS applied materials \& interfaces, ACS Publications, v. 7, n. 23, p. 12767-12773, 2015. Citado 3 vezes nas páginas 20, 46 e 61.

[7] PHAM, X.-H. et al. Silver nanoparticle-embedded thin silica-coated graphene oxide as an sers substrate. Nanomaterials, Multidisciplinary Digital Publishing Institute, v. 6, n. 10, p. 176, 2016. Citado 4 vezes nas páginas 20, 46, 55 e 61.

[8] CAO, X. et al. Sers-active metal-organic frameworks with embedded gold nanoparticles. Analyst, Royal Society of Chemistry, v. 142, n. 14, p. 2640-2647, 2017. Citado 3 vezes nas páginas 20, 46 e 61 .

[9] FERREIRA, J. et al. Tailored sers substrates obtained with cathodic arc plasma ion implantation of gold nanoparticles into a polymer matrix. Physical Chemistry Chemical Physics, Royal Society of Chemistry, v. 14, n. 6, p. 2050-2055, 2012. Citado 3 vezes nas páginas 20, 49 e 55.

[10] PRAKASH, J.; HARRIS, R.; SWART, H. Embedded plasmonic nanostructures: Synthesis, fundamental aspects and their surface enhanced raman scattering applications. International Reviews in Physical Chemistry, Taylor \& Francis, v. 35, n. 3, p. 353-398, 2016. Citado 2 vezes nas páginas 20 e 46.

[11] GOUL, R. et al. Quantitative analysis of surface enhanced raman spectroscopy of rhodamine $6 \mathrm{~g}$ using a composite graphene and plasmonic au nanoparticle substrate. Carbon, Elsevier, v. 111, p. 386-392, 2017. Citado 2 vezes nas páginas 20 e 46.

[12] MISHRA, Y. et al. Synthesis and characterization of ag nanoparticles in silica matrix by atom beam sputtering. Scripta Materialia, Elsevier, v. 56, n. 7, p. 629-632, 2007. Citado na página 20. 
[13] MURPHY, C. J. et al. Anisotropic metal nanoparticles: synthesis, assembly, and optical applications. [S.1.]: ACS Publications, 2005. Citado na página 20.

[14] PANÁCEK, A. et al. Silver colloid nanoparticles: synthesis, characterization, and their antibacterial activity. The Journal of Physical Chemistry B, ACS Publications, v. 110, n. 33, p. 16248-16253, 2006. Citado na página 20.

[15] NAG, J.; JR, R. H. Synthesis of vanadium dioxide thin films and nanoparticles. Journal of Physics: Condensed Matter, IOP Publishing, v. 20, n. 26, p. 264016, 2008. Citado na página 20.

[16] STEPANOV, A. L.; HOLE, D.; TOWNSEND, P. Formation of silver nanoparticles in soda-lime silicate glass by ion implantation near room temperature. Journal of noncrystalline solids, Elsevier, v. 260, n. 1-2, p. 65-74, 1999. Citado na página 20.

[17] KREIBIG, U.; VOLLMER, M. Optical properties of metal clusters. [S.l.]: SpringerVerlag, 1995. Citado 2 vezes nas páginas 22 e 55.

[18] OLSON, J. et al. Optical characterization of single plasmonic nanoparticles. Chemical Society Reviews, Royal Society of Chemistry, v. 44, n. 1, p. 40-57, 2015. Citado na página 22 .

[19] TEIXEIRA, F. d. S. et al. Surface plasmon resonance of gold nanoparticles formed by cathodic arc plasma ion implantation into polymer. Journal of Vacuum Science $\&$ Technology B: Microelectronics and Nanometer Structures Processing, Measurement, and Phenomena, AVS, v. 27, n. 5, p. 2242-2247, 2009. Citado 5 vezes nas páginas 22, 23, 27, 55] e 79.

[20] LINK, S.; EL-SAYED, M. A. Spectral properties and relaxation dynamics of surface plasmon electronic oscillations in gold and silver nanodots and nanorods. [S.l.]: ACS Publications, 1999. Citado 2 vezes nas páginas 22 e 37.

[21] MIE, G. Articles on the optical characteristics of turbid tubes, especially colloidal metal solutions. Ann. Phys, v. 25, n. 3, p. 377-445, 1908. Citado na página 23.

[22] VIONNET-MENOT, S. et al. Tunneling-percolation origin of nonuniversality: theory and experiments. Physical Review B, APS, v. 71, n. 6, p. 064201, 2005. Citado na página 23 .

[23] SALVADORI, M.; TEIXEIRA, F. d. S.; CATTANI, M. Determination of the tunneling decay length and electron affinity of the modified pmma in au-pmma nanocomposites. Trabalho a ser submetido pelo grupo. Citado na página 23.

[24] SALVADORI, M. et al. Conducting polymer formed by low energy gold ion implantation. Applied Physics Letters, AIP, v. 93, n. 7, p. 073102, 2008. Citado na página 23 .

[25] SALVADORI, M. et al. Surface modification by metal ion implantation forming metallic nanoparticles in an insulating matrix. Applied Surface Science, Elsevier, v. 310, p. 158-163, 2014. Citado na página 23. 
[26] HAN, S. et al. Tailoring the dielectric layer structure for enhanced performance of organic field-effect transistors: The use of a sandwiched polar dielectric layer. Materials, Multidisciplinary Digital Publishing Institute, v. 9, n. 7, p. 545, 2016. Citado na página 26 .

[27] DOBISZ, E. A. et al. Effects of molecular properties on nanolithography in polymethyl methacrylate. Journal of Vacuum Science \& Technology B: Microelectronics and Nanometer Structures Processing, Measurement, and Phenomena, AVS, v. 18, n. 1, p. 107-111, 2000. Citado na página 26.

[28] MICRO-CHEM. Nano PMMA and Copolymer. 2001. Disponível em: <http:// microchem.com/pdf/PMMA_Data_Sheet.pdf>. Acesso em: 2018-01-18. Citado na página 26.

[29] AKTARY, M.; STEPANOVA, M.; DEW, S. Simulation of the spatial distribution and molecular weight of polymethylmethacrylate fragments in electron beam lithography exposures. Journal of Vacuum Science \& Technology B: Microelectronics and Nanometer Structures Processing, Measurement, and Phenomena, AVS, v. 24, n. 2, p. 768-779, 2006. Citado 2 vezes nas páginas 26 e 29.

[30] ANDERS, A. Metal plasma immersion ion implantation and deposition: a review. Surface and Coatings Technology, Elsevier, v. 93, n. 2-3, p. 158-167, 1997. Citado na página 27.

[31] ANDERS, A. Energetic deposition using filtered cathodic arc plasmas. Vacuum, Elsevier, v. 67, n. 3, p. 673-686, 2002. Citado 2 vezes nas páginas 27 e 28 .

[32] ANDERS, A. A review comparing cathodic arcs and high power impulse magnetron sputtering (hipims). Surface and Coatings Technology, Elsevier, v. 257, p. 308-325, 2014. Citado na página 27.

[33] TEIXEIRA, F.; SALVADORI, M. Nucleation of gold nanoclusters in pmma during energetic plasma deposition: A molecular dynamics and tfmc-monte carlo study. Physica E: Low-dimensional Systems and Nanostructures, Elsevier, 2019. Citado na página 28.

[34] SYSTEMS, J. N. L. NPGS: System Description. 1996-2018. Disponível em: <http: //jcnabity.com/sysdesc.htm>. Acesso em: 2018-01-24. Citado na página 29.

[35] GOLDSTEIN, J. et al. Scanning Electron Microscopy and X-ray Microanalysis. [S.l.]: Springer Science, 2003. Citado 2 vezes nas páginas 31 e 32.

[36] JEOL. A Guide to Scanning Microscope Observation. Disponível em: $<$ http://www.jeolusa.com/DesktopModules/Bring2mind/DMX/Download.aspx?

EntryId=1\&Command=Core_Download\&language $=$ en-US\&PortalId $=2 \&$ TabId $=320>$ Acesso em: 2018-03-21. Citado na página 32.

[37] LUO, Z. A Practical Guide to Transmission Electron Microscopy: Fundamentals. [S.l.]: Momentum Press, 2015. Citado na página 32.

[38] EATON, P.; WEST, P. Atomic force microscopy. [S.l.]: Oxford University Press, 2010. Citado na página 33 . 
[39] SALVADORI, M. C. B. S. Notas de aula do curso de pós-graduação do Departamento de Fúsica Aplicada, PGF5205 - Microscopia De Força Atômica e Tunelamento. 2016. Citado na página 33 .

[40] CHEN, C. J. Introduction to scanning tunneling microscopy. [S.l.]: Oxford University Press on Demand, 1993. v. 4. Citado na página 33.

[41] Park Systems. Basic Contact AFM \& Dynamic Force Microscope (DFM). 2018. Disponível em: <http://www.parksystems.com/>. Acesso em: 2018-03-29. Citado na página 34 .

[42] CHU, W.-K. Backscattering spectrometry. [S.l.]: Elsevier, 2012. Citado na página 34.

[43] MAYER, M. SIMNRA: Computer simulation of RBS, ERDA, NRA and MEIS. 2017. Disponível em: <http://home.mpcdf.mpg.de/ mam/>. Acesso em: 2017-12-11. Citado na página 35.

[44] RAMAN, C. V.; KRISHNAN, K. S. A new type of secondary radiation. Nature, Nature Publishing Group, v. 121, n. 3048, p. 501, 1928. Citado na página 35.

[45] THE Nobel Prize in Physics 1930. 2001. Disponível em: <https://www.nobelprize. org/prizes/physics/1930/summary/>. Acesso em: 2018-11-08. Citado na página 35.

[46] SALA, O. Fundamentos da espectroscopia Raman e no infravermelho. [S.l.]: Unesp, 1996. Citado na página 36.

[47] RODRIGUES, D. C. Efeito da geometria de nanoestruturas de ouro na intensificação do espalhamento Raman. Tese (Doutorado) — Universidade de São Paulo, 2013. Citado na página 36.

[48] MILlEN, R. P.; FARIA, D. L. A. de; TEMPERINI, M. L. Modelos para dispersão raman em polímeros conjugados. Quim. Nova, SciELO Brasil, v. 28, n. 2, p. 289-295, 2005. Citado na página 36.

[49] FARIA, D. d.; TEMPERINI, M. L.; SALA, O. Vinte anos de efeito sers. Química Nova, v. 22, n. 4, 1999. Citado na página 36.

[50] UETSUKI, K. et al. Experimental identification of chemical effects in surface enhanced raman scattering of 4-aminothiophenol. The Journal of Physical Chemistry C, ACS Publications, v. 114, n. 16, p. 7515-7520, 2010. Citado na página 36.

[51] KERKER, M. Electromagnetic model for surface-enhanced raman scattering (sers) on metal colloids. Accounts of Chemical Research, ACS Publications, v. 17, n. 8, p. 271-277, 1984. Citado na página 36 .

[52] LOMBARDI, J. R.; BIRKE, R. L. A unified view of surface-enhanced raman scattering. Accounts of chemical research, ACS Publications, v. 42, n. 6, p. 734-742, 2009. Citado na página 36 .

[53] LOMBARDI, J. R.; BIRKE, R. L. The theory of surface-enhanced raman scattering. The Journal of chemical physics, AIP, v. 136, n. 14, p. 144704, 2012. Citado na página 36 .

[54] PARK, W.-H.; KIM, Z. H. Charge transfer enhancement in the sers of a single molecule. Nano letters, ACS Publications, v. 10, n. 10, p. 4040-4048, 2010. Citado na página 36. 
[55] SANTOS, D. P. d. Espalhamento Raman intensificado pela superfície (SERS) no regime de detecção de uma molécula. Tese (Doutorado) - Universidade de São Paulo, 2013. Citado na página 36 .

[56] RU, E. L.; ETCHEGOIN, P. Principles of Surface-Enhanced Raman Spectroscopy: and related plasmonic effects. [S.1.]: Elsevier, 2008. Citado 3 vezes nas páginas 37, 38 e 54.

[57] PERKAMPUS, H.-H. UV-VIS Spectroscopy and its Applications. [S.1.]: Springer Science \& Business Media, 2013. Citado na página 37.

[58] FERREIRA, J. et al. Ressonância de plasmon de superfície localizado e aplicação em biossensores e células solares. Química nova. Vol. 39, n. 9 (Nov. 2016), p. 1098-1111, 2016. Citado 2 vezes nas páginas 37 e 55 .

[59] VALEUR, B.; BERBERAN-SANTOS, M. N. Molecular fluorescence: principles and applications. [S.l.]: John Wiley \& Sons, 2012. Citado na página 38.

[60] ZIEGLER, J. F.; ZIEGLER, M. D.; BIERSACK, J. P. SRIM: the stopping and range of ions in matter. [S.l.]: Cadence Design Systems, 2008. Citado na página 39.

[61] MÖLLER, W.; ECKSTEIN, W. Tridyn - a trim simulation code including dynamic composition changes. Nuclear Instruments and Methods in Physics Research Section B: Beam Interactions with Materials and Atoms, Elsevier, v. 2, n. 1-3, p. 814-818, 1984. Citado na página 39.

[62] FAUPEL, F.; WILLECKE, R.; THRAN, A. Diffusion of metals in polymers. Materials Science and Engineering: R: Reports, Elsevier, v. 22, n. 1, p. 1-55, 1998. Citado na página 43 .

[63] BECHTOLSHEIM, C. v.; ZAPOROJTCHENKO, V.; FAUPEL, F. Influence of thermal treatment on the morphology and adhesion of gold films on trimethylcyclohexanepolycarbonate. Applied surface science, Elsevier, v. 151, n. 1-2, p. 119-128, 1999. Citado na página 43 .

[64] ROSENTHAL, L. et al. Diffusion and growth of metal clusters in nanocomposites: A kinetic monte carlo study. Contributions to Plasma Physics, Wiley Online Library, v. 51, n. 10, p. 971-980, 2011. Citado na página 43.

[65] THRAN, A. et al. Evidence of noble metal diffusion in polymers at room temperature and its retardation by a chromium barrier. Applied physics letters, AIP, v. 81, n. 2, p. 244-246, 2002. Citado na página 43.

[66] ROSENTHAL, L. et al. Kinetic monte carlo simulations of cluster growth and diffusion in metal-polymer nanocomposites. In: Complex Plasmas: Scientific Challenges and Technological Opportunities. Cham: Springer International Publishing, 2014. p. 321-370. ISBN 978-3-319-05437-7. Disponível em: <https://doi.org/10.1007/978-3-319-05437-7_ 10>. Citado na página 43 .

[67] PUBCHEM. Rhodamine 6G. Disponível em: <https://pubchem.ncbi.nlm.nih.gov/ substance/24899367>. Acesso em: 2019-05-12. Citado na página 44.

[68] JENSEN, L.; SCHATZ, G. C. Resonance raman scattering of rhodamine $6 \mathrm{~g}$ as calculated using time-dependent density functional theory. The Journal of Physical Chemistry A, ACS Publications, v. 110, n. 18, p. 5973-5977, 2006. Citado 2 vezes nas páginas 44 e 49. 
[69] BOROWICZ, P. et al. Raman spectra of high- $\kappa$ dielectric layers investigated with micro-raman spectroscopy comparison with silicon dioxide. The Scientific World Journal, Hindawi, v. 2013, 2013. Citado na página 44.

[70] MISHRA, P.; JAIN, K. First-and second-order raman scattering in nanocrystalline silicon. Physical Review B, APS, v. 64, n. 7, p. 073304, 2001. Citado na página 45.

[71] LI, J. F. et al. Shell-isolated nanoparticle-enhanced raman spectroscopy. nature, Nature Publishing Group, v. 464, n. 7287, p. 392, 2010. Citado na página 46.

[72] LI, J.-F. et al. Dielectric shell isolated and graphene shell isolated nanoparticle enhanced raman spectroscopies and their applications. Chemical Society Reviews, Royal Society of Chemistry, v. 44, n. 23, p. 8399-8409, 2015. Citado na página 46.

[73] LIZ-MARZÁN, L. M. Tailoring surface plasmons through the morphology and assembly of metal nanoparticles. Langmuir, ACS Publications, v. 22, n. 1, p. 32-41, 2006. Citado 2 vezes nas páginas 46 e 55 .

[74] LU, G.; LI, H.; ZHANG, H. Gold-nanoparticle-embedded polydimethylsiloxane elastomers for highly sensitive raman detection. Small, Wiley Online Library, v. 8, n. 9, p. 1336-1340, 2012. Citado na página 46.

[75] BOTTOMLEY, A. et al. Dynamics of nanocubes embedding into polymer films investigated via spatially resolved plasmon modes. Nanoscale, Royal Society of Chemistry, v. 8, n. 21, p. 11168-11176, 2016. Citado 2 vezes nas páginas 47 e 54.

[76] BUSHELL, M.; IANOUL, A. Interfacial diffusion of silver nanocrystals into polymer surfaces monitored by hybrid plasmon modes. The Journal of Physical Chemistry C, ACS Publications, v. 122, n. 18, p. 10197-10204, 2018. Citado na página 47.

[77] COLE, D. H. et al. Metal-polymer interactions in a polymer/metal nanocomposite. Physical review letters, APS, v. 78, n. 26, p. 5006, 1997. Citado na página 47.

[78] TEIXEIRA, F. d. S. et al. Annealing effects on nanostructured goldpolymethylmethacrylate composites: Small-angle x-ray scattering analysis. Journal of Applied Physics, AIP, v. 111, n. 10, p. 104311, 2012. Citado na página 47.

[79] TEIXEIRA, F. d. S. et al. Structure of disordered gold-polymer thin films using small angle x-ray scattering. Journal of Applied Physics, AIP, v. 108, n. 9, p. 093505, 2010. Citado 2 vezes nas páginas 47 e 58.

[80] WANG, M. et al. Generalized multiparticle mie modeling of light scattering by cells. Chinese Science Bulletin, Springer, v. 58, n. 21, p. 2663-2666, 2013. Citado na página 50.

[81] RU, E. L.; ETCHEGOIN, P. Rigorous justification of the| e| 4 enhancement factor in surface enhanced raman spectroscopy. Chemical Physics Letters, Elsevier, v. 423, n. 1-3, p. 63-66, 2006. Citado na página 51.

[82] FERREIRA, T.; RASBAND, W. ImageJ User Guide. 2012. Disponível em: <https: //imagej.nih.gov/ij/docs/guide/146-30.html>. Acesso em: 2018-12-05. Citado na página 52 . 
[83] LI, M. et al. Shape-dependent surface-enhanced raman scattering in gold-ramanprobe-silica sandwiched nanoparticles for biocompatible applications. Nanotechnology, IOP Publishing, v. 23, n. 11, p. 115501, 2012. Citado 2 vezes nas páginas 53 e 58 .

[84] CHATTERJEE, A. et al. Surface potential and morphology mapping to investigate analyte adsorption effects on surface enhanced raman scattering (sers). Chemical Communications, Royal Society of Chemistry, v. 53, n. 88, p. 12024-12027, 2017. Citado na página 54.

[85] GERVINSKAS, G.; DAY, D.; JUODKAZIS, S. High-precision interferometric monitoring of polymer swelling using a simple optofluidic sensor. Sensors and Actuators B: Chemical, Elsevier, v. 159, n. 1, p. 39-43, 2011. Citado 2 vezes nas páginas 54 e 57.

[86] KOBAYASHI, Y. et al. Silica coating of silver nanoparticles using a modified stöber method. Journal of colloid and interface science, Elsevier, v. 283, n. 2, p. 392-396, 2005. Citado na página 55 .

[87] CHOU, K.-S.; CHEN, C.-C. Fabrication and characterization of silver core and porous silica shell nanocomposite particles. Microporous and Mesoporous Materials, Elsevier, v. 98, n. 1-3, p. 208-213, 2007. Citado na página 55.

[88] EMBRASOL. Disponível em: <http://www.limpsonic.com.br>. Acesso em: 2018-0118. Citado na página 70 .

[89] PEREIRA, A. H. A. RT-ATCP-02 Limpeza Ultra-Sônica overview e estado da arte. 2010. Disponível em: <http://www.atcp.com.br/imagens/produtos/ceramicas/artigos/ RT-ATCP-02.pdf $>$. Acesso em: 2018-01-18. Citado na página 70.

[90] MADOU, M. J. Manufacturing techniques for microfabrication and nanotechnology. [S.1.]: CRC press, 2011. v. 2. Citado 2 vezes nas páginas 71 e 72 .

[91] WEBER, M. J. Handbook of optical materials. [S.1.]: CRC press, 2002. Citado na página 79 .

[92] HUARD, B. et al. Transport measurements across a tunable potential barrier in graphene. Physical Review Letters, APS, v. 98, n. 23, p. 236803, 2007. Citado na página 79 . 
Apêndices 


\section{APÊNDICE A - Limpeza de substratos e fabricação do filme de PMMA}

Para garantir substratos adequados para a deposição do filme polimérico, é necessário que a superfície apresente a menor quantidade possível de impurezas. Como substrato foi utilizado o silício obtido comercialmente. O procedimento de limpeza foi realizado em uma capela química da seguinte forma:

- Limpeza mecânica (esfregamento) com algodão embebido em acetona para a remoção do excesso de possíveis contaminantes;

- Banho ultrassônico (40 kHz 88]) com ciclos em tricloroetileno, acetona e álcool isopropílico, durante cinco minutos para cada ciclo.

- Secagem dos substratos utilizando jato de gás nitrogênio.

Na limpeza ultrassônica ocorre um fenômeno conhecido como cavitação, onde micro-bolhas, gases dissolvidos e não homogeneidade dão origem a cavidades (bolhas de cavitação) que se expandem até um tamanho crítico, no qual colapsam, gerando grandes diferenciais de pressão e temperatura [89], que auxiliam na remoção dos contaminantes presentes na superfície a ser limpa.

Após a limpeza cuidadosa, os substratos foram aquecidos, em hotplate por 10 minutos a $150^{\circ} \mathrm{C}$ para eliminação da umidade em sua superfície. Em seguida, a solução de PMMA 950K A2 foi depositada em quantidade suficiente para cobrir toda a superfície do substrato. O spinner foi acionado a uma rotação de $4000 \mathrm{rpm}$ por 50 segundos, obtendo um filme de aproximadamente $80 \mathrm{~nm}$ de espessura. Para remover resíduos do solvente foi feita uma etapa de cura, em hotplate, a $180^{\circ} \mathrm{C}$ por 20 minutos.

OBS: As amostras de silício utilizadas neste trabalho são provenientes de um set de lâminas de silício de três polegadas do tipo N (dopante: fósforo) de orientação <100>. 


\section{APÊNDICE B - Calibração da Litografia}

No processo de calibração, foi utilizado um conjunto de estruturas quadradas de dimensões $5 \mu \mathrm{m}$ x $5 \mu \mathrm{m}$ espaçados por $10 \mu \mathrm{m}$, no intuito de determinar uma dose crítica, isto é, quando o filme é completamente removido [90] após a revelação.

No processo de calibração, foi utilizado um conjunto de estruturas que consiste em uma matriz de 11 x 11 quadrados com as dimensões mencionadas. Utilizando a técnica de litografia por feixe de elétrons, o conjunto de estruturas foi litografado em três regiões diferentes de um filme de PMMA sobre um substrato de silício. Para cada conjunto de quadrados foi utilizado uma dose diferente $\left(30,35\right.$ e $\left.40 \mu \mathrm{C} / \mathrm{cm}^{2}\right)$ para uma mesma corrente de feixe de $40 \mathrm{pA}$. O filme foi revelado utilizando MIBK:IPA na proporção de 1:3. Cada conjunto litografado foi avaliado, utilizando AFM de contato intermitente, obtendo imagens com janela de varredura de $50 \mu \mathrm{m}$ x $50 \mu \mathrm{m}$ para cada dose utilizada. O processo de limpeza de substratos e fabricação de filmes de PMMA está descrito no Apêndice A

A Figura 27 mostra imagens de cross-section das estruturas litografadas. A dose ótima a ser utilizada deve gerar estruturas com remoção total do filme de PMMA, mas sem arredondamento das bordas dos patamares entre os quadrados. A remoção total do filme de PMMA exposto ao feixe de elétrons pode ser identificado através de um aspecto flat no fundo do quadrado e a uniformidade da profundidade, que indica a espessura do filme.

Figura 27 - Perfil em cross-section da imagem obtida por AFM de PMMA litografado por feixe de elétrons com corrente $40 \mathrm{pA}$. (a) dose $30 \mu \mathrm{C} / \mathrm{cm}^{2}$; (b) dose $35 \mu \mathrm{C} / \mathrm{cm}^{2}$; (c) dose $40 \mu \mathrm{C} / \mathrm{cm}^{2}$.

(a)

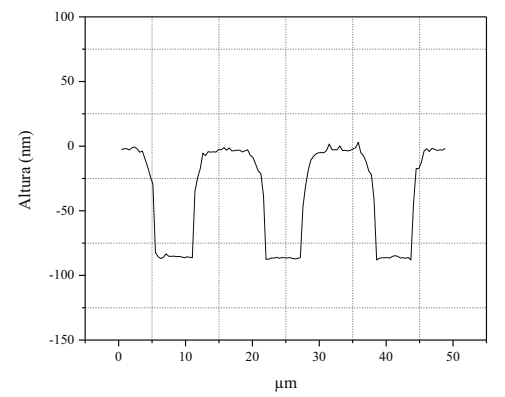

(b)

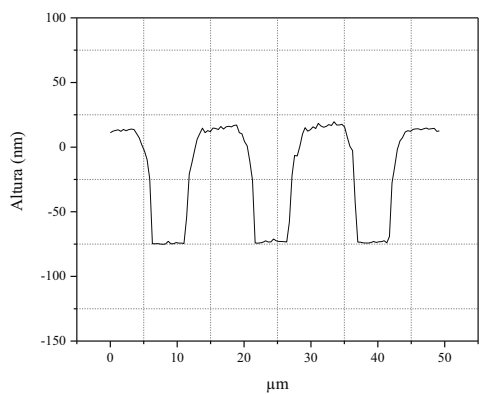

(c)

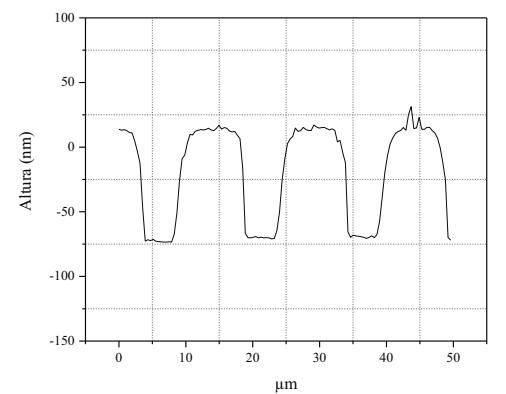

Fonte: A autora. dimensões que a calibração anterior, mas desta vez, utilizado um conjunto de 20x20 
quadrados. A dose foi variada em cada coluna da matriz, com um range de $15 \mu \mathrm{C} / \mathrm{cm}^{2}$ a $30 \mu \mathrm{C} / \mathrm{cm}^{2}$ com passo de $0,8 \mu \mathrm{C} / \mathrm{cm}^{2}$, uma vez que a dose de $30 \mu \mathrm{C} / \mathrm{cm}^{2}$ se mostrou suficiente na etapa anterior. A corrente do feixe foi mantida em $40 \mathrm{pA}$.

Um gráfico que relaciona a espessura normalizada do filme de resiste com o logaritmo da dose, chamado de curva de contraste [90], foi feito (Figura 28). Define-se como espessura normalizada a espessura restante após a exposição por feixe de elétrons, dividida pela espessura original do filme de polímero.

Figura 28 - Curva de contraste com variação de dose entre $15 \mu \mathrm{C} / \mathrm{cm}^{2}$ a $30 \mu \mathrm{C} / \mathrm{cm}^{2}$, com corrente do feixe igual à $40 \mathrm{pA}$.

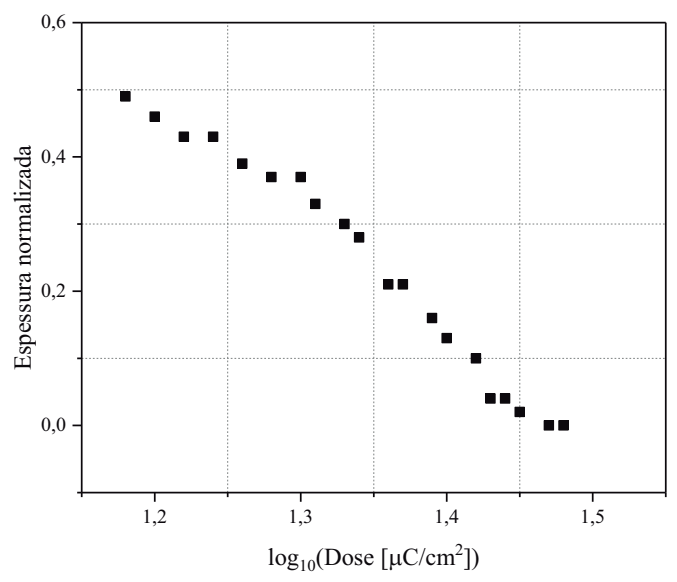

Fonte: A autora.

Analisando o gráfico da Figura 28, para doses acima da dose correspondente ao $\log _{10}($ Dose $)=1,45$ o filme de polímero é totalmente removido. Devido à resolução da litografia estar relacionada ao diâmetro do feixe de elétrons (spot-size), que é função da corrente do feixe, julga-se necessário realizar uma nova calibração, utilizando o mesmo conjunto de 20x20 quadrados, utilizando a dose de $30 \mu \mathrm{C} / \mathrm{cm}^{2}$ e corrente de $30 \mathrm{pA}$.

A Figura 29 mostra um comparativo entre imagens de cross-section de litografias utilizando corrente de $30 \mathrm{pA}$ (Figura 29a) e $40 \mathrm{pA}$ (Figura 29b). É possível notar que não houve um efeito significativo do efeito de arredondamento de bordas para ambas as correntes utilizadas, além de todo o filme ter sido removido. 
Figura 29 - Perfil em cross-section de PMMA litografado por feixe de elétrons ao utilizar dose de $30 \mu \mathrm{C} / \mathrm{cm}^{2}$ (a) para corrente de $30 \mathrm{pA}$ e (b) para corrente de $40 \mathrm{pA}$.

(a)

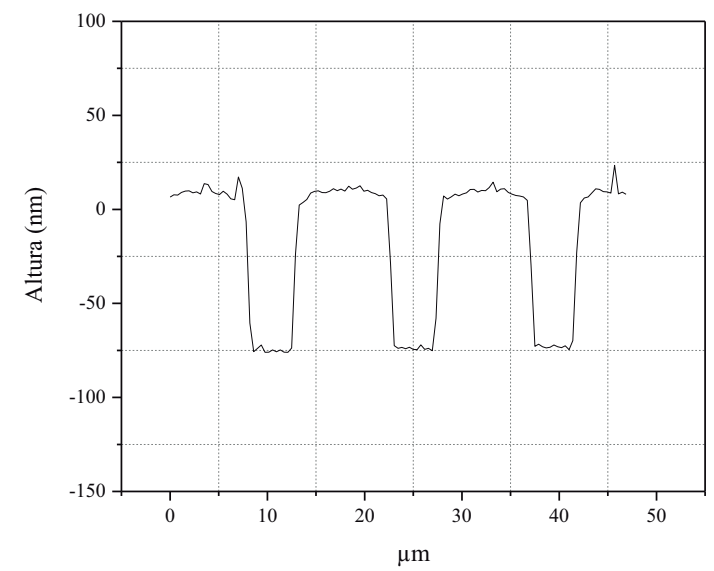

(b)

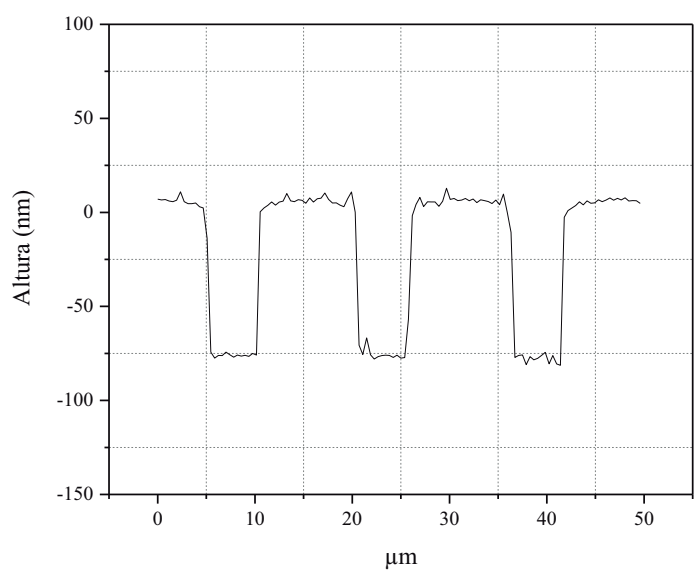

Fonte: A autora.

Uma vez que a corrente de 30 pA se mostrou suficiente para um bom resultado, foram realizadas litografias em diferentes amostras utilizando o padrão de conjunto de 20x20 quadrados, com dose de $30 \mu \mathrm{C} / \mathrm{cm}^{2}$ e corrente de $30 \mathrm{pA}$. 


\section{APÊNDICE C - Procedimentos para revelar filmes de PMMA em grades de Microscopia Eletrônica de Transmissão}

Para realizar esta etapa é necessário se certificar de ter em mãos:

- Pinça de precisão;

- Papel de filtro qualitativo $\left(80 \mathrm{~g} / \mathrm{m}^{2}\right)$ cortado em formato triangular;

- Dois pedaços de PDMS, que serão utilizados como suporte para a solução reveladora (1 MIBK:3 IPA) e para o álcool isopropílico;

- Micropipeta (KASVI; K1-100A; range de 10 a 100 L);

- Ponteiras para micropipeta com range de 10 a $200 \mu \mathrm{L}$;

- Béquer com álcool isopropílico;

- Solução reveladora;

- Cronômetro.

\section{Procedimentos}

1. Utilizando a micropipeta, colocar $20 \mu \mathrm{L}$ da solução reveladora sobre um pedaço de PDMS. Fazer o mesmo procedimento utilizando o álcool isopropílico;

2. Identificar o lado da grade que contém os cortes de PMMA;

3. Colocar o lado contendo os cortes em contato com a gota do revelador, acionando o cronômetro simultaneamente, marcando 1 minuto e 30 segundos;
Figura 30 - Secagem da grade com papel de filtro

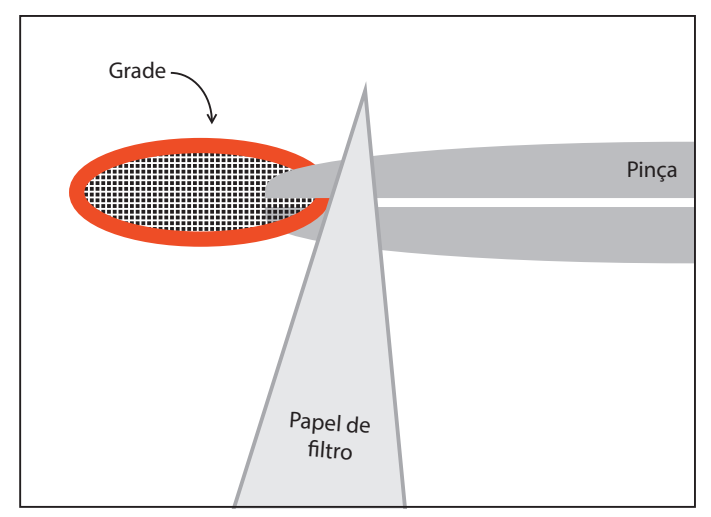

Fonte: A autora.

4. Após o tempo de revelação, retirar a grade e secar com papel de filtro, encostando-o nas laterais da grade, utilizando a pinça como apoio, como mostra a Figura 30. 
5. Ajustar o cronômetro em 30 segundos, e acionar ao colocar a grade com o lado contendo os cortes em contato com a gota de álcool isopropílico. Após o tempo decorrido, retirar a grade da gota e secar utilizando o papel de filtro;

6. Deixar as grades sobre um papel de filtro com o lado contendo os cortes para cima por aproximadamente cinco minutos, para garantir a secagem da grade. 


\section{APÊNDICE D - Parâmetros de obtenção dos espectros SERS}

Para a obtenção dos espectros SERS alguns cuidados devem ser tomados, assim, é necessário calibrar o equipamento antes de qualquer medida com a obtenção de um espectro Raman do silício cristalino, que possui uma banda característica em $520 \mathrm{~cm}^{-1}$. Outros parâmetros, como a rede de difração, objetiva utilizada e potência do laser podem ser vistos na Tabela 6, abaixo, ressaltando que todos os espectros apresentados neste trabalho foram obtidos com um laser de comprimento de onda de $633 \mathrm{~nm}$.

Tabela 6 - Parâmetros utilizados na obtenção dos espectros SERS.

\begin{tabular}{|c|c|c|c|c|}
\hline & $\begin{array}{l}\text { Rede de difração } \\
\text { (linhas/mm) }\end{array}$ & Objetiva & $\begin{array}{l}\text { Potência do laser } \\
\qquad(\%)\end{array}$ & $\begin{array}{c}\text { Tempo de } \\
\text { acumulação } \\
(\mathrm{s})\end{array}$ \\
\hline Figura 16 & 1200 & $20 x$ & 10 & 30 \\
\hline Figura $\overline{17}$ & 1200 & $50 \mathrm{x}$ & 5 & 50 \\
\hline Figuras 18 e 19 & 1200 & $50 \mathrm{x}$ & 5 & 10 \\
\hline Figura 20a & 1200 & $50 \mathrm{x}$ & 5 & 20 \\
\hline Figura $\overline{20 \mathrm{~b}}$ & 1200 & $50 \mathrm{x}$ & 5 & 40 \\
\hline
\end{tabular}

Fonte: A autora

O diâmetro da área analisada foi de cerca de $1 \mu \mathrm{m}$ e o tempo de acumulação é um recurso utilizado para obter uma melhor relação sinal/ruído. A potência média do laser foi determinada pela equipe do LEM e pode ser consultada na Tabela 7.

Tabela 7 - Potência média do laser de comprimento de onda de $633 \mathrm{~nm}$.

\begin{tabular}{cccccc}
\cline { 2 - 6 } & $100 \%$ & $50 \%$ & $10 \%$ & $5 \%$ & $1 \%$ \\
\hline $\begin{array}{c}\text { Potência } \\
\left(\mathrm{mW} / \mu \mathrm{m}^{2}\right)\end{array}$ & 7,55 & 3,7 & 0,74 & 0,36 & 0,099 \\
\hline
\end{tabular}

Fonte: Valores de potência obtidos pela equipe do LEM.

Para valores menores que $1 \%$ a medida da potência torna-se imprecisa, assim é considerado o valor proporcional em relação às potências apresentadas na Tabela 7. 


\section{APÊNDICE E - Parâmetros das curvas log-normal ajustadas aos histogramas}

Neste capítulo, serão apresentados os parâmetros utilizados para ajustar as curvas log-normal nos histogramas apresentados na Seção 3.5 (Figuras 31 e 32). Primeiramente, é necessário ajustar o tamanho amostral, isto é, o número de nanopartículas a serem analizadas, para que as amostras aquecida e não aquecida, sejam estatisticamente equivalentes. Assim, utilizando o Microsoft Excel®, foram escolhidas aleatoriamente cerca de 8000 dados (nanopartículas) de cada amostra, que foram utilizados para a montagem dos histogramas. Os histogramas e os ajustes foram realizados utilizando o Origin®.

Figura 31 - Parâmetros das curvas log-normal da amostra não aquecida.

(a)

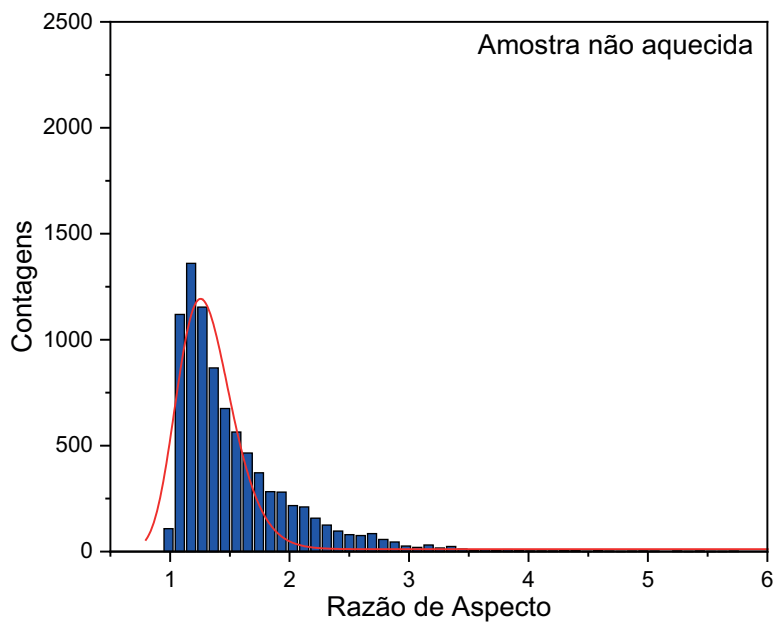

\begin{tabular}{|l|c|}
\hline Model & $\begin{array}{c}\text { LogNormal } \\
\text { Equation }\end{array}$ \\
\hline Plot & $\begin{array}{c}y=y 0+\mathrm{A} /\left(\operatorname{sqrt}\left(2^{*} \mathrm{pi}\right)^{*} \mathrm{w}^{*} \mathrm{x}\right)^{*} \exp (-( \\
\left.\ln (\mathrm{x} / \mathrm{xc}))^{\wedge} 2 /\left(2^{*} \mathrm{w}^{\wedge} 2\right)\right)\end{array}$ \\
\hline $\mathrm{y} 0$ & Counts \\
\hline $\mathrm{xc}$ & $11,11195 \pm 5,97933$ \\
\hline $\mathrm{w}$ & $1,2952 \pm 0,00919$ \\
\hline $\mathrm{A}$ & $0,17706 \pm 0,00709$ \\
\hline R-Square (COD) & $668,94523 \pm 22,95617$ \\
\hline Adj. R-Square & 0,89907 \\
\hline
\end{tabular}

(b)

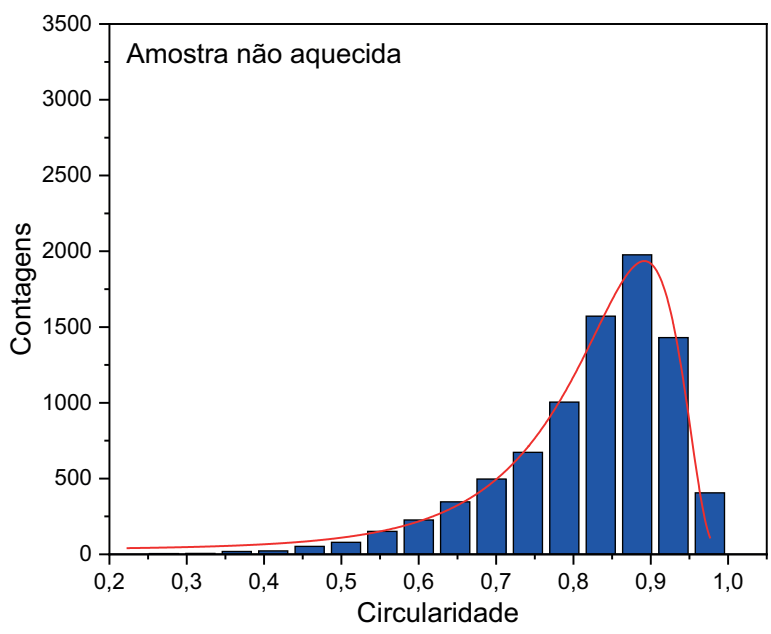

\begin{tabular}{|l|c|}
\hline Model & $\begin{array}{c}\text { LogNormal_invertido (User) } \\
\text { Equation }\end{array}$ \\
$\begin{array}{l}\mathrm{y}=\mathrm{y} 0+\mathrm{A} /\left(\operatorname{sqrt}\left(2^{*} \mathrm{pi}\right)^{*} \mathrm{w}^{*}(-\mathrm{x}+1)\right. \\
)^{*} \exp \left(-(\ln ((-\mathrm{(}+1) /(-\mathrm{xc}+1)))^{\wedge} 2 /(2\right. \\
\left.\left.{ }^{*} \mathrm{w}^{\wedge} 2\right)\right)\end{array}$ \\
\hline Plot & Counts \\
\hline $\mathrm{y} 0$ & $31,25562 \pm 42,43845$ \\
$\mathrm{xc}$ & $0,84365 \pm 0,00629$ \\
$\mathrm{w}$ & $0,60581 \pm 0,04054$ \\
\hline $\mathrm{A}$ & $376,31818 \pm 29,82281$ \\
\hline R-Square (COD) & 0,98133 \\
\hline Adj. R-Square & 0,97702 \\
\hline
\end{tabular}

Fonte: A autora. 
Figura 32 - Parâmetros das curvas log-normal da amostra aquecida.

(a)

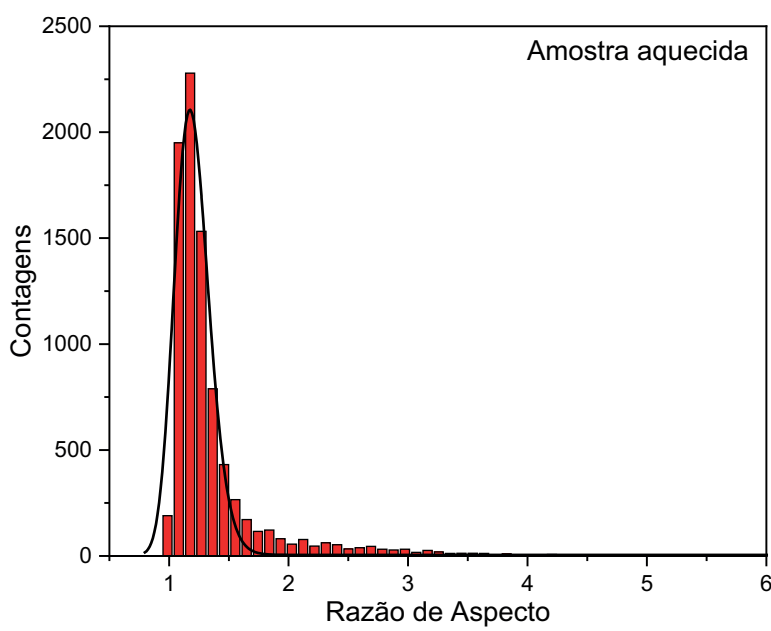

\begin{tabular}{|l|c|}
\hline Model & $\begin{array}{c}\text { LogNormal } \\
\text { Equation }\end{array}$ \\
\hline Plot & $\begin{array}{c}y=y 0+\mathrm{A} /\left(\operatorname{sqrt}\left(2^{*} \mathrm{pi}\right)^{*} \mathrm{w}^{*} \mathrm{x}\right)^{*} \exp (-( \\
\left.\ln (\mathrm{x} / \mathrm{xc}))^{\wedge} 2 /\left(2^{*} \mathrm{w}^{\wedge} 2\right)\right)\end{array}$ \\
\hline y0 & Counts \\
\hline $\mathrm{xc}$ & $5,16139 \pm 5,61014$ \\
\hline $\mathrm{w}$ & $1,19126 \pm 0,00385$ \\
\hline A & $0,12 \pm 0$ \\
\hline R-Square (COD) & 0,95089 \\
\hline Adj. R-Square & 0,95017 \\
\hline
\end{tabular}

(b)

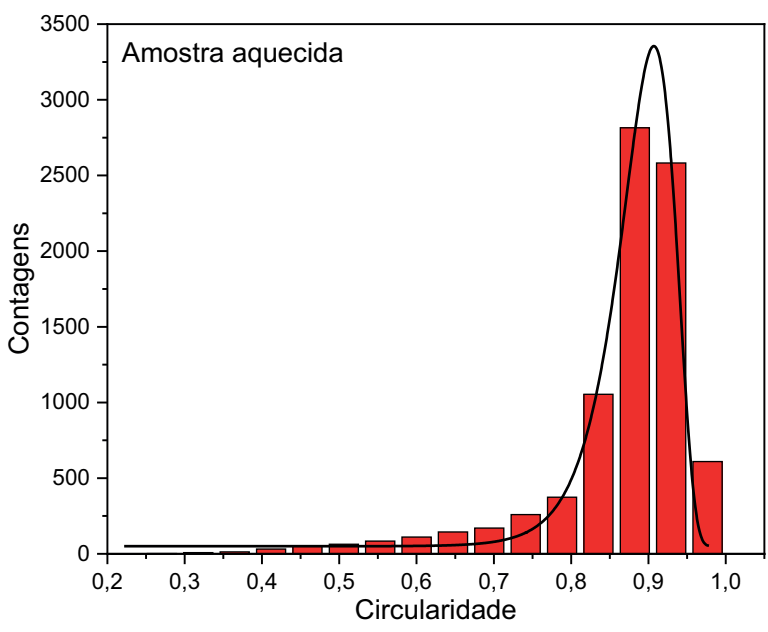

\begin{tabular}{|c|c|}
\hline Model & LogNormal_invertido (User) \\
\hline Equation & $\begin{array}{c}y=y 0+A /\left(\operatorname{sgrt}\left(2^{*} p i\right)^{*} w^{*}(-x+1)\right)^{*} \\
\exp \left(-(\ln ((-x+1) /(-x c+1)))^{\wedge} 2 /\left(2^{*} w^{\wedge}\right.\right. \\
2))\end{array}$ \\
\hline Plot & Counts \\
\hline yo & $50 \pm 0$ \\
\hline $\mathrm{xc}$ & $0,89247 \pm 0,00246$ \\
\hline w & $0,38125 \pm 0,02962$ \\
\hline$A$ & $315,79322 \pm 17,2232$ \\
\hline R-Square (COD) & 0,97074 \\
\hline Adj. R-Square & 0,96656 \\
\hline
\end{tabular}

Fonte: A autora.

onde, y0 é o offset, xc é a mediana, w desvio padrão do logaritmo e A é a área sob o pico. Os termos $R$-Square (COD) e $a d j$. $R$-Square são parâmetros mensuram a qualidade do ajuste. Quanto mais próximo de 1, melhor é o ajuste. 


\section{APÊNDICE F - Cálculo do tamanho da partícula através do espectro UV-Vis}

O cálculo do tamanho da nanopartícula utilizando o espectro UV-Vis foi realizado utilizando como base os procedimentos descritos na Referência [19]. Para isto, foram utilizadas as Equações 2 para o cálculo do coeficiente de absorção $\kappa(\lambda)$, apresentada anteriormente na Introdução, e F.1 para o cálculo do diâmetro $(D)$ da nanopartícula.

$$
D=\left[\frac{\kappa(\lambda)}{3 \pi^{2} N \varepsilon_{m}^{3 / 2}} \frac{\left(\varepsilon_{1}+2 \varepsilon_{m}\right)^{2}+\varepsilon_{2}^{2}}{\varepsilon_{2}}\right]^{1 / 3}
$$

Para estimar o valor de $(D)$, é necessário obter os valores de $L, N, A(\lambda), \varepsilon_{1}(\lambda)$, $\varepsilon_{2}(\lambda), \varepsilon_{m}$ e $\kappa(\lambda)$. O valor de $L$ é o comprimento do caminho óptico de interação, isto é, a largura da camada de intermixing (metal-polímero), obtido através da simulação TRIDYN considerando a dose de $0,65 \times 10^{16}$ átomos $/ \mathrm{cm}^{2}$ (Figura 26). $A(\lambda)$ é equivalente à área onde foram contadas as nanopartículas em uma micrografia de microscopia eletrônica de transmissão, no caso deste trabalho, foi considerado uma dose de $0,53 \times 10^{16}$ átomos $/ \mathrm{cm}^{2}$, pois não foi possível obter a micrografia para a dose correspondente à $0,65 \mathrm{x}$ $10^{16}$ átomos $/ \mathrm{cm}^{2}$. Com o número de partículas $n_{p}$ contabilizadas na área $A(\lambda)$, é possível estimar a densidade de partículas $N$ através da Equação F.2.

$$
N=\frac{n}{A L}
$$

Os termos $\varepsilon_{1}(\lambda)$ e $\varepsilon_{2}(\lambda)$ foram calculados de acordo com o índice de refração complexo $n+i k$ do ouro, lembrando que $\varepsilon_{1}(\lambda)=n^{2}-k^{2}$ e $\varepsilon_{2}(\lambda)=2 n k$ 91. Os valores de $n$ e $k$ foram obtidos utilizando as tabelas da Seção 4.2 da Referência 91 em relação à energia do fóton, calculada por meio da Equação de Plank em função do comprimento de onda do pico de extinção dos expectros da Figura 26. A constante dielétrica do PMMA equivale a $\varepsilon_{m}=4,592$. O coeficiente de absorção, que no caso deste trabalho é equivalente ao coeficiente de extinção, é calculado a partir do valor do pico de extinção e do comprimento do caminho óptico de interação.

Os parâmetros e resultados obtidos estão listados na Tabela 8. E mostram que os cálculos realizados estimam o aumento no tamanho da nanopartícula. 
Tabela 8 - Parâmetros e resultados do cálculo do tamanho da partícula através dos espectros UV-Vis.

\begin{tabular}{ccccccccc}
\cline { 2 - 6 } & $\begin{array}{c}L \\
(\mathrm{~nm})\end{array}$ & $\begin{array}{c}N \\
\left(\mathrm{~nm}^{-1}\right)\end{array}$ & $\begin{array}{c}\lambda \\
(\mathrm{nm})\end{array}$ & $\varepsilon_{1}(\lambda)$ & $\varepsilon_{2}(\lambda)$ & $A(\lambda)$ & $\begin{array}{c}\kappa(\lambda) \\
\left(\mathrm{nm}^{-1}\right)\end{array}$ & $\begin{array}{c}\boldsymbol{D} \\
(\mathbf{n m})\end{array}$ \\
\hline Não aquecida & 5,76 & 0,004 & $\begin{array}{c}639 \\
(2,00 \mathrm{eV})\end{array}$ & $-9,97$ & 0,82 & 0,02 & 0,01 & $\mathbf{3 , 3 7}$ \\
Aquecida & 5,76 & 0,004 & $\begin{array}{c}566 \\
(2,20 \mathrm{eV})\end{array}$ & $-6,39$ & 1,22 & 0,1 & 0,04 & $\mathbf{5 , 5 8}$ \\
\hline
\end{tabular}

Fonte: A autora 


\section{APÊNDICE G - Apresentação em \\ Congresso Nacional: XLIII Congresso da Sociedade Brasileira de Biofísica}

\section{PRODUCING SERS SUBSTRATES THROUGHT GOLD ION IMPLANTATION IN PMMA}

Natalia K. Gushiken ${ }^{1}$, Giordano T. Paganoto ${ }^{2}$, Márcia L. A. Temperini ${ }^{2}$ and Maria C. B. S. Salvadori ${ }^{3}$ ${ }^{1}$ Escola Politécnica of the Univ. of São Paulo, Univ. of São Paulo (email: nkgushiken@usp.br); ${ }^{2}$ Dept. of Fundamental Chemistry, Inst. of Chemistry, Univ. of São Paulo and ${ }^{3}$ Dept. of Appl. Physics, Inst. of Physics, Univ. of São Paulo (email: mcsalva@if.usp.br)

In this work, we formed a thin subsurface composite material formed by gold nanoparticles (AuNPs) in the polymer polymethylmethacrylate (PMMA). This material was tailored for producing SERS (Surface-Enhanced Raman Spectroscopy) substrates. The AuNPs were produced by low energy $(49 \mathrm{eV})$ ion implantation of gold in PMMA, using cathodic arc plasma. In this approach, the nanoparticles were formed about $10 \mathrm{~nm}$ below the polymer surface with mean nanoparticle diameter of $4.3 \mathrm{~nm}$. This composite material was tested as a SERS substrate using the analyte Rhodamine 6G (R6G), with concentration of $10 \mu \mathrm{M}$, and a laser with wavelength of $633 \mathrm{~nm}$ as a source of excitation. In the obtained spectra, we have verified the presence of the characteristic peaks of R6G and no signal was obseved when using a PMMA without gold implantation. It was also observed an increase of the SERS signal intensity with the increase of the implantation dose. SERS signal was also observed when the $10 \mathrm{~nm}$ of PMMA was removed from its top. But the better result was observed when the PMMA layer was maintained over the composite layer, i.e without removing the polymer layer above the nanoparticles. More experiments must be carried out in order to improve the performance of these substrates so that they can be used in sensing, since there is a great interest in the analysis by SERS in applications for biochemistry, biophysics and biomedicine.

This work was supported by Conselho Nac. Des. Cient. Tecnológico (CNPq), Fund. de Amparo à Pesquisa do Estado de São Paulo (FAPESP) and Coordenação de Aperfeiçoamento de Pessoal de Nível Superior (CAPES). 


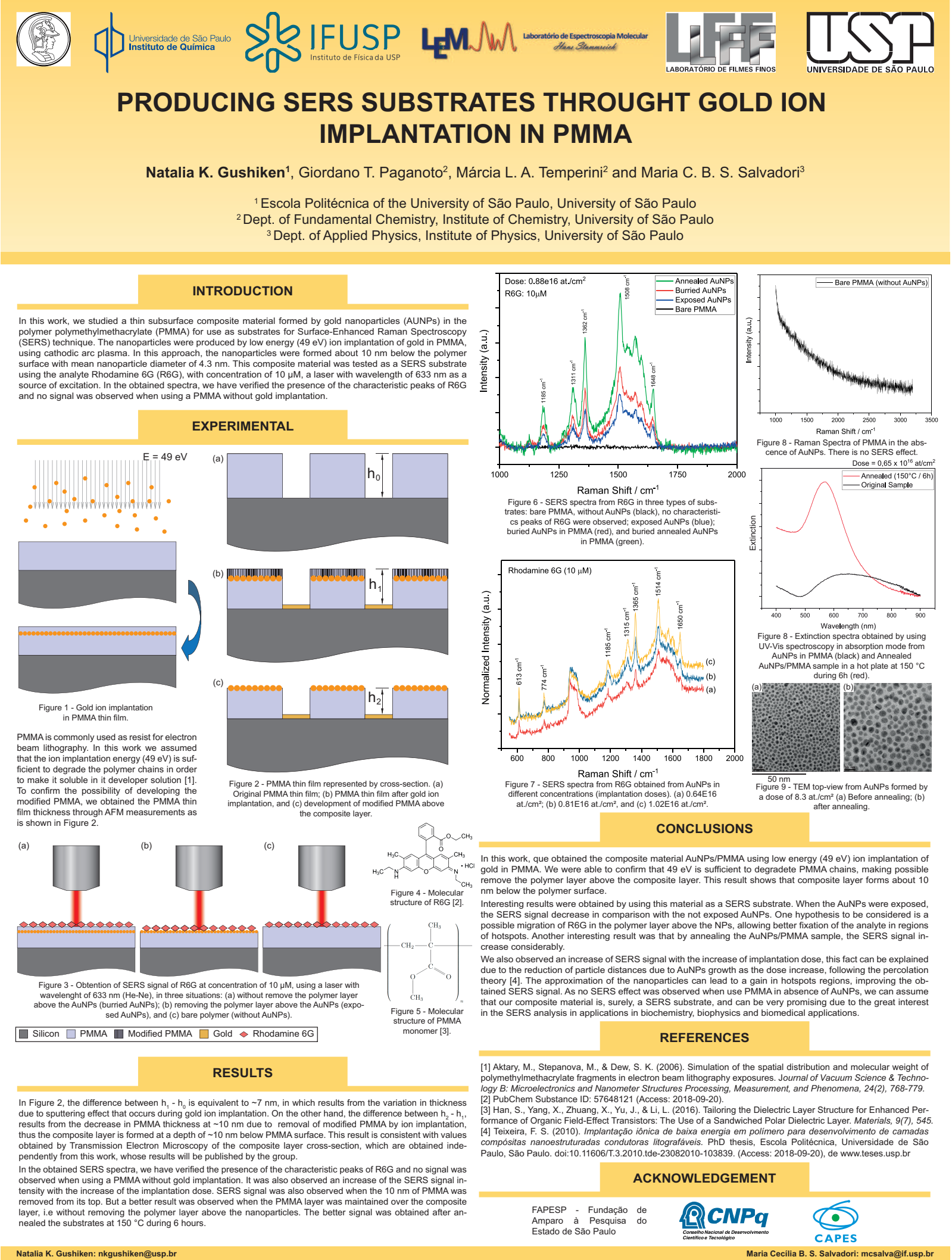

